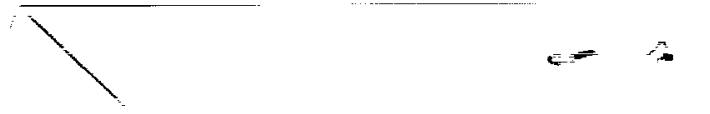

NASA Contractor Report 187187

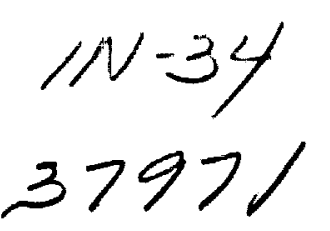

$\rho-137$

\title{
Bypass Transition in Boundary Layers Including Curvature and Favorable Pressure Gradient Effects
}

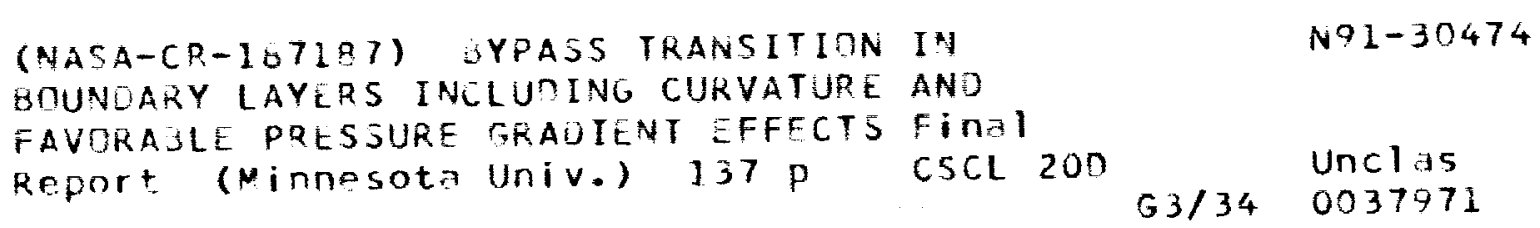

$N 91-30474$

R.J. Volino and T.W. Simon

University of Minnesota

Minneapolis, Minnesota

August 1991

Prepared for

Lewis Research Center

Under Grant NAG3-881

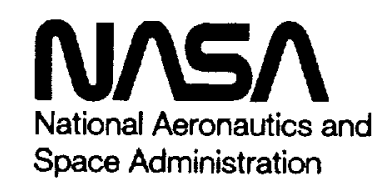





\section{CONTENTS}

Acknowledgments

List of Symbols

Abstract

Introduction 3

Turbulence Modelling 7

Governing Equations

Review of Experiments 22

Comparison of Data Sets 22

Boundary Layer Growth 27

Skin Friction 31

Heat Transfer 33

The Location of Transition 38

Intermittency. 42

Turbulent Spot Formation Rate 43

Conclusions and Recommendations 47

References 50

Tables 56

Figures 61

Appendix: Tabulated Data 93

Kim (1990) 94

Wang (1984) 99

Suder, O'Brien and Reshotko (1988) 106

Sohn and Reshotko (1991)

Kuan and Wang (1990) and Kuan (1987)

Blair (1981a) and Blair and Werle (1980)

Blair (1981b) and Blair and Anderson (1987)

Rued (1987) 


\section{ACKNOWLEDGEMENTS}

The following work was sponsored by the Lewis Research Center of NASA under grant NASA/NAG3-881. The authors thank the grant monitor, Mr. Fred Simon, for his guidance.

The assistance of K. H. Sohn and M. F. Blair in the collection of tabulated data is appreciated.

A preliminary version of this report was reviewed by M. F. Blair, F. F. Simon, T. Wang and J. Kim. The suggestions received have been incorporated into the report. 


\section{LIST OF SYMBOLS}

$\mathrm{c}_{\mathrm{f}}$

skin friction coefficient

D

isotropic turbulence dissipation rate

$\mathrm{D}_{\mathrm{ij}}$ isotropic dissipation tensor for Reynolds stresses

$\mathrm{E}(\mathbf{f})$ spectral energy distribution function

f frequency

function of intermittency

$\mathrm{H}_{\mathrm{j}}$

diffusive flux of $D$

$\mathrm{J}_{\mathrm{j}}$

diffusive flux of turbulent kinetic energy

$\mathrm{J}_{\mathrm{ijk}}$ diffusive flux tensor for Reynolds stresses

k

acceleration, $\frac{v}{U_{\infty}^{2}} \frac{\partial U_{\infty}}{\partial x}$

also, turbulent kinetic energy

L length scale

$\mathrm{L}_{\mathrm{e}}^{\mathrm{u}} \quad$ dissipation length scale

n

turbulent spot production rate

$\hat{\mathrm{n}}$

dimensionless turbulent spot production rate, $\frac{n v^{2}}{U_{s}}$

$P \quad$ production term for turbulent kinetic energy

$\mathrm{P}_{\mathrm{ij}} \quad$ production tensor for Reynolds stresses

p pressure

$\mathrm{p}^{\prime} \quad$ fluctuating component of pressure

Pr Prandtl number

$\operatorname{Pr}_{t} \quad$ turbulent Prandtl number

q

turbulence intensity, $q=\sqrt{\overline{u^{\prime 2}}+\overline{v^{\prime 2}}+\overline{w^{\prime 2}}}$

$q^{\prime \prime}$

wall heat flux 


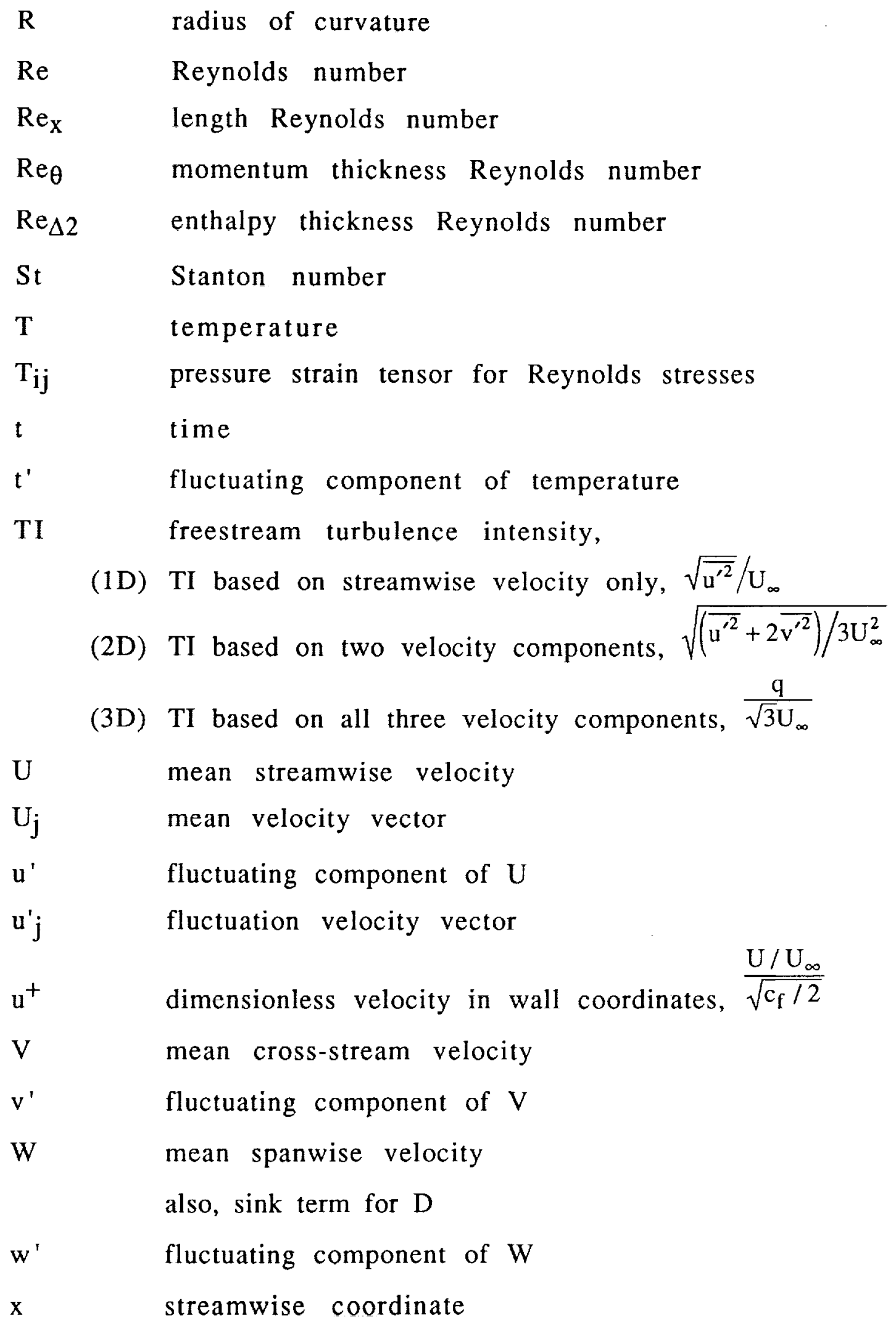




$\begin{array}{ll}\mathrm{y} & \text { cross-stream coordinate } \\ \mathrm{y}^{+} & \text {dimensionless wall coordinate, } \frac{\mathrm{yU} \mathrm{U}_{\infty} \sqrt{\mathrm{c}_{\mathrm{f}} / 2}}{\mathrm{v}} \\ \mathrm{z} & \text { spanwise coordinate } \\ \alpha & \text { thermal diffusivity } \\ \delta & \text { boundary layer thickness } \\ \delta_{99.5} & 99.5 \% \text { boundary layer thickness } \\ \delta^{*} & \text { displacement thickness } \\ \delta_{\mathrm{t}} & \text { thermal boundary layer thickness } \\ \theta & \text { momentum thickness } \\ \Delta_{2} & \text { enthalpy thickness } \\ \varepsilon & \text { turbulence dissipation } \\ \gamma & \text { intermittency } \\ \Lambda & \text { integral length scale } \\ \lambda & \text { Taylor microscale } \\ v & \text { kinematic viscosity } \\ \eta & \text { Kolmogorov length scale } \\ \rho & \text { density } \\ \sigma & \text { turbulent spot propagation parameter }\end{array}$

Subscripts

$\begin{array}{ll}\infty & \text { freestream } \\ \mathrm{i}, \mathrm{j}, \mathrm{k} & \text { tensor and vector indices } \\ \mathrm{e} & \text { end of transition } \\ \mathrm{s} & \text { start of transition } \\ \mathrm{pw} & \text { potential flow velocity at the wall } \\ \mathrm{w} & \text { wall }\end{array}$





\title{
BYPASS TRANSITION IN BOUNDARY LAYERS INCLUDING CURVATURE AND FAVORABLE PRESSURE GRADIENT EFFECTS
}

\author{
Ralph J. Volino and Terrence W. Simon \\ Department of Mechanical Engineering \\ University of Minnesota
}

\begin{abstract}
Recent studies of two-dimensional boundary layers undergoing bypass transition have been reviewed. Bypass transition is characterized by the sudden appearance of turbulent spots in the boundary layer without first the regular, observable growth of disturbances predicted by linear stability theory. There are no standard criteria or parameters for defining bypass transition, but it is known to be the mode of transition when the flow is disturbed by perturbations (e.g. freestream turbulence, surface roughness, acoustic fluctuations) of sufficient amplitude.
\end{abstract}

An examination of recent turbulence and transition modelling work indicates a need for more experimental data; particularly, transition data in which turbulence dissipation rates and length scales are documented. Transition models which incorporate the intermittent nature of the flow generally have more success than those which do not. Such models are still, however, dependent on case-specific experimental data and are not ready for predictive use.

A review of experimental work shows the effects of freestream turbulence level, acceleration and wall curvature on bypass transition. Results from several studies were cast in terms of "local" boundary layer coordinates (momentum and enthalpy thickness Reynolds numbers) and 
compared. Boundary layer growth is strongly affected by acceleration and by concave curvature. In unaccelerated flow on flat walls, skin friction coefficients match the analytical laminar solution before transition and quickly adjust to the fully-turbulent correlation after transition. Stanton numbers also match the correlation in the laminar region, but do not fit the correlation as well in the turbulent region. Acceleration appears to not affect skin friction when expressed in terms of momentum thickness Reynolds number. Stanton numbers were strongly affected by acceleration, however, indicating a breakdown in Reynolds analogy. Concave curvature causes the formation of Görtler vortices, which strongly influence the skin friction, Convex curvature had an opposite, and lesser effect. The location and length of the transition region generally follow the expected trends. Transition occurs earlier at higher freestream turbulence levels and on concave surfaces. Convex curvature and acceleration delay transition. When individual cases were compared, some inconsistencies were observed. These inconsistencies indicate a need to better characterize the flow. Better spectral and length scale measurements would help in this regard. Within the transition region, the intermittency data from the all cases on flat walls (no curvature) was consistent with an analytical prediction. Turbulent spot production rates were shown to be mostly dependent on free-stream turbulence, with a noted increase due to concave curvature and little effect of convex curvature. The acceleration effect on spot production rate was small for the cases studied. 


\section{INTRODUCTION}

Transition to turbulence is a complex phenomenon which has been studied extensively but is still not well understood. A better understanding of transition is needed since it is an important factor in determining the heat transfer from a surface. On a typical gas turbine blade, for example, the transition zone may cover a significant fraction of the blade surface and the heat transfer rate will increase severalfold through the transition zone. It is therefore important to know the location and length of the transition region as well as the behavior of the flow within the region.

The first studies of transition dealt with flows that were subject to only small disturbances. Tollmien (1936) found, using linear stability analysis, that transition occurs under small disturbance circumstances by a process which was later referred to as Tollmien-Schlichting (TS) transition. Described in detail by several authors, including Schlichting (1979), TS transition involves the growth of small perturbations in the flow into two-dimensional disturbances known as Tollmien-Schlichting waves. These disturbances or "wave packets" become three-dimensional due to secondary instabilities as they move downstream. Eventually they culminate as turbulent spots in the boundary layer flow. The location at which the infinitesimal disturbances first begin to grow can be predicted by stability theory. It is usually expressed as a critical Reynolds number. Schubauer and Skramstad (1948) experimented in a boundary layer grown in a very low-turbulence environment (freestream turbulence 
intensity, $\mathrm{TI}^{\dagger}<0.03 \%$ ), and presented data in agreement with Schlichting's (1933) stability plots, which were calculated based on Tollmien's (1931) theory (see Schlichting (1979) p. 479).

In bypass transition, the TS transition mechanisms are not so evident. Bypass transition is that which occurs in flows disturbed by finite perturbations such as freestream turbulence, surface roughness or acoustic excitation. Under high freestream turbulence conditions, turbulent eddies in the freestream are believed to buffet the boundary layer, providing a non-linear transition mechanism which acts either in place of or in combination with the linear growth of disturbances within the boundary layer (the operational mechanism when the disturbance level is low). Bypass transition is poorly understood in part because it is not amenable to analysis. It is the mode of transition believed to be operational in gas turbines where turbulence intensities of 5 to $20 \%$ are common.

Narasimha (1985) identified the following three modes of transition: "disturbance limited" transition at $\mathrm{TI}<0.1 \%$, "turbulence driven" transition at $0.1 \%<\mathrm{TI}<4 \%$, and "stability limited" transition at $\mathrm{TI}>4 \%$. The first mechanism is Tollmien-Schlichting transition and the third is clearly bypass transition. There is some discrepancy in the literature involving the intermediate TI cases. Suder, O'Brien and Reshotko (1988), for example, differentiated between TS and bypass transition based on the presence or absence of Tollmien-Schlichting waves. This led to the conclusion that a $\mathrm{TI}=0.3 \%$ case in which $\mathrm{TS}$ waves were detected

\footnotetext{
† Since only freestream turbulence values are referred to in this report, the notation "TI" will always refer to freestream turbulence intensity. Percentages are referenced to the mean freestream velocity.
} 
underwent Tollmien-Schlichting transition. Kendall (1990) similarly stated that a $\mathrm{TI}=0.2 \%$ case was not a bypass case. Disturbance growth in the range predicted for TS waves by linear stability theory may not, however, be sufficient for distinguishing between TS and bypass transition. Morkovin (1978) defined bypass as "those roads to transition which cannot be identified as starting from a known linear instability". It is not clear whether the presence of TS waves constitutes sufficient evidence to conclude that the "road" or path which ultimately resulted in transition began as a linear instability. Sohn and Reshotko (1991) present spectral measurements taken in boundary layers at six different freestream turbulence levels. At the three lowest turbulence levels (nominal $0.45 \%, 0.83 \%$ and $1.1 \%$ ) evidence of TS waves appeared as broadband humps in the spectra in the unstable ranges predicted by linear stability theory. In the $0.45 \%$ case the perturbations in the unstable range were amplified as the flow moved downstream, while the disturbances outside this range were damped. This behavior is in agreement with linear stability theory and provides evidence of TS transition. At $0.83 \%$ and $1.1 \%$, however, perturbations were amplified both within the band which was predicted to be unstable by linear theory and at higher frequencies. These two cases could be considered bypass transition cases since they show deviation from linear theory, despite the evidence of TS type disturbances at upstream stations. In a numerical study, Bertolotti, Herbert and Spalart (1990) investigated the growth of single-frequency disturbances and their harmonics in boundary layer flows. In one example a neutral stability curve was found for a disturbance of $1.4 \%$ amplitude (relative to the freestream velocity). This 
is believed to indicate that even for turbulence intensities as high as $1.4 \%$, bypass transition may not occur for some combinations of disturbance frequency and boundary layer thickness. In another example a disturbance of initial amplitude $0.25 \%$ was shown to grow and then decay in accordance with linear stability theory. A disturbance of the same frequency and $0.3 \%$ amplitude, however, grew faster than predicted by linear theory and continued to grow even when the theory predicted decay. Whether this behavior is evidence of bypass transition is not clear. Even TS transition must eventually display nonlinear behavior before turbulent spots can appear. It does demonstrate that both the frequency distribution and the amplitude of disturbances are important factors for determining how transition will proceed.

An attempt to more sharply define bypass transition than given above may be futile since the demarcation between TS and bypass transition is in actuality, rather fuzzy. A need is recognized for better understanding of the transition mechanisms at both intermediate and high TI ranges as well as the relationship of these mechanisms to each other and to the Tollmien-Schlichting transition mechanism. It is believed that more careful documentation and thoughtful study of boundary layer spectra will lead to a better understanding of transition and the relative importance of the different types of disturbances in initiating transition.

The existing literature which in some way involves bypass transition and TS transition is enormous. Given the current state of knowledge it would be impractical and nonproductive to attempt to include all of this material in a single review. Instead, emphasis will be placed on boundary layer flows which are known to undergo bypass 
transition. The separate and combined effects of variable freestream turbulence intensity, wall curvature and freestream acceleration will be examined.

The first part of this report is a brief review of turbulence and transition modelling. This review is not intended to be complete, but is presented to provide some insight into the transition process and how it is currently treated by modelers. This will provide some insight into how experimental programs should be structured to be most useful to support computational development. The second and main part of the report is a review of some recent bypass transition experiments.

\section{TURBULENCE MODELLING}

The continuity, Navier-Stokes and energy equations constitute an exact model for any continuum flow. The equations can be solved in principle for all flows; but in practice, exact solutions are possible at reasonable computational cost only for a few low-Reynolds-number flows in simple geometries. In order to predict most flows, it is necessary to simplify the governing equations. This involves time-averaging. The associated loss of temporal information must be replaced by models.

For turbulent flows which are steady in the long term, turbulent information in the original equations emerges as the Reynolds stress tensor in the time-averaged equations. Providing an estimate of the six unknown terms in the Reynolds stress tensor in terms of the mean flow is the essence of turbulence modelling. Modelling should be based as much as possible on the physics of a flow; but, since the physics of turbulence is 
not well understood, all models have at least some empiricism. This leads to models which are only applicable to a particular class of flows. Fortunately, a fair amount of success has been achieved with generality in fully-turbulent cases. This is apparently due to the similarity of much of the flow structure from one turbulent flow to the next. Reynolds (1976) discussed several types of turbulence models.

In transitional flow, models have been less successful than in fullyturbulent flow. This is believed to be mainly due to the long-term unsteadiness and three-dimensionality associated with transition. A transitional boundary layer flow can be divided in space into two distinct zones. One is the turbulent zone associated with turbulent spots. The other is the disturbed-laminar (also termed late-laminar, non-turbulent and inter-turbulent) zone in the fluid which is between the turbulent spots. At any point, the flow alternates in time between turbulent and disturbed-laminar flow as these zones are convected by. The fraction of the time spent in the turbulent zone is termed the intermittency, $\gamma$. When the governing equations are time-averaged, the important information associated with the intermittency and associated intermittent flow structure is lost. Modelling of transition by re-introduction of this information should be possible if the important characteristics of transition are recognized and properly incorporated into the models.

A few attempts have been recently made to calculate through transition with standard turbulence models (i.e. without special transition modelling). Some models have attempted to include information about the intermittency while others have ignored the intermittent flow structure and treated the transition zone as a homogeneous region. Blair 
and Anderson (1987) evaluated a few models by comparing them to their experimental data. McDonald and Fish's (1973) and McDonald and Kreskovsky's (1974) one-equation models (which did not take the intermittency into account) did predict transition, but Blair and Anderson found that the location and length of the transition region did not match the data well. A model based on experimental intermittency data and the Cebeci-Smith (1974) turbulence model was fairly successful in predicting Stanton numbers, but it had the drawback of requiring the intermittency data prior to calculation. The details of this model were not presented by Blair and Anderson, but it is believed to be based on an intermittencyweighted average of fully-laminar and fully-turbulent flow solutions. Gaugler (1986) used a modified version of the Crawford and Kays (1976) STAN5 program to match calculations to several experimental data sets. He chose the beginning and end of transition for the calculations to provide agreement with the experiments and used a formula from AbuGhannam and Shaw (1980) to specify the intermittency through the transition zone. Gaugler found that he could achieve good agreement for Stanton numbers within the transition zone for a wide range of flow conditions.

The two-equation, $k-\varepsilon$ model is currently the most popular model for turbulence closure. A two-equation model by Rodi and Scheuerer (1985), which ignored the intermittent flow structure and computed through transition by typical k-equation and $\varepsilon$-equation modelling, had limited success. Using a Lam-Bremhorst (1981) low-Reynolds-number turbulence model, Rodi and Scheuerer were able to predict transition in some cases but failed in others. The predicted length of transition was 
usually too short. The model had particular difficulty in nonzero-

pressure-gradient cases. Schmidt (1987) believed that the problem with the Rodi and Scheuerer model was that it ignored all stability considerations. Using this idea, he introduced empirical constants and functions into the Rodi and Scheuerer model to adjust the beginning and end of transition. The transition location was set to fit the empirical correlations for flat plates developed by Abu-Ghannam and Shaw (1980). Schmidt's (1987) model fit some of the flat plate data well since it had been forced to do so. It showed improvement over Rodi and Scheuerer's model, but still had difficulty in more complex situations, such as with accelerated flow. Stephens and Crawford (1990) provided a recent review of the performance and shortcomings of turbulence models which they applied to transition situations.

Vancoillie (1984) and Vancoillie and Dick (1988) had some success in calculating within the transition region using the experimentallydetermined start and end locations of the transition zone, a model of a turbulent spot and an intermittency model developed by Dhawan and Narasimha (1958) which relates $\gamma$ to the location in the transition region. Vancoillie and Dick derived an interesting and plausible model. They performed separate, but coupled, $2-\mathrm{D}, \mathrm{k}-\varepsilon$ calculations for the turbulent and disturbed-laminar regions of the flow. They presented mean and fluctuation velocity profiles and boundary layer thicknesses. These quantities compared well with experimental data, however no attempt was made to calculate skin friction or Stanton numbers, which would have provided a more meaningful comparison to experiments. The rms velocity fluctuation profiles were found to depend heavily on switching 
between turbulent and disturbed-laminar zones of the flow at each location. The accuracy of the model in predicting the actual turbulence within each zone was unknown since no conditional results were presented. Vancoillie's method is not useful as a predictive tool since it depends on prior knowledge of the location of the transition region, but the idea of modelling the turbulent spots is believed to be a good step toward improving transition modelling.

The above studies suggest a need to incorporate more information about the flow structure into transition models. Models which ignore the presence of turbulent spots and intermittency have had difficulty in predicting transition, and, although empirical adjustments can be used to force a numerical solution to match data, it is questionable whether any of such models can be developed into good predictive tools applicable to more than a restricted set of flow conditions. Those models which in some way include the intermittency, although not yet ready for predictive use since they require the input of case-specific experimental data, had more success.

Future experiments should be designed with the above conclusions in mind. More information detailing the structure of transitional flow (and turbulent flow as well) is needed. To identify which quantities would be most useful from experiments, the governing equations and most important model equations must be reviewed. Only exact terms of the equations will be considered. There is little point in measuring modelling terms since they are only approximations to the actual terms and the accuracy with which they do so is uncertain. An exception will be 
made for the term that represents the dissipation of turbulent energy, $\varepsilon$, since it is of particular importance but is difficult to measure directly.

\section{Governing Equations:}

The governing continuity, Navier-Stokes and energy equations are given below in index notation:

$$
\begin{gathered}
\frac{\partial U_{i}}{\partial x_{i}}=0 \\
U_{j} \frac{\partial U_{i}}{\partial x_{j}}=-\frac{1}{\rho} \frac{\partial p}{\partial x_{i}}+\frac{\partial}{\partial x_{j}}\left(v \frac{\partial U_{i}}{\partial x_{j}}-\overline{u_{i}^{\prime} u_{j}^{\prime}}\right) \\
U_{j} \frac{\partial T}{\partial x_{j}}=\frac{\partial}{\partial x_{j}}\left(\alpha \frac{\partial T}{\partial x_{j}}-\overline{t^{\prime} u_{j}^{\prime}}\right)
\end{gathered}
$$

All of the terms in the equations can be measured and would be valuable in describing the flow. Assuming two-dimensional flow and standard boundary layer approximations, the following quantities are identified as important for measurement:

$$
\mathrm{U}, \mathrm{v}, \overline{\mathrm{u}^{\prime 2}}, \overline{\mathrm{v}^{\prime 2}}, \overline{\mathrm{w}^{\prime 2}}, \overline{\mathrm{u}^{\prime} \mathrm{v}^{\prime}} \text { and } \overline{\mathrm{t}^{\prime} \mathrm{v}^{\prime}}
$$

Data should be taken with sufficient spatial resolution to allow a description of the variation of these quantities in both the streamwise and cross-stream directions. This will allow the evaluation of the partial derivatives with respect to $\mathrm{x}$ and $\mathrm{y}$ of all quantities. The terms $\frac{\partial \overline{u^{\prime} v^{\prime}}}{\partial y}, \frac{\partial \overline{v^{\prime 2}}}{\partial y}, \frac{\partial \overline{v^{\prime} t^{\prime}}}{\partial y}$, and $\operatorname{Prt}$ should be the most useful. Since transitional flow is known to be three-dimensional, data must be taken with sufficient spanwise resolution that the degree of non-two-dimensionality can be 
assessed. In the transition region, measurements should be taken both with and without conditional sampling (sampling with segregation according to the intermittency function, a term that identifies the flow to be either laminar-like or turbulent-like).

The measurement of fluctuation quantities, especially $\overline{\mathrm{u}^{\prime 2}}$, in the transition region presents a problem due to the unsteadiness attributed to the passage of turbulent spots. Figure 1, which shows a typical velocitytime trace from Kim (1990), illustrates this. When conditional sampling is not applied, the mean velocity, labeled "Overall Mean", represents a timeaverage of the velocity in the turbulent and disturbed-laminar zones. The term $\overline{\mathbf{u}^{\prime 2}}$ is based on differences relative to this mean. Such differences are composed of both the turbulent fluctuations and the difference between the overall mean and the time-means within each zone (labeled "Disturbed-Laminar Mean" in the laminar-like and "Turbulent Mean" in the turbulent-like). Streamwise unsteadiness, $u^{\prime}$, is therefore not representative of turbulence level. Figure 2 provides evidence of the problem. In Figure $2 \mathrm{a}$ a fully developed turbulent velocity profile and a Blasius profile are plotted in dimensionless coordinates. In Figure $2 b$, the difference between the two profiles is shown along with a typical $\sqrt{\overline{{\mathrm{u}^{\prime 2}}^{2}}}$ profile from Kim (1990). The peaks in both curves occur at approximately the same $y / \theta$. This strongly suggests that the measured $u^{\prime}$ is largely influenced by switching between turbulent and laminar flow. This fact was recognized by early researchers such as Liepmann (1943). The problem can be lessened, particularly in the turbulent zone, through conditional sampling. In the disturbed-laminar region, however, a problem still exists due to the relatively slow "coast-down" or relaxation 
(see "A" of Figure 1) of the velocity after the passage of a turbulent spot. While the velocity adjusts quickly to the onset of turbulence at the beginning of a turbulent zone (due to efficient mixing within the turbulent spot), the velocity in the disturbed-laminar flow behind the spot adjusts slowly, resulting in an additional rms unsteadiness in discretely sampled values of $U$ which is not associated with turbulent-like fluctuations.

Filtering the velocity signal may allow separation of the real turbulence contribution from this coast-down anomaly, but this has not been tried. Monitoring on the term $w^{\prime}$ may provide a better estimate of the turbulence in the transition zone, since $\mathrm{W}=0$.

Since the $k-\varepsilon$ turbulence closure model is the most commonly used turbulence model in transition modelling, the $k$ and $\varepsilon$ equations will be examined.

\section{k-Equation:}

The $\mathrm{k}$ (or as presented here, $q$ ) equation can be derived exactly from the governing equations and is given by Reynolds (1976) as

$$
\frac{\partial q^{2}}{\partial t}+U_{j} \frac{\partial q^{2}}{\partial x_{j}}=2(P-\varepsilon)-\frac{\partial J_{j}}{\partial x_{j}}
$$

$q=\sqrt{\overline{u^{\prime 2}}+\overline{v^{\prime 2}}+\overline{w^{\prime 2}}}$. The term $\frac{q^{2}}{2}$ is the turbulent kinetic energy. The production term, $P$, is given as

$$
P=-\overline{u_{i}^{\prime} u_{j}^{\prime}} \frac{\partial U_{i}}{\partial x_{j}}
$$


The terms $-\overline{u^{\prime 2}} \frac{\partial U}{\partial x}, \overline{-\overline{u^{\prime} v^{\prime}} \frac{\partial U}{\partial y}}$ and $-\overline{v^{\prime 2}} \frac{\partial v}{\partial y}$, should be the most significant contributors to production. Along curved surfaces, additional production terms become significant, and the other terms are modified with the appropriate matrix coefficients. These terms can be found by expanding the equations given here into general curvilinear or polar coordinates. Details are given by Bradshaw (1973).

The dissipation of turbulent energy, $\varepsilon$, is given as

$$
\varepsilon=\frac{v}{2} \overline{\left(\frac{\partial u_{i}^{\prime}}{\partial x_{j}}+\frac{\partial u_{j}^{\prime}}{\partial x_{i}}\right)^{2}}
$$

All the dissipation term components require instantaneous measurement of spatial derivatives with fine spatial resolution. They cannot be measured with existing equipment, but the importance of $\varepsilon$ suggests that new measurement techniques or an approximation of the terms should be sought. Based on dimensional analysis, one can show

$$
\varepsilon \propto \frac{q^{3}}{L}
$$

where $\mathrm{L}$ is a characteristic length scale related to the dissipation of turbulent energy. The Taylor microscale, $\lambda$, can be used to find such a length scale. Hinze (1975, pp. 224-225) related the Taylor microscale to the Kolmogorov scale, $\eta$, at which dissipation occurs. He showed,

$$
\varepsilon=15 v \frac{\overline{u^{\prime 2}}}{\lambda^{2}}=\frac{v^{3}}{\eta^{4}}
$$


Using autocorrelations of the velocity in the time domain, $\lambda$ can be computed and used to find $\varepsilon$. An integral length scale, $\Lambda$, can also be found through an autocorrelation to characterize the large-scale turbulent motion. Details of the autocorrelation technique are available in Kim (1990). Work in evaluating $\varepsilon$, or length scales has been lacking in previous studies. Recent works by Suder, O'Brien and Reshotko (1988), Blair and Anderson (1987), and Kim (1990) include some documentation of length scales in the freestream. These are good first steps, but more should be done to determine length scales throughout the flow.

An equation for a "dissipation length scale" was presented by Hancock and Bradshaw (1989) as

$$
\mathrm{L}_{\mathrm{e}}^{\mathrm{u}}=\frac{\left(\overline{\mathrm{u}^{\prime 2}}\right)^{3 / 2}}{\mathrm{U} \frac{\partial \mathrm{u}^{\prime 2}}{\partial \mathrm{x}}}
$$

The term $L_{e}^{u}$ is often referenced and can be presented as an alternative length scale. A comparison of $L$ and $L_{e}^{u}$ suggests $U \frac{\partial \overline{u^{\prime 2}}}{\partial x}$ as an approximation for $\varepsilon$. This term can be measured.

The approximations given for $\varepsilon$ are thought to be reasonable, but direct measurement of $\varepsilon$ would still be very valuable. Direct measurement would require at least four probes close enough together to instantaneously determine terms such as $\left(\frac{\partial u^{\prime}}{\partial y}+\frac{\partial v^{\prime}}{\partial x}\right)$. This would be extremely difficult, but is possible. Browne, Antonia and Shah (1987) measured 9 of the 12 terms of the dissipation tensor in a free jet. They used various probes including a double cross wire. Such measurements 
would be more difficult in a boundary layer. The Browne, et al. results showed considerable anisotropy in the turbulence. In isotropic turbulence all derivatives of all three turbulence components are equal. If the fluctuations of this size in the boundary layer are assumed isotropic (which would be a reasonable assumption for the smallest scales where dissipation occurs) it would only be necessary to measure $\frac{\partial u^{\prime}}{\partial x}$. This would require two probes, and, while still difficult, it would be less complicated than four-probe measurements. Alternatively, since $\frac{\partial \mathrm{u}^{\prime}}{\partial \mathrm{x}} \cong \frac{1}{\mathrm{U}} \frac{\partial \mathrm{u}^{\prime}}{\partial \mathrm{t}}$, a single probe could be used if measurements were made at a sufficiently high sampling rate. The question of how close the two probes must be or how fast the sampling rate must be cannot be answered at this time, but a separation distance on the order of the scale at which dissipation occurs, or smaller, is a reasonable estimate. Kim (1990) measured the Taylor microscale in the freestream in his $8.3 \%$ TI case and found $\lambda=6.1 \mathrm{~mm}$. Based on this example and Hinze's (1975) ratio of the Kolmogorov scale to the Taylor microscale, a probe spacing of the order $0.1 \mathrm{~mm}$ might be adequate for measuring dissipation rates in the freestream. In a $10 \mathrm{~m} / \mathrm{s}$ flow this would correspond to a $100 \mathrm{kHz}$ sampling rate. Closer spacing or faster sampling might be required in the boundary layer.

The diffusive flux term, $\frac{\partial \mathrm{J}_{j}}{\partial \mathrm{x}_{\mathrm{j}}}$, is given as

$$
\frac{\partial J_{j}}{\partial x_{j}}=\frac{\partial}{\partial x_{j}}\left(\overline{u_{i}^{\prime} u_{i}^{\prime} u_{j}^{\prime}}+\frac{2 \overline{p^{\prime} u_{j}^{\prime}}}{\rho}-2 v \overline{u_{i}^{\prime}\left(\frac{\partial u_{i}^{\prime}}{\partial x_{j}}+\frac{\partial u_{j}^{\prime}}{\partial x_{i}}\right)}\right)
$$


The pressure fluctuation terms, $\frac{\partial}{\partial x_{j}}\left(\frac{2 \overline{p^{\prime} u_{j}^{\prime}}}{\rho}\right)$, would be nearly impossible to measure with present techniques. The turbulent transport terms, $\frac{\partial \overline{u^{\prime 3}}}{\partial x}$, $\frac{\partial \overline{u^{\prime 2} v^{\prime}}}{\partial y}$ and $\frac{\partial u^{\prime} v^{2}}{\partial x}$ can be found and presented. The viscous transport term, $-2 v u_{i}^{\prime}\left(\frac{\partial u_{i}^{\prime}}{\partial x_{j}}+\frac{\partial u_{j}^{\prime}}{\partial x_{i}}\right)$, would be difficult to measure for the same reason $\varepsilon$ is difficult to measure. The term is equal to $-v \frac{\partial q^{2}}{\partial x_{j}}$ in isotropic turbulence. This term, $-v \frac{\partial q^{2}}{\partial y}$, can be measured with existing techniques. The eddy transport of streamwise turbulence, $\overline{v^{\prime} u^{\prime} u^{\prime}}$, is an important term that can be easily measured.

\section{$\varepsilon$-Equation:}

The $\varepsilon$-equation is usually written under the assumption of isotropic turbulence. Measurements of anisotropy would be useful for assessing the accuracy of this assumption. The exact equation for the isotropic dissipation is given by Reynolds (1976) as

$$
\frac{\partial D}{\partial t}+U_{j} \frac{\partial D}{\partial x_{j}}=-W-\frac{\partial H_{j}}{\partial x_{j}}
$$

where $\mathrm{D}=\boldsymbol{\varepsilon}$ for isotropic turbulence. $\mathrm{H}$ and $\mathrm{W}$ represent the diffusive flux of $\mathrm{D}$ and the sink term for reduction of $\mathrm{D}$ respectively. 


$$
\begin{aligned}
& H_{j}=v \overline{\frac{\partial u_{i}^{\prime}}{\partial x_{k}} \frac{\partial u_{i}^{\prime}}{\partial x_{k}} u_{j}^{\prime}}+2 v \frac{\partial u_{j}^{\prime} \frac{\partial p^{\prime}}{\partial x_{k}}}{\partial x_{k}}-v \frac{\partial D}{\partial x_{j}} \\
& W=2 v \overline{\frac{\partial u_{i}^{\prime}}{\partial x_{j}} \frac{\partial u_{j}^{\prime}}{\partial x_{k}} \frac{\partial u_{k}^{\prime}}{\partial x_{i}}}+2 v^{2} \overline{\frac{\partial^{2} u_{i}^{\prime}}{\partial x_{j}^{2}} \frac{\partial^{2} u_{i}^{\prime}}{\partial x_{k}^{2}}}+2 v\left(\overline{\frac{\partial u_{i}^{\prime}}{\partial x_{j}} \frac{\partial u_{i}^{\prime}}{\partial x_{k}}} \frac{\partial U_{j}}{\partial x_{k}}+\overline{\frac{\partial u_{i}^{\prime}}{\partial x_{k}} \frac{\partial u_{j}^{\prime}}{\partial x_{k}}} \frac{\partial U_{i}}{\partial x_{j}}\right)+2 v \overline{u_{j}^{\prime} \frac{\partial u_{i}^{\prime}}{\partial x_{k}}} \frac{\partial^{2} U_{i}}{\partial x_{j} \partial x_{k}}
\end{aligned}
$$

They consist of complicated terms which cannot be easily measured. Derivatives of instantaneous pressure measurements would be needed to determine $\mathrm{H}$, and a six-wire probe capable of measuring three velocity components at two nearby points would be needed to find $W$. These terms will not be considered further here. The convection terms $U \frac{\partial D}{\partial x}$ and $\mathrm{V} \frac{\partial \mathrm{D}}{\partial \mathrm{y}}$ could be presented if proportional to $15 v \frac{\overline{u^{\prime 2}}}{\lambda^{2}}$. Current models of the dissipation equation are very empirical and could stand considerable improvement if measurements or terms computed from direct numerical simulations could lead the way. Determination of $D$ (or better still $\varepsilon$ ) would provide a significant start in the right direction.

\section{Reynolds Stress Equations:}

In anisotropic turbulence it will be advantageous in some cases to use a Reynolds stress model instead of the simpler $k-\varepsilon$ model. The Reynolds stress model uses individual equations to solve for each of the six unknown Reynolds stresses. This is in contrast to the $k-\varepsilon$ model which assumes isotropic turbulence and uses the turbulence intensity as a basis 
for all the Reynolds stresses. From Reynolds (1976), the exact Reynolds stress equations are

$$
\frac{\partial \overline{u_{i}^{\prime} u_{j}^{\prime}}}{\partial t}+U_{k} \frac{\partial \overline{u_{i}^{\prime} u_{j}^{\prime}}}{\partial x_{k}}=P_{i j}+T_{i j}-D_{i j}-\frac{\partial s_{i j k}}{\partial x_{k}}
$$

where

$$
\begin{gathered}
P_{i j}=-\overline{u_{i}^{\prime} u_{k}^{\prime}} \frac{\partial U_{j}}{\partial x_{k}}-\overline{u_{j}^{\prime} u_{k}^{\prime}} \frac{\partial U_{i}}{\partial x_{k}} \\
T_{i j}=\frac{1}{\rho} \overline{p^{\prime}} \overline{\left.\frac{\partial u_{i}^{\prime}}{\partial x_{j}}+\frac{\partial u_{j}^{\prime}}{\partial x_{i}}\right)} \\
D_{i j}=2 v \overline{\frac{\partial u_{i}^{\prime}}{\partial x_{k}} \frac{\partial u_{j}^{\prime}}{\partial x_{k}}}
\end{gathered}
$$

and

$$
J_{i j k}=\frac{1}{\rho}\left(\overline{p^{\prime} u_{i}^{\prime} \delta_{j k}}+\overline{p^{\prime} u_{j}^{\prime} \delta_{i k}}\right)+\overline{u_{i}^{\prime} u_{j}^{\prime} u_{k}^{\prime}}-v \frac{\partial \overline{u_{i}^{\prime} u_{j}^{\prime}}}{\partial x_{k}}
$$

Measurable quantities from the $T, D$ and $J$ terms have been considered above. Terms to consider from the production term, $P$, are

$$
-\overline{u^{\prime} v^{\prime}} \frac{\partial V}{\partial y},-\overline{v^{\prime 2}} \frac{\partial U}{\partial y},-\overline{u^{\prime 2}} \frac{\partial V}{\partial x}, \text { and }-\overline{u^{\prime} v^{\prime}} \frac{\partial U}{\partial x}
$$

for the $u^{\prime} v^{\prime}$ equation,

$$
-2 \overline{u^{\prime 2}} \frac{\partial U}{\partial x} \text { and }-2 \overline{u^{\prime} v^{\prime}} \frac{\partial U}{\partial y}
$$

for the $u^{\prime}$ equation, and

$$
-2 \overline{u^{\prime} v^{\prime}} \frac{\partial V}{\partial x} \text { and }-2 \overline{v^{\prime 2}} \frac{\partial V}{\partial y}
$$


for the $v^{\prime}$ equation. The terms $-\overline{v^{\prime 2}} \frac{\partial U}{\partial y},-2 \overline{u^{\prime 2}} \frac{\partial U}{\partial x},-2 \overline{u^{\prime} v^{\prime}} \frac{\partial U}{\partial y}$, and $-2 \overline{v^{\prime 2}} \frac{\partial v}{\partial y}$ would be the most significant contributors to the above terms. An important term in the flux equations, the eddy transport of Reynolds shear stress, $\overline{\mathrm{v}^{\prime 2} \mathrm{u}^{\prime}}$, can be easily measured.

In summation, the important measurable quantities are given in Table 1. The significant terms which can be calculated from these quantities are listed in Table 2.

In addition to the quantities listed in Tables 1 and 2, spectral measurements of $\mathrm{u}^{\prime}$ and $\mathrm{v}^{\prime}$ should be taken throughout the boundary layer. As already evidenced by Blair and Anderson (1987), Suder, O'Brien and Reshotko (1988) and Sohn and Reshotko (1991), spectra can be useful in explaining the transition process and in showing links between bypass and TS transition. Examining the spectra of two velocity components should help to explain the nature of any anisotropy in the flow. It would be very useful to determine the effect, if any, of the freestream spectra on bypass transition. This area has received little attention in the past.

The above suggestions should serve as a guide both for the review of experiments and for design of future experiments where it will be possible to examine more of the quantities of interest. 


\section{REVIEW OF EXPERIMENTS}

\section{Comparison of Data Sets}

The review which follows concentrates on recent experimental studies of bypass transition in two-dimensional boundary layers. The studies to be considered are listed in Table 3 along with a brief description of each. The extent to which each study is included in the review depends on the quantity and type of data available in each case. Most data used in this study were taken from Kim (1990), Wang (1984), Suder, O'Brien and Reshotko (1988), Sohn and Reshotko (1991), Blair and Werle (1980 and 1981), Blair (1981a and 1981b), Blair and Anderson (1987), Kuan (1987), Kuan and Wang (1990) and Rued (1987). The other references in Table 3 (i.e. Wang, Simon and Buddhavarapu (1985), Wang and Simon (1985), Kim, Simon and Kestoras (1989), Kim, Simon and Russ (1990), Sohn, O'Brien and Reshotko (1989), Blair (1982 and 1983) and Rued and Wittig (1985 and 1986) ) are shorter, more readily available papers based on the above references. Data used in this study are reproduced in tabulated form in the Appendix. The studies of Suder, O'Brien and Reshotko (1988) and Sohn and Reshotko (1991) were done in the same facility under the same nominal conditions. Both studies are included in the Appendix, but since they include the same cases, only the more recent study of Sohn and Reshotko (1991) is included in the graphical comparisons which follow.

The strategy for comparing the various data sets will be to concentrate on integral quantities such as boundary layer thicknesses, skin friction coefficients and Stanton numbers. An effort will be made to 
document and determine the effects of the turbulence spectra and length scales whenever possible. Given the available data, the prospects for this are limited, however.

Before a review of experimental results can proceed, careful definition of the parameters in question should be established. The parameter $k=\frac{v}{U_{\infty}^{2}} \frac{\partial U_{\infty}}{\partial x}$ has been used to characterize the streamwise pressure gradient in most studies. To characterize curvature, the radius, $\mathrm{R}$, of the test wall and the ratio of boundary layer thickness to $\mathrm{R}$ at a chosen point should be specified. The ratio $\theta / \mathrm{R}$ at the start of transition will be used as this descriptor.

A consistent definition of freestream turbulence level has been lacking in previous work. Some researchers have measured only streamwise velocity and have set $\mathrm{TI}=\sqrt{\overline{\mathrm{u}^{\prime 2}}} / \mathrm{U}_{\infty}$. Others have measured all three components of velocity and have set $T I=\frac{q}{\sqrt{3} U_{\infty}}$. Grid generated turbulence contains considerable anisotropy, especially at upstream locations. The above definitions could lead to measurably different TI values for a given experiment. The streamwise freestream turbulence $\mathrm{TI}=\sqrt{\overline{\mathrm{u}^{\prime 2}}} / \mathrm{U}_{\infty}$ could be chosen to provide consistency between all studies, but $\mathrm{u}^{\prime}$ does not provide as complete a description of the turbulence as does an expression with all three components. The total freestream turbulence $\mathrm{TI}=\frac{\mathrm{q}}{\sqrt{3} \mathrm{U}_{\infty}}$ is a better choice and will be used whenever possible. Blair and Werle (1980 and 1981), Blair (1981a and 1981b) and Blair and Anderson (1987) presented all three velocity components. Russ (1989) measured all three components for Kim's (1990) flat-wall cases. When only $\mathrm{u}^{\prime}$ and $\mathrm{v}^{\prime}$ are available, $\mathrm{v}^{\prime} \approx \mathrm{w}^{\prime}$ will be assumed and 
$\mathrm{TI}=\sqrt{\frac{\mathrm{u}^{\prime 2}}{3 \mathrm{U}_{\infty}^{2}}+\overline{\mathrm{v}^{\prime 2}}}$ will be computed. This was done for Rued's (1987) and Kuan and Wang's (1990) studies and for Kim's (1990) curved wall cases. In cases where only $\mathrm{u}^{\prime}$ is available, $\mathrm{TI}=\sqrt{\overline{\mathrm{u}^{\prime 2}}} / \mathrm{U}_{\infty}$ will be used for lack of a better alternative. The freestream turbulence $T I=\sqrt{\overline{u^{\prime 2}}} / U_{\infty}$ is used with Sohn and Reshotko (1991), Suder, et al. (1988) and Wang's (1984) studies. To distinguish the basis for the TI values quoted in this report, the numerical values will be followed by the descriptor (1D) for cases based only on $u^{\prime},(2 D)$ for cases based on $u^{\prime}$ and $v^{\prime}$, and (3D) for cases based on all three velocity components.

The location where the TI should be specified also must be clarified. Especially in high freestream turbulence, the TI level decays significantly with streamwise distance and a single value may not be characteristic of values for the entire test section. Figure 3 shows TI plotted vs $\mathrm{x}$ for several experimental cases. In accordance with the practice of AbuGhannam and Shaw (1980), the published TI level is based on the measured level midway between the transition start location and the leading edge. This results in slightly different values than presented by the authors of the various data sets who used leading edge values only. When the transition end is of interest, the TI level midway between the transition end location and the leading edge is given.

The length scales associated with the freestream turbulence should be specified, although it is not yet clear how these scales affect the flow. Kim (1990) used an autocorrelation technique and determined the Taylor microscale and the integral length scale near the leading edge for his highest TI case. Suder, O'Brien and Reshotko (1988) and Blair and Werle 
(1980) both determined the integral scale for all of their turbulence grids at several streamwise points. The results of the three studies are in reasonable agreement. Integral length scales are highest for the coarsest grids. The integral scales increase with streamwise distance since the smallest scales of the turbulence dissipate faster than the larger scales. An attempt was made to determine Hancock and Bradshaw's (1989)

dissipation length scale, $\mathrm{L}_{\mathrm{e}}^{\mathrm{u}}=\frac{\left(\overline{\mathrm{u}^{\prime 2}}\right)^{3 / 2}}{\mathrm{U} \frac{\partial \mathrm{u}^{\prime 2}}{\partial \mathrm{x}}}$, but no observable trends or correlations within or between data sets existed. Given the uncertainty in $u^{\prime}$ and the difficulty in evaluating $\frac{\partial \overline{u^{\prime 2}}}{\partial x}$, the inconsistency in $L_{e}^{u}$ could have been expected.

Freestream turbulence spectra were presented by Kim (1990), Sohn and Reshotko (1991), Suder, et al. (1988) and Blair and Anderson (1987). Suder, et al. and Blair and Anderson nondimensionalized their spectra using a technique from Hinze $\left(1975\right.$, p. 66) and presented plots of $\frac{\mathrm{UE}(f)}{\mathrm{u}^{\prime 2} \Lambda}$ vs $\frac{\Lambda f}{U}$, where $E(f)$ is a measure of the fluctuation energy at a particular frequency. The nondimensional spectra were shown to be in good agreement with Taylor's analytical spectral distribution

$$
\frac{\mathrm{UE}(\mathrm{f})}{\mathrm{u}^{\prime 2} \Lambda}=\frac{4}{1+(2 \pi \Lambda \mathrm{f} / \mathrm{U})^{2}}
$$

as presented by Hinze (1975). The experimental evidence indicates a similarity in the makeup of all grid-generated turbulence. In both of 
these studies the turbulence generating grid was located upstream of the wind tunnel contraction. A grid downstream of the contraction may have produced different results. Neither study includes spectra for their lowest TI cases, which were done without grids. Kim (1990) presented spectra data taken near the leading edge for his three turbulence levels including the low TI case which was done without a grid. Kim's data does not allow a quantitative comparison to Taylor's theory, but efforts are currently underway to remeasure these spectra more quantitatively. Preliminary findings agree with Kim's results, but suggest that his presentation may be somewhat misleading due to the range of frequencies included in his plots. A preliminary test (which is still subject to verification) in conditions corresponding to Kim's low TI case suggests that the spectrum in this case does agree with Taylor's analytical curve. The energy in this case is concentrated at low frequencies, with approximately $99 \%$ below 25 $\mathrm{Hz}$. It is suspected that such low-frequency fluctuations are present to some extent in all studies, with variations from facility to facility. They are probably most pronounced in low TI cases. The effect of the lowfrequency fluctuations on transition is not known. Since these frequencies are well below the "dangerous" frequencies predicted by the linear stability theory, they probably have little effect on transition. Thus, some question is raised as to the appropriateness of the TI levels quoted, especially for the low TI cases. It may be more appropriate to filter the data and present TI levels based only on the contributions in frequency bands for which disturbances are suspected to affect transition. Boundary layer spectra which show the growth of disturbances at particular frequencies tend to support the idea that some disturbances contribute 
more to transition than others. The limited amount of spectral data available does not suggest any conclusive recommendation on what frequency band should be used to determine the TI, so TI levels based on the entire spectrum will be used in this study.

In previous studies, data is often presented in terms of $\mathrm{x}$ or $\operatorname{Re}_{\mathrm{X}}$. This is convenient since the streamwise location of any measurement station is easily found. It would be more appropriate, however, to present data in terms of "local" boundary layer coordinates. This is particularly true after transition, where $\mathrm{x}$-based coordinates become dependent upon a virtual origin and, thus, the leading edge position loses significance. Several local coordinates, including $\delta 99.5, \delta^{*}$ and $\theta$, are possible. The momentum thickness, $\theta$, is chosen for all hydrodynamic comparisons. Both $\theta$ and the enthalpy thickness, $\Delta_{2}$, are used for heat transfer comparisons. The momentum thickness, $\theta$, is chosen to provide a single, consistent basis for comparison of all quantities, and $\Delta_{2}$ is chosen because the relationship of St to $\Delta_{2}$ can be analogous to the relationship of $\mathrm{c}_{\mathrm{f}}$ to $\theta$.

\section{Boundary Layer Growth}

Figures 4 through 7 show $\operatorname{Re}_{\theta}$ plotted $v s e_{x}$. TI is specified in each case near the start of transition. Figure 4 shows several unaccelerated, flat-wall cases. $\operatorname{Re}_{\theta}$ follows the expected laminar solution until transition begins. Transition occurs increasingly early as the TI increases. For TI above about $2 \%$, the change in the transition start location becomes small with further increases in TI. This is expected since at $\mathrm{TI}=2 \%$ the transition start is already near the leading edge. There is some unexpected behavior in some of the individual cases shown in Figure 4. The last case to start 
transition is Wang's $0.68 \%$ (1D) TI case. It started transition after Kim's $0.3 \%$ (3D) and Sohn and Reshotko's 0.45\% (1D) cases. Wang's case was not simply out of order, however. Once transition started, the boundary layer in Wang's $0.68 \%$ (1D) case grew faster than in the lower TI cases and, by the end of transition, was in the expected position relative to Kim's $0.3 \%$ (3D) case. Sohn and Reshotko's $0.83 \%$ (1D) and $1.1 \%$ (1D) cases provide another example of unexpected behavior. These cases appear out of order with respect to Kuan and Wang's $0.9 \%$ (2D) case, Rued's $1.3 \%$ (2D) case and Kim's $1.5 \%$ (3D) case.

The expected end of transition, in terms of $\operatorname{Re}_{\mathrm{X}}$ and $\mathrm{Re}_{\theta}$, was calculated for each of the cases in Figure 4 using the indicated TI level and the following empirical correlations from Abu-Ghannam and Shaw (1980).

$$
\begin{gathered}
\operatorname{Re}_{\theta_{\mathrm{e}}}=2.667 \operatorname{Re}_{\theta_{s}} \\
\operatorname{Re}_{\theta_{s}}=163+\exp (6.91-\mathrm{TI}) \\
\operatorname{Re}_{\mathrm{x}_{\mathrm{e}}}=\operatorname{Re}_{\mathrm{x}_{\mathrm{s}}}+16.8\left(\operatorname{Re}_{\mathrm{x}_{\mathrm{s}}}\right)^{0.8} \\
\operatorname{Re}_{\mathrm{x}_{\mathrm{s}}}=\left(\operatorname{Re}_{\theta_{s}} / 0.664\right)^{2}
\end{gathered}
$$

The subscripts $s$ and e designate the start and end of transition respectively. A virtual origin was then calculated for the post-transition data in each case, and the curves in Figure 4 were shifted appropriately. The results are shown in Figure 5. Also shown is a fully-turbulent correlation from Kays and Crawford (1980, eqn. 10-22). Most of the post- 
transition data matches the fully-turbulent prediction. An exception is Blair's $0.165 \%$ (3D) TI case. The curve in this case appears to be shifted too far to the left, indicating that the actual TI in this case may be significantly higher than the value indicated. A TI of $1 \%$ in this case would have resulted in better agreement with the turbulent correlation. Sohn and Reshotko's $0.83 \%$ (1D) and $1.1 \%$ (1D) cases also appear to be shifted too far to the left. These two cases were also out of place in Figure 4. Wang's $0.68 \%$ (1D) case, which stood out in Figure 4 , follows the expected correlation in Figure 5.

Figure 6 shows the effects of curvature on boundary layer growth. Flat and concave wall data are taken from Kim (1990), and flat and convex wall data are taken from Wang (1984). At $\mathrm{TI}=0.68 \%$ (1D), convex curvature delays transition. Once transition starts, $\operatorname{Re}_{\theta}$ increases with approximately the same slope in both the flat and curved cases. For Wang's weaker curvature case $(R=180 \mathrm{~cm})$, departure from the laminar solution occurs at $\operatorname{Re}_{\theta} \approx 900$, which corresponds to $\theta / R \approx 2.5 \times 10^{-4}$. It is interesting that increasing the curvature from $R=180 \mathrm{~cm}$ to $R=90 \mathrm{~cm}$ did not further delay transition. This may signal a problem with the test. It is possible that corner effects may have caused early transition in this case, thereby violating the two-dimensional boundary layer assumption. It is also recognized that there is some three-dimensionality of the transition onset position. If the difference of curvature effects between the two cases is sufficiently small, case to case variations at any particular spanwise location (such as the wall center-span) due to the streakiness of transition and the possible reorientation of the streaks by small perturbations may explain the unexpected behavior in Wang's data. In 
the higher freestream turbulence (TI=2\% (1D)) case, convex curvature appears to have no effect on the transition position. Departure from the laminar solution occurs at $\operatorname{Re}_{\theta} \approx 300$ or $\theta / R \approx 0.7 \times 10^{-4}$. Freestream turbulence effects appear to dominate over curvature in this case. Kim's results show a marked upstream movement of transition with concave curvature in the $\mathrm{TI}=0.6 \%$ (2D) case. Curvature caused the formation of Görtler vortices (shown as upwash and downwash cases) which certainly must have played a role in causing early transition. Transition occurred first at upwash locations. In Kim's $\mathrm{TI} \approx 8 \%$ (3D,2D) cases, transition occurred upstream of the first measurement station so the effect of curvature could not be seen. Görtler vortices were not observed in the high TI case.

Figure 7 shows the effects of acceleration using data from Blair's (1981b) study. Also shown are the results of numerical simulations of laminar and fully-turbulent cases computed with Crawford's TEXSTAN program and a mixing length closure model (TEXSTAN is an updated version of Crawford and Kays' (1976) STAN5 program). Unlike curvature, which was dominated by turbulence effects at higher $\mathrm{TI}$, acceleration is seen to play a role in suppressing the boundary layer growth at all TI levels. For $\mathrm{TI}=0.93 \%$ (3D) with $\mathrm{k}=0.2 \times 10^{-6}$, and $\mathrm{TI}=1.9 \%$ (3D) with $\mathrm{k}=0.75 \times 10^{-6}$ transition is delayed significantly in terms of $\operatorname{Re}_{\mathrm{X}}$ (compare to Figure 4). Accelerations with $\mathrm{k}=0.2 \times 10^{-6}$ and $\mathrm{k}=0.75 \times 10^{-6}$ are not particularly strong. Acceleration in gas turbines can be considerably higher. It would be interesting to study the combined effects of curvature and acceleration. The thinner boundary layer of the accelerated flow may tend to lessen the curvature effects, but the delayed transition due to 
acceleration may increase the importance of curvature. To the authors' knowledge, no systematic study of the combined effects of curvature and acceleration has been done.

\section{Skin Friction}

The skin friction coefficient, $c_{f}$, is plotted vs $\operatorname{Re}_{\theta}$ in Figures 8 through 10. Figure 8 shows the results of flat-wall, zero-pressure-gradient cases. Before transition, $\mathrm{c}_{\mathrm{f}}$ follows the laminar solution, and, after transition, it matches a fully-turbulent correlation from Schlichting (1979, eqn. 21-12). Within transition, most of the data appears reasonable, showing the expected trend toward earlier transition as TI is increased. As with the boundary layer thickness data in Figure 4, there is some unexpected behavior apparent in Figure 8. Wang's $0.68 \%$ (1D) TI case undergoes transition after Kim's $0.3 \%$ (3D) case. Kuan and Wang's 0.9\% (2D) case starts transition after Sohn and Reshotko's $0.83 \%$ (1D) and $1.1 \%$ (1D) cases, but then crosses these two cases and Sohn and Reshotko's 2.6\% (1D) case in the transition region. Sohn and Reshotko's 2.6\% (1D) case appears out of order with respect to Kim's 1.5\% (3D) case and Wang's $2.2 \%$ (1D) case. There appears to be some transition behavior which is not fully explained by the TI values given. There must be some other factors, possibly associated with the turbulence spectra or length scales, which are influencing transition. It should also be noted that Sohn and Reshotko's results were not in good agreement with Suder, et al.'s data (which are not shown in the figure), although both studies were done in the same facility under the same conditions. The differences in the data may have resulted 
from modification to the test wall done to allow heat transfer measurements in the latter study.

Figure 9 shows the effect of curvature on skin friction. In Wang's $0.68 \%$ (1D) TI cases, weak curvature $(\mathrm{R}=180 \mathrm{~cm})$ delayed transition as expected, but stronger curvature $(\mathrm{R}=90 \mathrm{~cm})$ caused transition to shift back upstream. This behavior was noted above in the boundary layer thickness discussion. At $\mathrm{TI}=2 \%$ (1D), convex curvature had little effect on transition. The effect of concave curvature is obvious. The results at the upwash and downwash locations were very different from one another and from the convex and flat-wall cases. At the downwash locations in particular, $c_{f}$ was well above the fully-turbulent correlation line even after transition was complete. The upwash data appears to more or less agree with the flat wall data. It may be that transition proceeds at the upwash in a similar manner to that on the flat wall, at least in terms of $\operatorname{Re}_{\theta}$. The flow in the downwashes may be prematurely tripped to turbulence by the adjacent upwashes.

Figure 10 shows the effects of acceleration on $c_{f}$ using Blair's (1981b) data. The skin friction coefficient, $c_{f}$, in transition was calculated in this study from Blair's velocity profile data. After transition, Blair gives $c_{f}$ obtained using the Clauser technique. There is considerable scatter in the transition region data due to the uncertainty involved in computing $\frac{\partial U}{\partial y}$. Agreement with the empirical correlations for unaccelerated flow is good in both the laminar and fully-turbulent regions. Crawford's TEXSTAN program predicts higher $c_{f}$ in terms of $\operatorname{Re}_{\theta}$ for accelerated cases in both laminar and fully-turbulent flow. This is particularly apparent in 
Figure 10 for the fully-turbulent, $k=0.75 \times 10^{-6}$ simulation. Blair's data tend to agree with the TEXSTAN predictions, although there is not enough high $\operatorname{Re}_{\theta}$ data at the higher acceleration to confirm the turbulent flow TEXSTAN prediction.

\section{Heat Transfer}

The effects of freestream turbulence, curvature and acceleration on Stanton number are shown in Figures 11 through 17 . Stanton number is plotted vs $\operatorname{Re}_{\theta}$ and $\operatorname{Re}_{\Delta 2}$. $\operatorname{Re}_{\theta}$ is used as the independent variable to provide consistency with, and allow comparison to, the skin friction results presented above. If Reynolds analogy between heat and momentum transport were to strictly hold, plotting Stanton number vs $\operatorname{Re}_{\theta}$ should be equivalent to plotting vs $\operatorname{Re}_{\Delta 2}$. By plotting vs both $\operatorname{Re}_{\theta}$ and $\operatorname{Re}_{\Delta 2}$, violations of Reynolds analogy should be made apparent. In most of the studies in which heat transfer quantities were considered, all quantities (Stanton numbers, velocity profiles, temperature profiles, etc.) were measured with the test wall heated. In Kim's (1990) $0.3 \%$ (3D) TI study, however, hydrodynamic quantities such as velocity profiles and intermittency measurements were taken with the test wall unheated. In fully-turbulent flow, wall heating at the levels considered here has only a minor effect on hydrodynamic quantities. In transitional flow, however, heating tends to destabilize the flow (through viscosity effects), moving transition upstream. Evidence of this effect is provided by Kim (1990) and Rued (1987). Some caution should, therefore, be exercised in evaluating Kim's $0.3 \%$ (3D) TI data when presented in terms of St vs $\operatorname{Re}_{\theta}$. 
Figure 11 shows $S t$ plotted vs $\operatorname{Re}_{\theta}$ for several flat-wall, unaccelerated cases. Laminar and fully developed turbulent correlations are taken from Kays and Crawford (1980). (The laminar correlation combines Kays and Crawford's equations 9-40 and 7-20. The turbulent correlation combines equations $12-27$ and 10-22.) Before transition, the match to the laminar solution is good. After transition the agreement with the turbulent correlation is not good. The higher TI cases match the correlation best. The behavior of the Stanton number is somewhat different than that of the skin friction coefficient, which is seen in Figure 8. The $c_{f}$ data match the turbulent correlation relatively quickly after transition. From Blair's (1981a) data in Figure 11, St is seen to be lower in the turbulent flow for lower TI cases. Figure 12 is an expanded version of Figure 11, showing the transition region more clearly. Transition occurs at lower $\operatorname{Re}_{\theta}$ for higher TI cases, as expected. There is some unexpected crossing of cases and cases out of the expected order as was seen with $c_{f}$ vs $\operatorname{Re}_{\theta}$ in Figure 8. Wang's (1984) data indicates unusually low St in the transition and fully-turbulent region. Wang presented energy balances which deviate significantly from 2-dimensional closure at downstream locations. The deviations are large enough to explain the unusual Stanton numbers after the onset of transition in Figure 11 . This may be due to a loss of 2-dimensionality in this case. Later experiments by Kim (1990) and Sohn and Reshotko (1991) show closer energy balance closure.

Figure 13a shows Stanton number plotted vs enthalpy thickness Reynolds number, $\operatorname{Re}_{\Delta 2}$, for the cases shown in Figures 11 and 12. Also shown are laminar and turbulent correlations obtained using a solution procedure from Ambrok as described by Kays and Crawford (1980, page 
218). Note that Blair's (1981a) $\Delta_{2}$ data were modified to conform to the definition of enthalpy thickness used in this report (see the appendix of this report, pp. 117-121). Figure 13a is similar to Figures 11 and 12, verifying Reynolds analogy in terms of the integral quantities $\operatorname{Re}_{\theta}$ and $\mathrm{Re}_{\triangle 2}$. A TEXSTAN solution (not shown in the figure) agrees with the turbulent correlation. Wang's data still shows unusual behavior as discussed above. Figure $13 \mathrm{~b}$ shows the Reynolds analogy factor, $2 \mathrm{St} / \mathrm{c}_{\mathrm{f}}$, plotted vs $\operatorname{Re}_{\theta}$ for the flat wall, unaccelerated cases. The Reynolds analogy factor provides a means of evaluating how well a flow obeys Reynolds analogy in terms of the wall values $c_{f}$ and St. Based on laminar and turbulent correlations for $\mathrm{c}_{\mathrm{f}}$ and St (see Figs. 8 and 11), one should expect $2 \mathrm{St} / \mathrm{c}_{\mathrm{f}}$ to drop from approximately 1.7 in laminar flow to 1.2 in fully-turbulent flow. There is considerable scatter in the data in Figure $13 \mathrm{~b}$, but in general it follows the expected trend. The higher TI cases start transition earliest and approach the fully-turbulent value more quickly than the lower TI cases. Wang's (1984) data undershoots the other fully-turbulent data and the expected value of 1.2 . This is consistent with the low Stanton numbers shown in Figures 12 and 13a for this data.

Figure 14 shows the effects of curvature. Stanton number is plotted vs $\operatorname{Re}_{\theta}$. As with the skin friction coefficient in Figure 9, the effect of increasing the strength of convex curvature from $R=180 \mathrm{~cm}$ to $R=90 \mathrm{~cm}$ is hard to distinguish. In Kim's study, complete Stanton number and $\operatorname{Re}_{\theta}$ data is available only at the downwash location, making it difficult to fully see the effects of concave curvature. The flat plate correlations are included in the figure. All of the data fall below the fully-turbulent 
correlation. Figure $15 \mathrm{a}$ shows Stanton number plotted vs $\operatorname{Re}_{\Delta 2}$ for the curved-wall cases. In Kim's lower turbulence intensity case, Stanton numbers were measured at both upwash and downwash locations. This was accomplished by varying the flow conditions so that either an upwash or downwash fell over the thermocouples at the wall center-span. To measure the downwash Stanton numbers, the mean freestream velocity was set to $U_{p w}=17.2 \mathrm{~m} / \mathrm{s}$. The corresponding freestream turbulence level was $0.6 \%$ (2D). To measure the upwash Stanton numbers, the mean freestream velocity was set to $U_{p w}=6.74 \mathrm{~m} / \mathrm{s}$. The freestream turbulence intensity was not measured for this case. In terms of the Stanton number, transition started at approximately the same $\operatorname{Re}_{\Delta 2}$ for both the upwash and downwash cases. In the upwash, transition proceeded more quickly and the Stanton numbers rose to higher values than in the downwash. In both the upwash and the downwash, the data fell below the turbulent correlation. Kim's high (8.3\% (2D)) TI case falls well above the turbulent correlation. Görtler vortices were not observed in this case. The convex wall cases appear similar in Figures 14 and 15a. Figure 15b shows the Reynolds analogy factor plotted vs $\operatorname{Re}_{\theta}$ for the curved wall cases. Other than the effect of curvature on transition $\operatorname{Re}_{\theta}$, the results are similar to those in Figure 13b for the flat wall cases.

Acceleration effects are shown in Figures 16 and 17 . Stanton number is plotted vs $\operatorname{Re}_{\theta}$ in Figure 16 for Blair's (1981b) accelerated flow cases. The data follow the laminar correlation (which was derived for unaccelerated flow) before transition. TEXSTAN solutions show only slight deviation of acceleration cases from the unaccelerated laminar solution. In and after transition the effects of acceleration are very apparent. At 
$\mathrm{TI} \approx 2 \%$ (3D), higher acceleration clearly delays transition. This was even more apparent in the original paper (Blair and Werle, 1981) where St was plotted vs x. Downstream of transition, higher acceleration causes a faster drop in St with increasing $\operatorname{Re}_{\theta}$. TEXSTAN simulations of fully-turbulent cases at the two given acceleration values are in good agreement with the trends of the experimental data. Figure 17a shows the same cases in St vs $\operatorname{Re}_{\Delta 2}$ coordinates. Blair's (1981b) $\Delta_{2}$ data were modified to conform to the definition of enthalpy thickness used in this report (see the appendix of this report, pp. 122-129). The experimental results appear quite different from those of Figure 16. Stanton numbers match the laminar, unaccelerated correlation and agree with the TEXSTAN simulations in the laminar region. Higher acceleration at the intermediate TI level causes a delay in transition and a lengthening of the transition region in $\operatorname{Re}_{\Delta 2}$ coordinates. The trends of the experimental data are in good agreement with the TEXSTAN turbulent flow simulations downstream of transition. The effects of acceleration are apparent in $\operatorname{Re}_{\Delta 2}$ coordinates, but are not as dramatic as in $\operatorname{Re}_{\theta}$ coordinates. The different appearance of the effects of acceleration in $\operatorname{Re}_{\theta}$ and $\operatorname{Re}_{\Delta 2}$ coordinates may be due to a breakdown in Reynolds analogy in the transition region. In and after transition, the analogy between heat and momentum transport is weakened, so the appropriateness of comparing Stanton numbers in terms of $\operatorname{Re}_{\theta}$ breaks down. Acceleration weakens the analogy further by inhibiting the growth of the momentum boundary layer. This is apparent in Figure 17b, which shows the Reynolds analogy factor plotted vs $\operatorname{Re}_{\theta}$ for the accelerated flow cases. There is a significant drop below the expected fully-turbulent, flat wall value of 1.2. Figure 18 shows $\operatorname{Re}_{\Delta 2}$ plotted vs $\operatorname{Re}_{\theta}$ for several cases. 
With only a few exceptions, the data from the unaccelerated cases, both on flat and curved walls, lie along a line with slope near one. The accelerated cases all show a much steeper slope, further illustrating the more pronounced breakdown in Reynolds analogy due to acceleration. Kim's (1990) unaccelerated, low TI $(0.3 \%$, (3D)) case also deviates significantly from the other unaccelerated cases. As mentioned above, $\operatorname{Re}_{\Delta 2}$ was determined in this case with the test wall heated, while $\operatorname{Re}_{\theta}$ was calculated from velocity profiles taken in unheated flow. Recall that there was a noticeable effect of heating the wall on transition for this case. Figure 18 shows that transition region data taken under heated and unheated conditions cannot always be compared, particularly under low TI conditions.

\section{The Location of Transition}

The location of the transition zone can be determined by a number of methods. Kuan and Wang (1990) list the following seven:

1. the origin of the turbulent boundary layer obtained by extrapolating the boundary layer thickness backward to a zero thickness,

2. the point of minimum skin friction coefficient,

3. the point where the near wall intermittency reaches a prescribed small value, for example, $\gamma(x, y \approx 0)=0.1$,

4. the location of minimum dynamic pressure in the streamwise direction at a small, fixed distance from the wall,

5. the point where the shape factor $\left(\delta^{*} / \theta\right)$ starts to deviate from the laminar flow value of 2.6 , 
6. the first occurrence of a breakdown signal overriding on the sinusoidal signal (applies more appropriately to TS transition), or

7. the first appearance of a turbulent streak or turbulent spot.

An additional criterion is the point of minimum heat transfer (minimum St). The data sets under consideration allow the determination of the transition location based on the skin friction coefficient, the Stanton number and the intermittency. An attempt was made to use the skin friction, but since it is only available in most studies at points where velocity profiles were taken, the spacing between measurements was usually too large to allow a reasonably close estimate of the transition zone start or end. Another problem with $c_{f}$ is the variability in the methods used to find it. Kim (1990), for example, chose $c_{f}$ to fit the nearwall velocity profile to $\mathrm{u}^{+}=\mathrm{y}^{+}$. Suder, et al. (1988) used the momentum thickness to find $c_{f}=2 \frac{\partial \theta}{\partial x}$. Blair $(1981 b)$ did not calculate $c_{f}$ in transition, although he presents all the necessary data with which to do so. Stanton numbers were determined in most studies with more spatial resolution than $c_{f}$, through the use of wall thermocouples. The beginning of transition was taken as the point of minimum Stanton number. The end of transition was taken as the local maximum which followed. The corresponding $\operatorname{Re}_{\theta}$ and $\mathrm{TI}$ were determined by interpolating or extrapolating the available data from the velocity profile and turbulence measurements. The results are listed in Table 4 and are plotted in Figures 19 through 21. Also in the figures are the empirical curves of AbuGhannam and Shaw (1980). These curves are based on older studies, 
which based transition location on such criteria as the minimum skin friction coefficient, the minimum dynamic pressure near the wall and flow visualization. Also shown in Figure 19 are correlations from McDonald and Fish (1973) and Van Driest and Blumer (1963) which are in reasonable agreement with Abu-Ghannam and Shaw (1980). The correlations differ by as much as $\operatorname{Re}_{\theta}=100$, but this is small compared to the scatter in the experimental data. The agreement between the experimental data and the correlations for zero-pressure-gradient, flatwall cases in Figure 19 is reasonable. Given the difficulties of specifying the TI described above, no better fit could be expected.

In the curved wall cases shown in Figure 20, the limited amount of data makes it difficult to draw any clear conclusions. The expected trends of convex curvature delaying transition and concave curvature causing a shorter transition zone are supported, but more experimental results would be desirable. The correlations shown are for flat plates.

Figure 21 shows the effect of acceleration. Favorable pressure gradients appear to have little effect on $\operatorname{Re}_{\theta}$ at the start of transition. This is in agreement with the findings of Abu-Ghannam and Shaw (1980), who showed only a small acceleration effect on transition onset (the curves shown are for unaccelerated flow). Although transition is delayed significantly in terms of $\mathrm{x}$ or $\mathrm{Re}_{\mathrm{X}}$, the slower boundary layer growth in accelerated flow results in a largely unchanged $\operatorname{Re}_{\theta}$ at the start of transition.

A second method of determining transition location, based on the intermittency, was also used. The method is based on Narasimha's (1984) theory, which is in turn derived from Emmons' (1951) theory of turbulent 
spots. The highest $\gamma$ value in the flow at each streamwise measuring station in a test was used to calculate the function

$$
f(\gamma)=(-\ln (1-\gamma))^{1 / 2}
$$

$f(\gamma)$ was then plotted vs x. An example using Blair and Anderson's (1987) data is shown in Figure 22. The data for higher $f$ values $(>0.3)$ falls along a straight line. For lower $\mathrm{f}$, the data has a different slope. Narasimha (1984) and Blair and Anderson (1987) both observed this change in slope for accelerated flow cases and referred to it as a "subtransition", although it may be merely an artifact of a changing Pohlhausen acceleration parameter (in a constant-k flow). To determine the start and end of transition, attention is focussed on the data points downstream of any subtransition. A least-squares fit to these data points was extrapolated to $f=0$ and $f=2.146$, which correspond to $\gamma=0$ and $\gamma=0.99$, respectively. The corresponding $\mathrm{x}$ at the two extrapolated points were taken as the locations of the start and end of transition. $\operatorname{Re}_{\theta}, \mathrm{Re}_{\mathrm{X}}$ and $\mathrm{TI}$ at the indicated $\mathrm{x}_{\mathrm{S}}$ and $\mathrm{x}_{\mathrm{e}}$ were found using the original data sets. The results for several studies in both unaccelerated and accelerated flow are presented in Table 5 and Figure 23. Agreement with the Stanton-number-based transition locations of Table 4 and Figures 19 and 21 is reasonable. In a few cases, the extrapolated start of transition was upstream of the leading edge (i.e. $x_{S}<0$ ). The negative $x_{S}$ are obviously physically unrealistic, and indicate a limitation of the extrapolation technique. Since the negative $x_{S}$ are not representative of the actual transition start, they are not included in Table 5 or Figure 23. The cases involved are Suder, et al.'s (1988) $2.0 \%$ and $4.3 \%$ (1D) TI cases and Kuan and Wang's (1990) 0.9\% (2D) case. Figure 24 
shows the results from those cases where both Stanton number and $\gamma$ data are available. Some differences in the results should be expected since the point of minimum Stanton number is located somewhat downstream of the point where the intermittency first becomes nonzero. The intermittency based start of transition in Sohn, O'Brien and Reshotko's (1989) $2.6 \%$ (1D) TI case is in significantly better agreement with the Abu-Ghannam and Shaw (1980) correlation than the Stanton-numberbased transition start. The differences in the other cases are less dramatic.

\section{Intermittency}

The intermittency within the transition zone is plotted as a function of dimensionless streamwise coordinate in Figure 25. The abscissa is a modified version of Dhawan and Narasimha's (1958) coordinate. Dhawan and Narasimha used $\frac{x-x_{S}}{x_{e}-x_{S}}$ where $x_{S}$ is taken at $\gamma=0.25$ and $x_{e}$ is taken at $\gamma=0.75$. Here, $x_{S}$ is taken at the extrapolated $\gamma=0$ location and $x_{e}$ at the extrapolated $\gamma=0.99$ location. The modification was done to give $x$ estimates which are closer to the actual start and end of transition. The change was purely algebraic; the theory remains exactly as Dhawan and Narasimha presented it. Dhawan and Narasimha present a formula which, when modified to take the changed abscissa into account is

$$
\gamma=1-\exp \left(-4.6\left(\frac{x-x_{s}}{x_{c}-x_{s}}\right)^{2}\right)
$$

This curve is plotted along with experimental data from Kim (1990), Kuan and Wang (1990), Sohn, O'Brien and Reshotko (1989), and Blair and 
Anderson (1987), in Figure 25. The negative $\mathrm{x}_{\mathbf{s}}$ values mentioned above were used in the intermittency data reduction. Unaccelerated and accelerated cases agree well with the analytical curve. Results presented by Gostelow and Walker (1990) show that the agreement is also good for adverse pressure gradient cases. Whether the agreement is good for curved surfaces should be checked in future experiments. The variation of the Stanton number with the intermittency is shown in Figure 26. $\frac{\mathrm{St}-\mathrm{St}_{3}}{\mathrm{St}_{\mathrm{e}}-\mathrm{St}_{\mathrm{s}}}$ is plotted verses $\gamma . \mathrm{St}_{\mathrm{S}}$ and $\mathrm{St}_{\mathrm{e}}$ are the Stanton numbers used to determine the Stanton-number-based start and end of transition. The data collapses fairly well in these coordinates. Stanton numbers do not begin to rise significantly until the intermittency reaches approximately 25 to $35 \%$. This indicates a significant delay between the first appearance of turbulent spots and a corresponding reaction in the heat transfer. In accelerated flow, the Stanton numbers continue decreasing at low $\gamma$, as they would in laminar flow. This is particularly apparent in Blair's $\mathrm{k}=0.75 \times 10^{-6}$ cases. Above $\gamma \approx 20 \%$, however, the accelerated cases are in agreement with the unaccelerated.

\section{Turbulent Spot Formation Rate}

The production and growth of turbulent spots in the transition region can be predicted according to Dhawan and Narasimha's (1958) theory. As given by Mayle (1991),

$$
\gamma=1-\exp \left[-\frac{n \sigma}{U}\left(x-x_{s}\right)^{2}\right]
$$


where $n$ is the turbulent spot production rate and $\sigma$ is the turbulent spot propagation parameter. A dimensionless spot production rate, $\hat{n}, \hat{s}$ defined as $\frac{n v^{2}}{U_{s}^{3}}$. The velocity $U_{S}$ is the freestream velocity at the start of transition. The product no is directly related to the length of the transition zone. Given the location of the transition start and $\hat{n} \sigma$, it should be possible to calculate the location of the end of transition and the intermittency within the transition region. From the discussion above, one can show

$$
\hat{n} \sigma=\frac{4.6}{\left(\operatorname{Re}_{\mathbf{x}_{\mathrm{e}}}-\operatorname{Re}_{\mathbf{x}_{\mathrm{s}}}\right)^{2}}
$$

in unaccelerated flow, where $\operatorname{Re}_{\mathrm{XS}}$ and $\operatorname{Re}_{\mathrm{X}}$ are taken at $\gamma=0$ and $\gamma=0.99$. A single value of no is applied through transition. For accelerating flows, Mayle (1991) proposed a formulation which is based on the work of Chen and Thyson (1971). He replaced $\sigma$ by the modified propagation parameter $\frac{\overline{U_{s}}}{\bar{U}}$, where $\bar{U}$ is an average velocity for the transition zone. This results in

$$
\hat{n} \bar{\sigma}=\frac{4.6 \bar{U} v^{2}}{\left(x_{e}-x_{s}\right)^{2} U_{s}^{3}}
$$

Using the intermittency-based data from Table 5, no were calculated and plotted verses TI in Figure 27. Also shown is an empirical curve given by Mayle (1991) based on flat wall, unaccelerated flow data. The unaccelerated data in Figure 27 tends to agree with the trend of Mayle's 
curve, but the fit is not as good as that shown for the data presented by Mayle (1991). Kuan and Wang's (1990) 0.9\% (2D) TI case shows ñ significantly lower than the correlation value when no is calculated from intermittency-based data. As mentioned above, the intermittency data from this case gives $\operatorname{Re}_{\mathrm{xs}}<0$ when processed in the manner shown in Figure 22. When Kuan and Wang's skin friction data was used to determine $\operatorname{Re}_{\mathrm{XS}}$ and $\mathrm{Re}_{\mathrm{Xe}}$, however, the resulting $\hat{n} \sigma$ was in better agreement with Mayle's curve and the data point presented by Mayle for this particular case (see Fig. 27).

The accelerated flow cases shown in Figure 27 deviate somewhat from the flat wall correlation. Acceleration causes a lower spot propagation rate, although the differences between the accelerated cases and the correlation are small for the cases shown.

In Figure 28, no calculated from the Stanton number based data in Table 4 are shown plotted verses TI. Most of the flat wall, unaccelerated data is in reasonable agreement with Mayle's correlation. The two lowest TI cases shown are exceptions. Blair's $0.165 \%$ (3D) TI case was also shown in Figure 5 to exhibit behavior consistent with a higher TI. The accelerated flow cases appear similar in Figures 27 and 28.

The curved wall cases are also shown in Figure 28. Convex curvature appears to have little effect on spot propagation. Wang's data is in reasonable agreement with the flat wall correlation for both strengths of curvature shown. Concave curvature appears to have a significant effect on n̂. Kim's $0.6 \%$ (2D) TI case shows n̂ $\sigma$ approximately 16 times higher than the flat wall correlation at the same TI. It is not clear what effect concave curvature would have at higher TI. One can speculate that 
the effects seen at $0.6 \%$ might persist at higher freestream turbulence levels, but because of the very early transition experienced in the concave-curved, high $\mathrm{TI}$ case $(\mathrm{TI}=8.3 \%)$ of $\mathrm{Kim}$, one cannot quantitatively support this speculation. 


\section{CONCLUSIONS AND RECOMMENDATIONS}

Local coordinates, $\left(\Delta_{2}\right.$ and $\left.\theta\right)$ used in the various comparisons, were useful in reducing the data. Data in the laminar and fully-turbulent regions of the flow matched the expected correlations well in these coordinates. The overshoot of the turbulent correlations after transition, seen in $x$ or $\operatorname{Re}_{\mathrm{X}}$ coordinates, was avoided when using local coordinates by eliminating the problem of a shift in virtual origin.

The variation in location of the transition region from case to case could not be completely explained by the TI level alone. Other effects such as the spectra and length scales of the freestream turbulence must play a role in the transition process. These factors should be investigated in future experiments.

The current practice of reporting a single value for the freestream TI is insufficient. Future experiments should include better documentation including the frequency range over which the reported TI was measured. Some thought should be given to standardization of the basis for the reported values.

The intermittency values in the transition region closely follow the behavior predicted by Dhawan and Narasimha (1958). This was true even for those cases which show unexpected behavior in other comparisons (such as Kuan and Wang's case in the $c_{f}$ vs $\operatorname{Re}_{\theta}$ comparison). The 
intermittency behavior in curved wall cases should be studied in future experiments.

Curvature was seen to play a significant role in transition. Convex curvature tended to delay transition at lower TI values. Concave curvature shifted the transition zone upstream and, for low TI values, introduced three-dimensionality in the form of Görtler vortices. Transition begins at the vortex upwashes and proceeds along a path similar, in terms of $\operatorname{Re}_{\theta}$, to that seen in flat-wall cases. The behavior at the downwash locations is significantly different. Further investigation of spanwise variations in curved-wall cases should proceed. In general, a better understanding of the structure of transitional and turbulent flow is needed.

Acceleration has a pronounced effect both on transitional and turbulent flow behavior. Acceleration appears to enhance the breakdown in Reynolds analogy seen in transition. Transition onset position cast in terms of momentum thickness Reynolds number for the accelerated flow cases matches the flat-wall cases, however. Further investigation of acceleration effects, including the combined effects of curvature and acceleration should be made.

The turbulent spot formation rate was found to depend strongly on the freestream turbulence level. Agreement with Mayle's (1991) empirical correlation was reasonable for the flat-wall cases considered. Convex curvature had little effect on the spot formation rate, but concave 
curvature caused a significant increase in the spot formation rate in Kim's low TI $(0.6 \%(2 \mathrm{D}))$ case. Acceleration had a relatively small but still noticeable effect of decreasing the spot formation rate in the cases considered. 


\section{REFERENCES}

Abu-Ghannam, B. J. and Shaw, R. (1980). "Natural Transition of Boundary Layers - The Effects of Turbulence, Pressure Gradient, and Flow History," J. Mechanical Engineering Science, Vol. 22, No. 5, pp. 213-228.

Bertolotti, F. P., Herbert, Th. and Spalart, P. R. (1990). "Linear and Nonlinear Stability of the Blasius Boundary Layer," submitted to the J. Fluid Mechanics.

Blair, M. F. (1981a). "Final Data Report - Vol. I -Velocity and Temperature Profile Data for Zero Pressure Gradient, Fully Turbulent Boundary Layers," United Technologies Research Center report R81-914388-15.

Blair, M. F. (1981b). "Final Data Report - Vol. II -Velocity and Temperature Profile Data for Accelerating, Transitional Boundary Layers," United Technologies Research Center report R81-914388-16.

Blair, M. F. (1982). "Influence of Free-Stream Turbulence on Boundary Layer Transition in Favorable Pressure Gradients," J. of Engineering for Power, Vol. 104, pp. 743-750.

Blair, M. F. (1983). "Influence of Free-Stream Turbulence on Turbulent Boundary Layer Heat Transfer and Mean Profile Development, Part-I, Experimental Data," J. Heat Transfer, Vol. 150, pp. 33-40.

Blair, M. F. and Anderson, O. L. (1987). "Study of the Structure of Turbulence in Accelerating Transitional Boundary Layers," United Technologies Research Center report R87-956900-1.

Blair, M. F. and Werle, M. J. (1980). "The Influence of Free-Stream Turbulence on the Zero Pressure Gradient Fully Turbulent Boundary Layer," United Technologies Research Center report R80-914388-12.

Blair, M. F. and Werle, M. J. (1981). "Combined Influence of Free-Stream Turbulence and Favorable Pressure Gradients on Boundary Layer Transition and Heat Transfer," United Technologies Research Center report R $81-914388-17$.

Bradshaw, P. (1973). "Effects of Streamline Curvature on Turbulent Flow," AGARDograph No. 169. 
Browne, L. W. B., Antonia, R. A. and Shah, D. A. (1987). "Turbulent Energy

Dissipation in a Wake," J. Fluid Mech. Vol. 179, pp. 307-326.

Cebeci, T. and Smith, A. M. O. (1974). Analysis of Turbulent Boundary Layers, Academic Press, New York.

Chen, K. K. and Thyson, N. A. (1971). "Extension of Emmons' Spot Theory to Flows on Blunt Bodies," AIAA Journal, Vol. 9, pp. 821-825.

Crawford, M. E. and Kays, W. M. (1976). "STAN5 - A Program for Numerical Computation of Two-Dimensional Internal and External Boundary Layer Flows," NASA CR-2742.

Dhawan, S. and Narasimha, R. (1958) "Some Properties of Boundary Layer Flow During the Transition from Laminar to Turbulent Motion," J. Fluid Mech., Vol. 3, pp. 418-436.

Emmons, H. W. (1951). "The Laminar-Turbulent Transition in a Boundary Layer - Part I," J. Aeronautical Science, Vol. 18, pp. 490-498.

Gaugler, R. E. (1986). "A Review and Analysis of Boundary Layer Transition Data for Turbine Applications," NASA TM-86880.

Gostelow, J. P. and Walker, G. J. (1990). "Similarity Behavior in Transitional Boundary Layers Over a Range of Adverse Pressure Gradients and Turbulence Levels," ASME paper 90-GT-130.

Hancock, P. and Bradshaw, P. (1989). "Turbulence Structure of a Boundary Layer beneath a Turbulent Free-Stream," J. Fluid Mech., Vol. 205, pp. 4576.

Hinze, J. (1975). Turbulence, Second Edition, McGraw Hill, New York.

Kays, W. M. and Crawford, M. E. (1980). Convective Heat and Mass Transfer, McGraw Hill, New York.

Kendall, J. M. (1990). "Boundary Layer Receptivity to Freestream Turbulence," AIAA paper 90-1504.

Kim, J. (1990) "Free-stream Turbulence and Concave Curvature Effects on Heated, Transitional Boundary Layers," Ph.D. Thesis, Department of 
Mechanical Engineering, U. of Minnesota. Also to appear as NASA CR (1991).

Kim, J., Simon, T. W. and Kestoras, M. (1989). "Fluid Mechanics and Heat Transfer Measurements in Transitional Boundary Layers Conditionally Sampled on Intermittency," ASME HTD-Vol. 107, Heat Transfer in Convective Flows, pp. 69-81, presented at the 1989 National Heat Transfer Conference.

Kim, J., Simon, T. W. and Russ, S. (1990). "Free-Stream Turbulence and Concave Curvature Effects on Heated Transitional Boundary Layers," accepted by the J. Heat Transfer.

Kuan, C. L. (1987). "An Experimental Investigation of Intermittent Behavior in the Transitional Boundary Layer," M.S. Thesis, Clemson University.

Kuan, C. L. and Wang, T. (1990). "Investigation of the Intermittent Behavior of Transitional Boundary Layer Using a Conditional Averaging Technique," Experimental Thermal and Fluid Science, Vol. 3, pp. 157-173.

Lam, C. K. G. and Bremhorst, K. (1981). "A Modified Form of the k- $\varepsilon$ Model for predicting Wall Turbulence," J. Fluids Engineering, Vol. 103, pp. 456460 .

Liepmann, H. W. (1943). "Investigation of Laminar Boundary-Layer Stability and Transition on Curved Boundaries," NACA Wartime Report W-107. Originally issued 1943 as NACA ACR $3 \mathrm{H} 30$.

Mayle, R. E. (1991). "The Role of Laminar-Turbulent Transition in Gas Turbine Engines," ASME paper 91-GT-261.

McDonald, H. and Kreskovsky, J. P. (1974). "Effects of Free Stream Turbulence on the Turbulent Boundary Layer," Int. J. Heat Mass Transfer, Vol. 17, pp. 705-716.

McDonald, H. and Fish, R. W. (1973). "Practical Calculation of Transitional Boundary Layers," Int. J. Heat Mass Transfer, Vol. 16, pp. 1729-1744.

Morkovin, M. V. (1978). "Instability, Transition to Turbulence and Predictability," AGARD-AG-236. 
Narasimha, R. (1984). "Subtransitions in the Transition Zone," Proc. 2nd IUTAM Symposium on Laminar-Turbulent Transition, Novosibirsk, pp. $141-151$.

Narasimha, R. (1985). "The Laminar - Turbulent Transition Zone in the Boundary Layer," Progress in Aerospace Science, Vol. 22, No. 1, pp. 29-80.

Reynolds, W. C. (1976). "Computation of Turbulent Flows," Annual Review of Fluid Mechanics, Vol. 8, pp. 183-208.

Rodi, W. and Scheuerer, G. (1985). "Calculation of Laminar-Turbulent Boundary Layer Transition of Turbine Blades," Heat Transfer and Cooling in Gas Turbines, AGARD-CP-390, pp. 18-1 through 18-13.

Rued, K. (1987). "Transitional Boundary Layers under the Influence of High Free Stream Turbulence, Intensive Wall Cooling and High Pressure Gradients in Hot Gas Circulation," NASA TM-88524.

Rued, K. and Wittig, S. (1985). "Free-Stream Turbulence and Pressure Gradient Effects on Heat Transfer and Boundary Layer Development on Highly Cooled Surfaces," J. Engineering for Gas Turbines and Power, Vol. 107, pp. 54-59.

Rued, K. and Wittig, S. (1986). "Laminar and Transitional Boundary Layer Structures in Accelerating Flow with Heat Transfer," ASME paper 86-GT97.

Russ, S. G. (1989). "The Generation and Measurement of Turbulent Flow Fields," M.S. Thesis, Department of Mechanical Engineering, U. of Minnesota.

Schlichting, H. (1933). "Zur Entstehung der Turbulenz bei der Plattenströmung," Nachr. Ges. Wiss. Göttingen, Math. Phys. Klasse, pp. 182 208. See also ZAMM, Vol. 13, pp. 171-174.

Schlichting, H. (1979). Boundary Layer Theory, 7th Edition, McGraw Hill, New York.

Schmidt, R. (1987). "Two-Equation Low-Reynolds-Number Turbulence Modelling of Transitional Boundary Layer Flows Characteristic of Gas Turbine Blades," Ph.D. Thesis, Department of Mechanical Engineering, U. of Minnesota. 
Schubauer, G. B. and Skramstad, H. K. (1948). "Laminar-Boundary-Layer Oscillations and Transition on a Flat Plate," NACA report 909. Originally issued 1943 as NACA ACR.

Sohn, K. H., O'Brien, J. E. and Reshotko, E. (1989). "Some Characteristics of Bypass Transition in a Heated Boundary Layer," NASA TM-102126.

Sohn, K. H. and Reshotko, E. (1991). "Experimental Study of Boundary Layer Transition With Elevated Freestream Turbulence on a Heated Flat Plate," NASA CR-187068.

Stephens, C. A. and Crawford, M. E. (1990). "An Investigation into the Numerical Prediction of Boundary Layer Transition using the K. Y. Chien Turbulence Model," NASA CR-185252.

Suder, K., O'Brien, J. E. and Reshotko, E. (1988). "Experimental Study of Bypass Transition in a Boundary Layer," NASA TM-100913.

Tollmien, W. (1931). "The Production of Turbulence," NACA TM-609.

Tollmien, W. (1936). "General Instability Criterion of Laminar Velocity Distributions," NACA TM No. 792.

Vancoillie, G. (1984). "A Turbulence Model for the Numerical Simulation of Transitional Boundary Layers," Proc. 2nd IUTAM Symposium on LaminarTurbulent Transition, Novosibirsk, pp. 87-92.

Vancoillie, G. and Dick, E. (1988). "A Model for the Numerical Simulation of the Transition Zone in a Boundary Layer," Int. J. Engineering Fluid Mech., Vol. 1, No. 1, pp. 29-49.

Van Driest, E. R. and Blumer, C. B. (1963). "Boundary Layer Transition: Freestream Turbulence and Pressure Gradient Effects," AIAA Journal, Vol. 1, No. 6, pp. 1303-1306.

Wang, T. (1984). "An Experimental Investigation of Curvature and Freestream Turbulence Effects on Heat Transfer and Fluid Mechanics in Transitional Boundary Layer Flows," Ph.D. Thesis, Department of Mechanical Engineering, U. of Minnesota. 
Wang, T. and Simon, T. W. (1985). "Heat Transfer and Fluid Mechanics Measurements in a Boundary Layer Undergoing Transition on a ConvexCurved Wall," ASME paper 85-HT-60, J. Turbomachinery, Vol. 109, No. 3, pp. 443-452, (1987).

Wang, T., Simon, T. W. and Buddhavarapu, J. (1985). "Heat Transfer and Fluid Mechanics Measurements in Transitional Boundary Layer Flows," ASME paper 85-GT-113, J. Engineering for Gas Turbines and Power, Vol. 107, No. 4, pp. 1007-1015. 
Table 1. Quantities to be Measured

\begin{tabular}{|c|c|c|}
\hline $\mathrm{U}$ & $\mathrm{V}$ & $\mathrm{W}$ \\
\hline$\overline{\mathrm{u}^{\prime 2}}$ & $\overline{\mathrm{v}^{\prime 2}}$ & $\overline{\mathrm{w}^{\prime 2}}$ \\
\hline$\overline{\mathrm{u}^{\prime} \mathrm{v}^{\prime}}$ & $\overline{\overline{\mathrm{t}}^{\prime} \mathrm{v}^{\prime}}$ & $\overline{\mathrm{u}^{\prime 3}}$ \\
\hline$\overline{\mathrm{u}^{\prime} \mathrm{v}^{\prime 2}}$ & $\overline{\mathrm{u}^{\prime 2} \mathrm{v}^{\prime}}$ & $\lambda$ \\
\hline & $\Lambda$ & \\
\hline
\end{tabular}

Table 2. Quantities to be Computed

\begin{tabular}{|c|c|c|c|}
\hline$\frac{\partial \overline{u^{\prime} v^{\prime}}}{\partial y}$ & $\frac{\partial \overline{v^{\prime 2}}}{\partial y}$ & $\frac{\partial \overline{\mathrm{t}^{\prime} \mathrm{v}^{\prime}}}{\partial \mathrm{y}}$ & $\mathrm{L}_{\mathrm{e}}^{\mathrm{u}}=\frac{\left(\overline{\left.\mathrm{u}^{\prime 2}\right)^{\frac{3}{2}}}\right.}{\mathrm{U} \frac{\partial \mathrm{u}^{\prime 2}}{\partial \mathrm{x}}}$ \\
\hline$-\overline{u^{\prime 2}} \frac{\partial U}{\partial x}$ & $-\overline{u^{\prime} v^{\prime}} \frac{\partial U}{\partial y}$ & $-\overline{v^{\prime 2}} \frac{\partial V}{\partial y}$ & $q=\sqrt{{u^{\prime 2}}^{2}+\overline{v^{\prime 2}}+\overline{w^{\prime 2}}}$ \\
\hline $\mathrm{TI}=\frac{\mathrm{q}}{\sqrt{3}}$ & $\eta$ & $\operatorname{Pr}_{t}$ & $\varepsilon=15 v \frac{\overline{u^{\prime 2}}}{\lambda^{2}}=\frac{v^{3}}{\eta^{4}}$ \\
\hline$\varepsilon \propto U \frac{\partial \overline{u^{\prime 2}}}{\partial x}$ & $-v \frac{\partial q^{2}}{\partial y}$ & $U \frac{\partial D}{\partial x}$ & $\mathrm{v} \frac{\partial \mathrm{D}}{\partial \mathrm{y}}$ \\
\hline$\left(\frac{\partial u^{\prime}}{\partial t}\right)^{2}$ & $\overline{\left(\frac{\partial u^{\prime}}{\partial x}\right)^{2}}$ & $D \cong \frac{2 v}{U^{2}} \overline{\left(\frac{\partial u^{\prime}}{\partial t}\right)^{2}}$ & $\mathrm{D}=2 v \overline{\left(\frac{\partial \mathrm{u}^{\prime}}{\partial \mathrm{x}}\right)^{2}}$ \\
\hline$\frac{\partial \overline{u^{\prime 3}}}{\partial x}$ & $\frac{\partial \overline{u^{\prime} v^{\prime 2}}}{\partial x}$ & $\frac{\partial \overline{u^{\prime 2} v^{\prime}}}{\partial y}$ & $-\overline{v^{\prime 2}} \frac{\partial U}{\partial y}$ \\
\hline
\end{tabular}


Table 3. Studies Considered

\begin{tabular}{|c|c|c|c|c|}
\hline Location & References & Configuration & $\mathrm{TI}(\%)$ & $\begin{array}{l}\text { Measured } \\
\text { Quantities } \\
\end{array}$ \\
\hline \multirow[t]{4}{*}{$\begin{array}{l}\text { University of } \\
\text { Minnesota }\end{array}$} & $\begin{array}{c}\text { Wang (1984); } \\
\text { Wang, Simon } \\
\text { and } \\
\text { Buddhava- } \\
\text { rapu (1985) }\end{array}$ & Flat Wall & $\begin{array}{c}0.3(1 \mathrm{D}) \\
0.68(1 \mathrm{D}) \\
2.2(1 \mathrm{D})\end{array}$ & $\begin{array}{c}\mathrm{U}, \mathrm{T}, \mathrm{u}^{\prime} \text { profiles; } \\
\text { Wall } \mathrm{T}\end{array}$ \\
\hline & $\begin{array}{l}\text { Wang (1984); } \\
\text { Wang and } \\
\text { Simon (1985) }\end{array}$ & $\begin{array}{l}\text { Convex Wall, } \\
\mathrm{R}=180 \mathrm{~cm} \text { and } \\
\mathrm{R}=90 \mathrm{~cm}\end{array}$ & $\begin{array}{l}0.69 \text { (1D) } \\
2.2 \text { (1D) }\end{array}$ & $\begin{array}{c}\mathrm{U}, \mathrm{T}, \mathrm{u}^{\prime} \text { profiles; } \\
\text { Wall } \mathrm{T}\end{array}$ \\
\hline & $\begin{array}{c}\text { Kim }(1990) ; \\
\text { Kim, Simon } \\
\text { and Kestoras } \\
(1989)\end{array}$ & Flat Wall & $\begin{array}{l}0.3(3 \mathrm{D}) \\
1.5(3 \mathrm{D}) \\
8.3(3 \mathrm{D})\end{array}$ & $\begin{array}{c}\mathrm{U}, \mathrm{V}, \mathrm{u}^{\prime}, \mathrm{v}^{\prime}, \mathrm{u}^{\prime} \mathrm{v}^{\prime}, \\
\mathrm{t}^{\prime}, \mathrm{u}^{\prime} \mathrm{t}^{\prime}, \mathrm{u}^{\prime} \mathrm{v}^{\prime}{ }^{2}, \\
\mathrm{v}^{\prime 2} \mathrm{t}^{\prime}, \mathrm{v}^{\prime} \mathrm{t}^{\prime}, \mathrm{T}, \mathrm{Pr}_{\mathrm{t}}, \\
\gamma \text { profiles; } \\
\text { Wall T; } \\
\text { Freestream } \\
\text { spectra }\end{array}$ \\
\hline & $\begin{array}{c}\text { Kim }(1990) ; \\
\text { Kim, Simon } \\
\text { and Russ } \\
(1990)\end{array}$ & $\begin{array}{c}\text { Concave } \text { Wall, } \\
R=-97 \mathrm{~cm}\end{array}$ & $\begin{array}{l}0.6(2 \mathrm{D}) \\
8.3(2 \mathrm{D})\end{array}$ & $\begin{array}{c}U, V, u^{\prime}, v^{\prime}, u^{\prime} v^{\prime}, \\
t^{\prime}, u^{\prime} t^{\prime}, u^{\prime} v^{\prime 2}, \\
v^{\prime 2} t^{\prime}, v^{\prime} t^{\prime}, T, P_{t} \\
\text { profiles; } \\
\text { Wall T; } \\
\Lambda, \lambda \text { in } \\
\text { freestream }\end{array}$ \\
\hline \multirow[t]{2}{*}{$\begin{array}{c}\text { Case Western } \\
\text { Reserve } \\
\text { University }\end{array}$} & $\begin{array}{c}\text { Suder, O'Brien } \\
\text { and Reshotko } \\
(1988)\end{array}$ & Flat Wall & $\begin{array}{l}0.3 \text { (1D) } \\
0.65 \text { (1D) } \\
0.92 \text { (1D) } \\
2.0 \text { (1D) } \\
4.3 \text { (1D) } \\
5.2 \text { (1D) }\end{array}$ & $\begin{array}{c}\text { U,u' profiles; } \\
\text { Freestream } \\
\text { and boundary } \\
\text { layer spectra; } \\
\Lambda \text { in } \\
\text { freestream; } \\
\gamma \text { at wall } \\
\end{array}$ \\
\hline & $\begin{array}{c}\text { Sohn and } \\
\text { Reshotko } \\
\text { (1991); } \\
\text { Sohn, O'Brien } \\
\text { and Reshotko } \\
\text { (1989) }\end{array}$ & Flat Wall & $\begin{array}{l}0.45 \text { (1D) } \\
0.83 \text { (1D) } \\
1.1 \text { (1D) } \\
2.6 \text { (1D) } \\
6.0 \text { (1D) } \\
6.6 \text { (1D) }\end{array}$ & $\begin{array}{c}\text { U,u',T, } \gamma, v^{\prime}, t^{\prime}, \\
u^{\prime} v^{\prime}, v^{\prime} t t^{\prime} \\
\text { profiles; } \\
\text { Wall T; } \\
\text { Freestream } \\
\text { and boundary } \\
\text { layer spectra; } \\
\Lambda \text { in } \\
\text { freestream; }\end{array}$ \\
\hline $\begin{array}{l}\text { United } \\
\text { Technologies } \\
\text { Research } \\
\text { Center }\end{array}$ & $\begin{array}{l}\text { Blair and } \\
\text { Werle (1980); } \\
\text { Blair (1981a); } \\
\text { Blair (1983) }\end{array}$ & Flat Wall & $\begin{array}{c}0.165(3 \mathrm{D}) \\
1.25(3 \mathrm{D}) \\
2.6(3 \mathrm{D}) \\
6.4(3 \mathrm{D}) \\
7.6(3 \mathrm{D})\end{array}$ & $\begin{array}{l}\text { U,T profiles; } \\
\text { Wall T; } \\
\mathrm{u}^{\prime}, \mathrm{v}^{\prime}, \mathrm{w}^{\prime}, \Lambda \text { in } \\
\text { freestream }\end{array}$ \\
\hline
\end{tabular}


Table 3. Studies Considered (Cont'd)

\begin{tabular}{|c|c|c|c|c|}
\hline & $\begin{array}{l}\text { Blair and } \\
\text { Werle (1981); } \\
\text { Blair (1981b); } \\
\text { Blair (1982); } \\
\text { Blair and } \\
\text { Anders on } \\
\text { (1987) }\end{array}$ & $\begin{array}{c}\text { Flat Wall, } \\
\text { Accelerated } \\
\text { Flow, } \\
\mathrm{k}=0.2 \times 10^{-6} \text { and } \\
\mathrm{k}=0.75 \times 10^{-6}\end{array}$ & $\begin{array}{l}0.93(3 \mathrm{D}) \\
2.0(3 \mathrm{D}) \\
5.3(3 \mathrm{D})\end{array}$ & $\begin{array}{l}\text { U,T, u', } v^{\prime}, w^{\prime}, \\
w^{\prime} v^{\prime}, u^{\prime} v^{\prime}, \gamma \\
\text { profiles; Wall } \\
T \text {; Freestream } \\
\text { and boundary } \\
\text { layer spectra; } \\
\Lambda \text { in } \\
\text { freestream }\end{array}$ \\
\hline $\begin{array}{c}\text { Clemson } \\
\text { University }\end{array}$ & $\begin{array}{c}\text { Kuan (1987); } \\
\text { Kuan and } \\
\text { Wang (1990) }\end{array}$ & Flat Wall & 0.9 (2D) & $\begin{array}{l}U^{\prime}, u^{\prime}, v^{\prime}, u^{\prime} v^{\prime}, \gamma \\
\text { profiles }\end{array}$ \\
\hline $\begin{array}{l}\text { University } \\
\text { Karlsruhe }\end{array}$ & $\begin{array}{l}\text { Rued (1987); } \\
\text { Rued and } \\
\text { Wittig (1985); } \\
\text { Rued and } \\
\text { Wittig (1986) } \\
\end{array}$ & $\begin{array}{c}\text { Flat Wall, } \\
\text { Accelerated } \\
\text { and } \\
\text { Unaccelerated } \\
\text { Cases } \\
\end{array}$ & $\begin{array}{l}1.3(2 \mathrm{D}) \\
2.0(2 \mathrm{D}) \\
3.5(2 \mathrm{D}) \\
5.6(2 \mathrm{D}) \\
8.7(2 \mathrm{D}) \\
\end{array}$ & $\begin{array}{c}\text { U,T profiles; } \\
\mathrm{u}^{\prime}, v^{\prime} \text { in } \\
\text { freestream }\end{array}$ \\
\hline
\end{tabular}


Table 4. Transition Start and End based on Stanton Number

\begin{tabular}{|c|c|c|c|c|c|c|c|c|}
\hline Study & & TI start & $\begin{array}{l}\operatorname{Re}_{\mathrm{Xs}} \\
\times 10^{-6} \\
\end{array}$ & $\operatorname{Re}_{\theta s}$ & TI end & $\begin{array}{r}\mathrm{Re}_{\mathrm{xe}} \\
\times 10^{-6} \\
\end{array}$ & $\operatorname{Re}_{\theta e}$ & $\begin{array}{l}\hat{\mathrm{n} \sigma} \\
\times 10^{-11} \\
\end{array}$ \\
\hline & & & & & & & & \\
\hline \multirow{4}{*}{$\begin{array}{l}\mathrm{Kim} \\
(1990)\end{array}$} & & $0.3(3 \mathrm{D})$ & 0.884 & 620 & 0.3 (3D) & 1.379 & -- & 1.88 \\
\hline & & $1.5(3 \mathrm{D})$ & 0.264 & 322 & $1.5(3 \mathrm{D})$ & 0.710 & 1017 & 2.32 \\
\hline & $\begin{array}{l}\text { concave } \\
\mathrm{R}=-97 \mathrm{~cm} \\
\text { downwash }\end{array}$ & $0.6(2 \mathrm{D})$ & 0.276 & 441 & $0.6(2 \mathrm{D})$ & 0.491 & 832 & 9.97 \\
\hline & upwash & $0.3<\mathrm{TI}<1.5$ & 0.217 & $\cdots$ & $0.3<\mathrm{TI}<1.5$ & 0.336 & $\ldots$ & 32.6 \\
\hline \multirow{7}{*}{$\begin{array}{l}\text { Wang } \\
(1984)\end{array}$} & & $0.3(1 \mathrm{D})$ & 1.15 & 760 & & & -- & \\
\hline & & $0.68(1 \mathrm{D})$ & 1.05 & 750 & $0.68(1 \mathrm{D})$ & 2.16 & 2100 & 0.374 \\
\hline & & $2.2(1 \mathrm{D})$ & 0.195 & 336 & $2.2(1 \mathrm{D})$ & 0.513 & 948 & 4.56 \\
\hline & $\begin{array}{l}\text { convex } \\
\mathrm{R}=180 \mathrm{~cm}\end{array}$ & 0.69 (1D) & 1.72 & 981 & 0.69 (1D) & 2.55 & 1864 & 0.669 \\
\hline & $\begin{array}{l}\text { convex } \\
\mathrm{R}=180 \mathrm{~cm}\end{array}$ & $2.2(1 \mathrm{D})$ & 0.226 & 349 & 2.1 (1D) & 0.578 & 1014 & 3.72 \\
\hline & $\begin{array}{l}\text { convex } \\
R=90 \mathrm{~cm}\end{array}$ & $0.70(1 \mathrm{D})$ & 1.65 & 882 & 0.73 (1D) & 2.24 & 1610 & 1.32 \\
\hline & $\begin{array}{l}\text { conve } x \\
R=90 \mathrm{~cm} \\
\end{array}$ & $2.2(1 \mathrm{D})$ & 0.256 & 367 & $2.2(1 \mathrm{D})$ & 0.605 & 1019 & 3.78 \\
\hline \multirow{6}{*}{$\begin{array}{l}\text { Sohn } \\
\text { and } \\
\text { Reshotko } \\
(1991)\end{array}$} & & 0.45 (1D) & 0.894 & 660 & 0.45 (1D) & 1.67 & - & 0.766 \\
\hline & & 0.83 (1D) & 0.423 & 448 & 0.83 (1D) & 1. & 1480 & 1.38 \\
\hline & & 1.1 (1D) & 0.358 & 419 & 1.1 (1D) & 0.90 & 1501 & 1.57 \\
\hline & & $2.6(1 \mathrm{D})$ & 0.271 & 406 & $2.6(1 \mathrm{D})$ & 0.571 & 1065 & 5.12 \\
\hline & & $6.0(1 \mathrm{D})$ & -- & -- & 5.6 (1D) & 0.380 & 885 & -- \\
\hline & & $6.6(1 \mathrm{D})$ & $\cdots$ & $\ldots$ & 6.5 (1D) & 0.229 & 588 & $\cdots$ \\
\hline \multirow{4}{*}{$\begin{array}{l}\text { Blair and } \\
\text { Werle } \\
(1981)\end{array}$} & $k=0.2 \times 10^{-6}$ & $0.93(3 \mathrm{D})$ & 0.86 & 480 & $0.82(3 \mathrm{D})$ & 2.3 & 1500 & 0.499 \\
\hline & $k=0.2 \times 10^{-6}$ & $2.0(3 \mathrm{D})$ & 0.29 & 365 & $1.9(3 \mathrm{D})$ & 0.70 & 897 & 3.63 \\
\hline & $\begin{array}{l}\mathrm{k}= \\
0.75 \times 10^{-6}\end{array}$ & $1.9(3 \mathrm{D})$ & 0.58 & 390 & $1.4(3 \mathrm{D})$ & 2.50 & 925 & 1.65 \\
\hline & $\begin{array}{l}\mathrm{k}= \\
0.75 \times 10^{-6}\end{array}$ & $5.3(3 \mathrm{D})$ & 0.0815 & 134 & $3.8(3 \mathrm{D})$ & 0.336 & 487 & 9.86 \\
\hline \multirow{3}{*}{$\begin{array}{l}\text { Blair and } \\
\text { Werle } \\
(1980)\end{array}$} & $\mathrm{k}=0$ & $0.165(3 \mathrm{D})$ & 1.275 & 750 & $0.165(3 \mathrm{D})$ & 1.772 & 2450 & 1.87 \\
\hline & $\mathrm{k}=0$ & $1.25(3 \mathrm{D})$ & 0.465 & 453 & $1.2(3 \mathrm{D})$ & $\begin{array}{l}.057 \\
\end{array}$ & 1400 & 1.32 \\
\hline & $\mathrm{k}=0$ & $2.6(3 \mathrm{D})$ & 0.2658 & 342 & $2.5(3 \mathrm{D})$ & 0.5303 & 850 & 6.59 \\
\hline \multirow{5}{*}{$\begin{array}{l}\text { Rued } \\
(1987)\end{array}$} & $\mathrm{k}=0$ & $1.3(2 \mathrm{D})$ & 0.24 & 325 & $\ldots$ & $\ldots$ & $\ldots$ & $\ldots$ \\
\hline & $\mathrm{k}=0$ & $2.1(2 \mathrm{D})$ & 0.18 & 281 & $1.9(2 \mathrm{D})$ & 0.50 & 1000 & 4.5 \\
\hline & $k=0$ & $3.5(2 \mathrm{D})$ & $\ldots$ & -- & 3.1 (2D) & 0.20 & 460 & $\ldots$ \\
\hline & $\mathrm{k}=0$ & $5.6(2 \mathrm{D})$ & $\cdots$ & $\cdots$ & $5.6(2 \mathrm{D})$ & 0.15 & 400 & $\cdots$ \\
\hline & $\mathrm{k}=0$ & 8.7 (2D) & $\cdots$ & $\cdots$ & $7.8(2 \mathrm{D})$ & 0.11 & 250 & $\ldots$ \\
\hline
\end{tabular}


Table 5. Transition Start and End Based on $\gamma$

\begin{tabular}{|c|c|c|c|c|c|c|c|c|}
\hline Study & & TI stant & $\begin{array}{l}\mathrm{Re}_{\mathrm{xs}} \\
\times 10^{-6} \\
\end{array}$ & $\operatorname{Re}_{\theta s}$ & TI end & $\begin{array}{l}\mathrm{Re}_{\mathrm{xe}} \\
\times 10^{-6} \\
\end{array}$ & $\operatorname{Re}_{\theta \mathrm{e}}$ & $\begin{array}{l}\hat{\mathrm{n} \sigma} \sigma \\
\times 10^{-11} \\
\end{array}$ \\
\hline \multirow{2}{*}{$\begin{array}{l}\text { Kim } \\
(1990)\end{array}$} & & 0.3 (3D) & 0.886 & 620 & 0.3 (3D) & 1.94 & 1627 & 0.412 \\
\hline & & 1.5 (3D) & 0.277 & 332 & 1.5 (3D) & 0.757 & 1104 & 2.01 \\
\hline \multirow{5}{*}{$\begin{array}{l}\text { Suder, et } \\
\text { al. (1988) }\end{array}$} & & 0.3 (1D) & 1.697 & 763 & 0.3 (1D) & 2.394 & 1463 & 0.949 \\
\hline & & 0.65 (1D) & 0.2751 & 324 & 0.65 (1D) & 1.214 & 1413 & 0.523 \\
\hline & & 0.92 (1D) & 0.1465 & 254 & 0.92 (1D) & 0.8935 & 977 & 0.826 \\
\hline & & 2.0 (1D) & $\ldots$ & - & 2.0 (1D) & 5.215 & 908 & 0.016 \\
\hline & & $4.3(1 \mathrm{D})$ & $\cdots$ & - & $4.3(1 \mathrm{D})$ & 0.4209 & 863 & 1.09 \\
\hline \multirow{3}{*}{$\begin{array}{l}\text { Sohn and } \\
\text { Reshotko } \\
(1991)\end{array}$} & & 11 (1D) & 0264 & 347 & 1 1 1D & 0872 & 1362 & 148 \\
\hline & & 1.1 (ID) & 0.204 & & 1.1 (ID) & 0.822 & 1302 & 1.48 \\
\hline & & $2.6(1 \mathrm{D})$ & 0.139 & 247 & 2.6 (1D) & 0.527 & 954 & 3.06 \\
\hline \multirow{4}{*}{$\begin{array}{l}\text { Blair and } \\
\text { Ander- } \\
\text { son } \\
\text { (1987) } \\
\end{array}$} & $\begin{array}{l}\mathrm{k}= \\
0.2 \times 10^{-6}\end{array}$ & 0.93 (3D) & 0.892 & 489 & $0.82(3 \mathrm{D})$ & 2.19 & 1398 & 0.594 \\
\hline & $\begin{array}{l}\mathrm{k}= \\
0.2 \times 10^{-6}\end{array}$ & $2.0(3 \mathrm{D})$ & 0.174 & 262 & 1.9 (3D) & 0.707 & 912 & 2.19 \\
\hline & $\begin{array}{l}k= \\
0.75 \times 10^{-6}\end{array}$ & $1.9(3 \mathrm{D})$ & 0.401 & 325 & $1.6(3 D)$ & 2.84 & 934 & 1.23 \\
\hline & $\begin{array}{l}\mathrm{k}= \\
0.75 \times 10^{-6}\end{array}$ & $5.3(3 \mathrm{D})$ & 0.019 & 90 & $4.2(3 \mathrm{D})$ & 0.491 & 655 & 3.40 \\
\hline $\begin{array}{l}\text { Ku an } \\
\text { a nd } \\
\text { W ang } \\
(1990)\end{array}$ & & $0.9(2 \mathrm{D})$ & -- & -- & $0.9(2 \mathrm{D})$ & 1.231 & 1591 & 0.262 \\
\hline
\end{tabular}




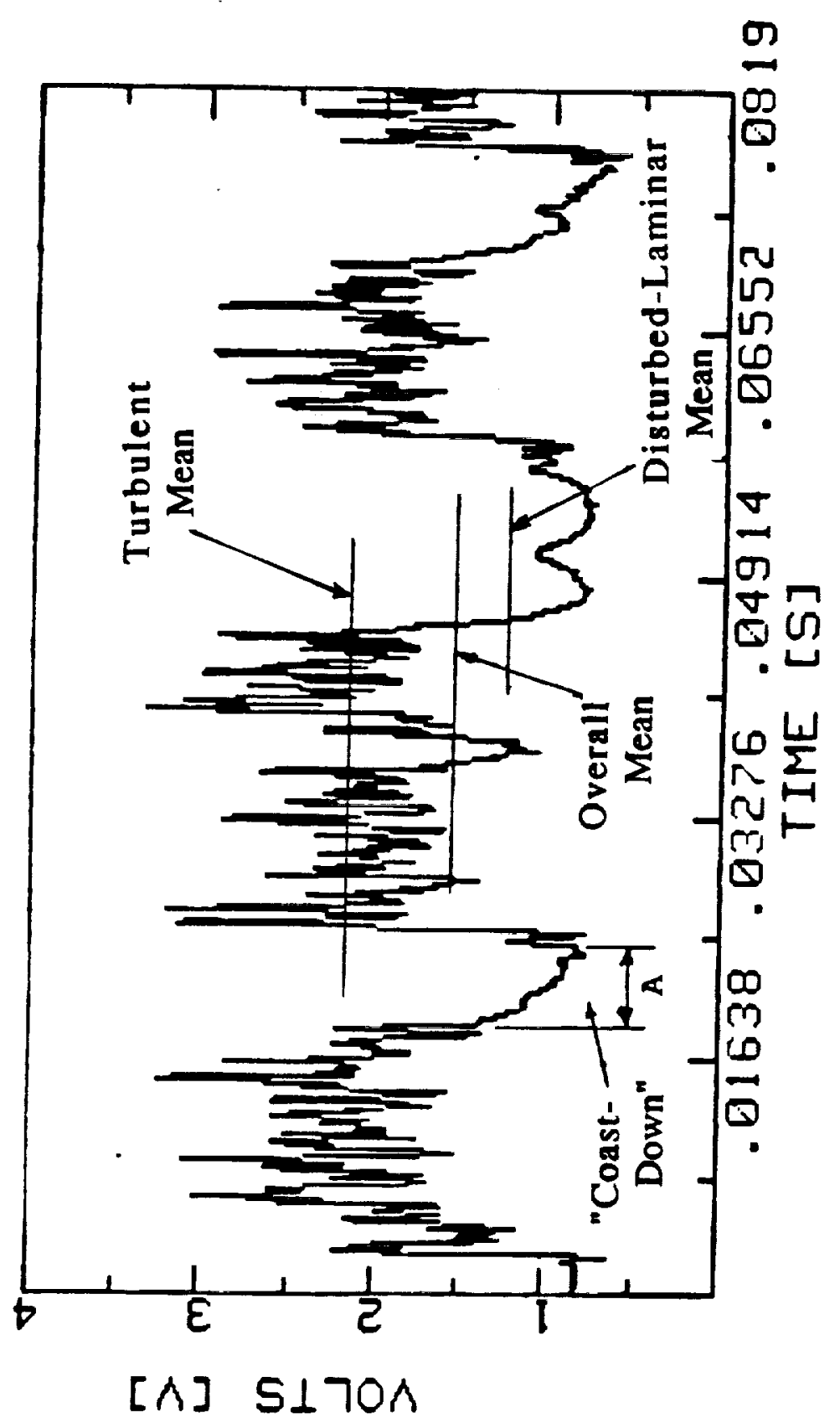

窇完

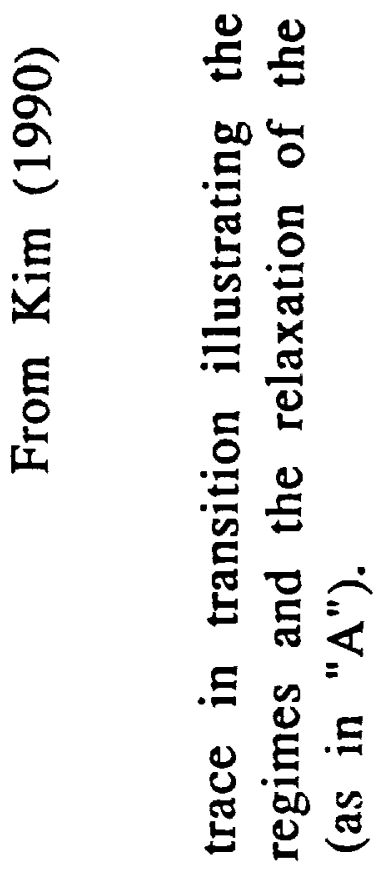

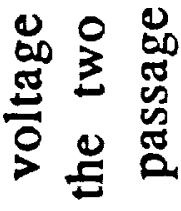

.

능

㟔

- \&

跑

$3: \Xi$

I

눙응

之

离总导 


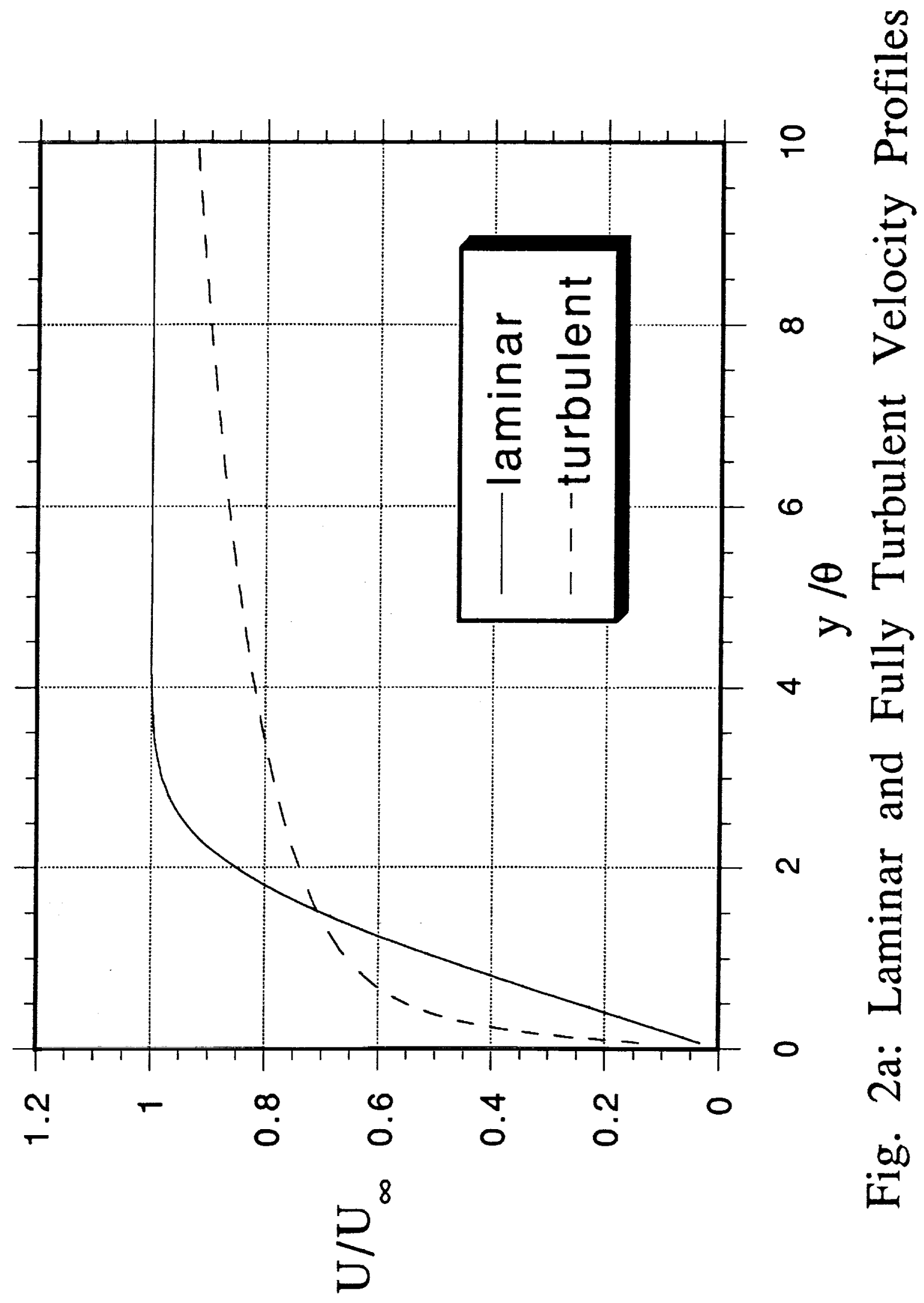




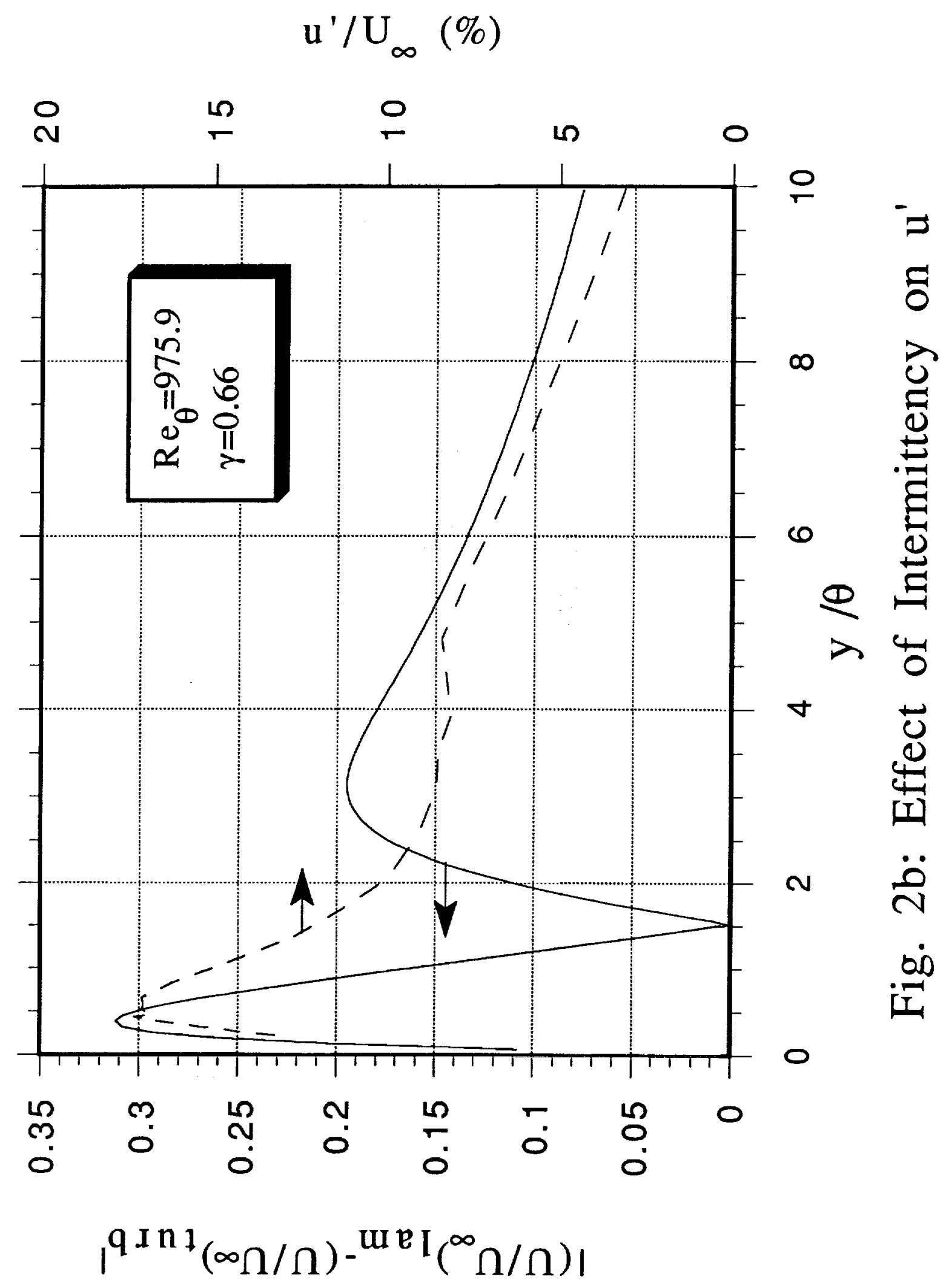




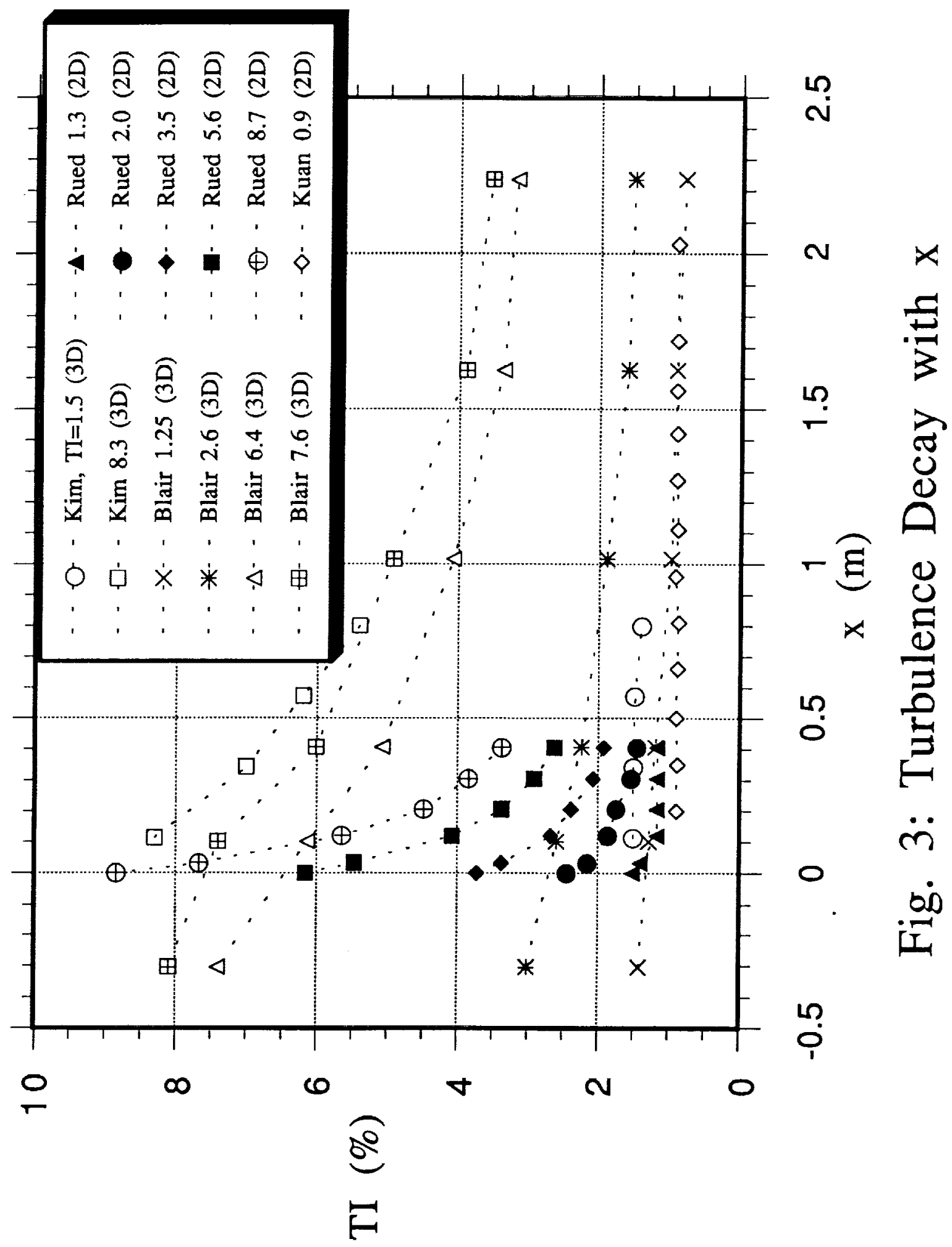




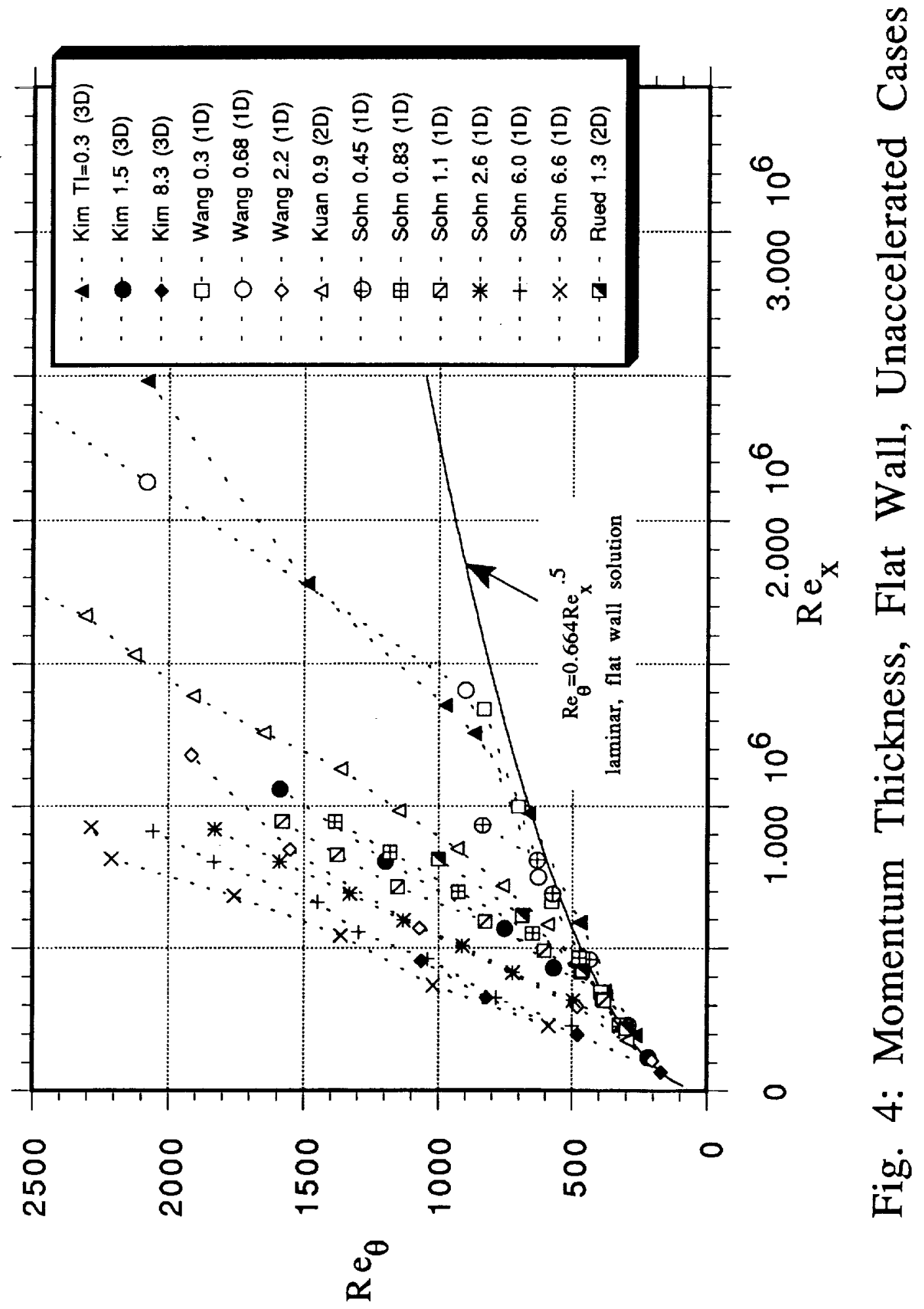




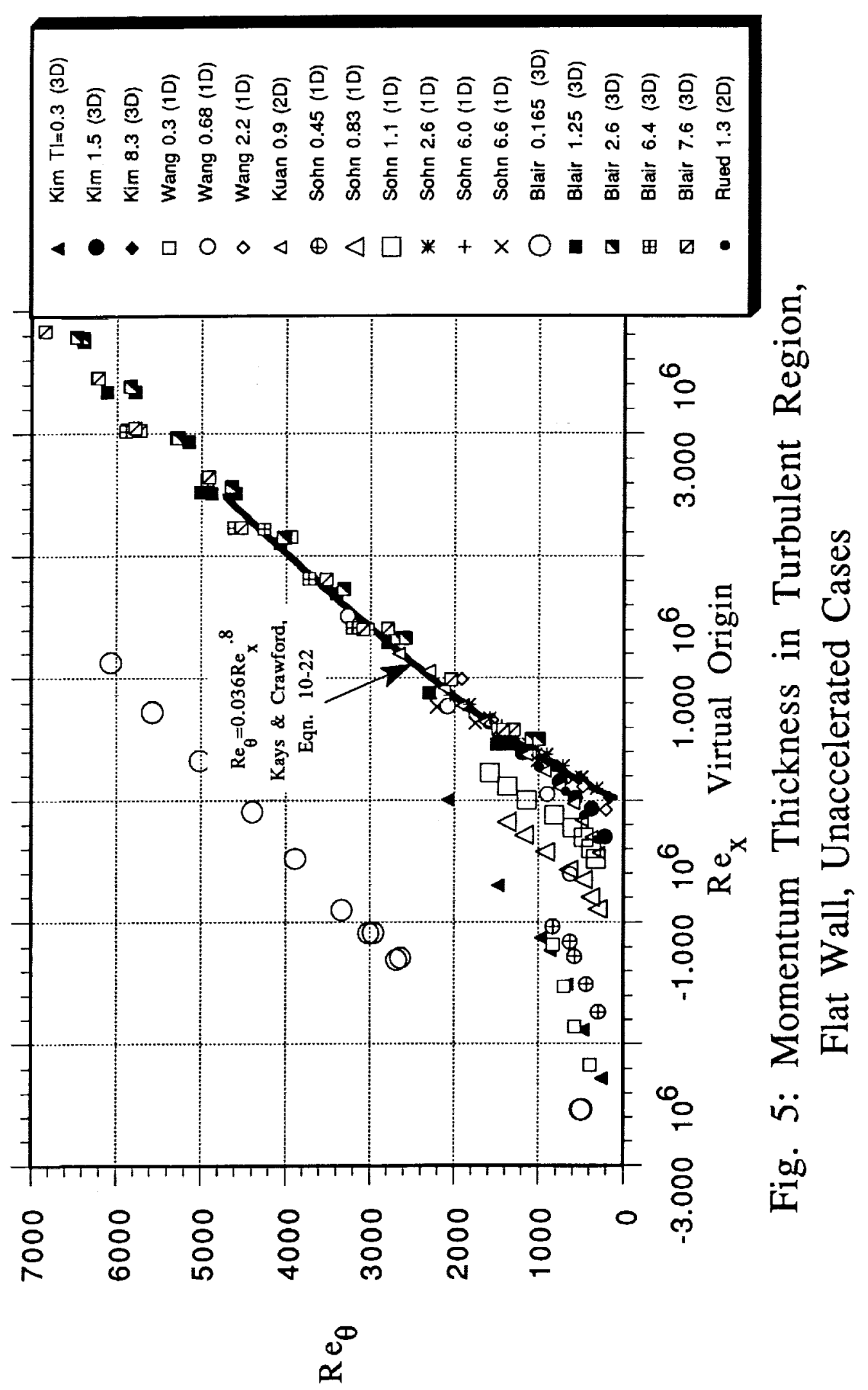




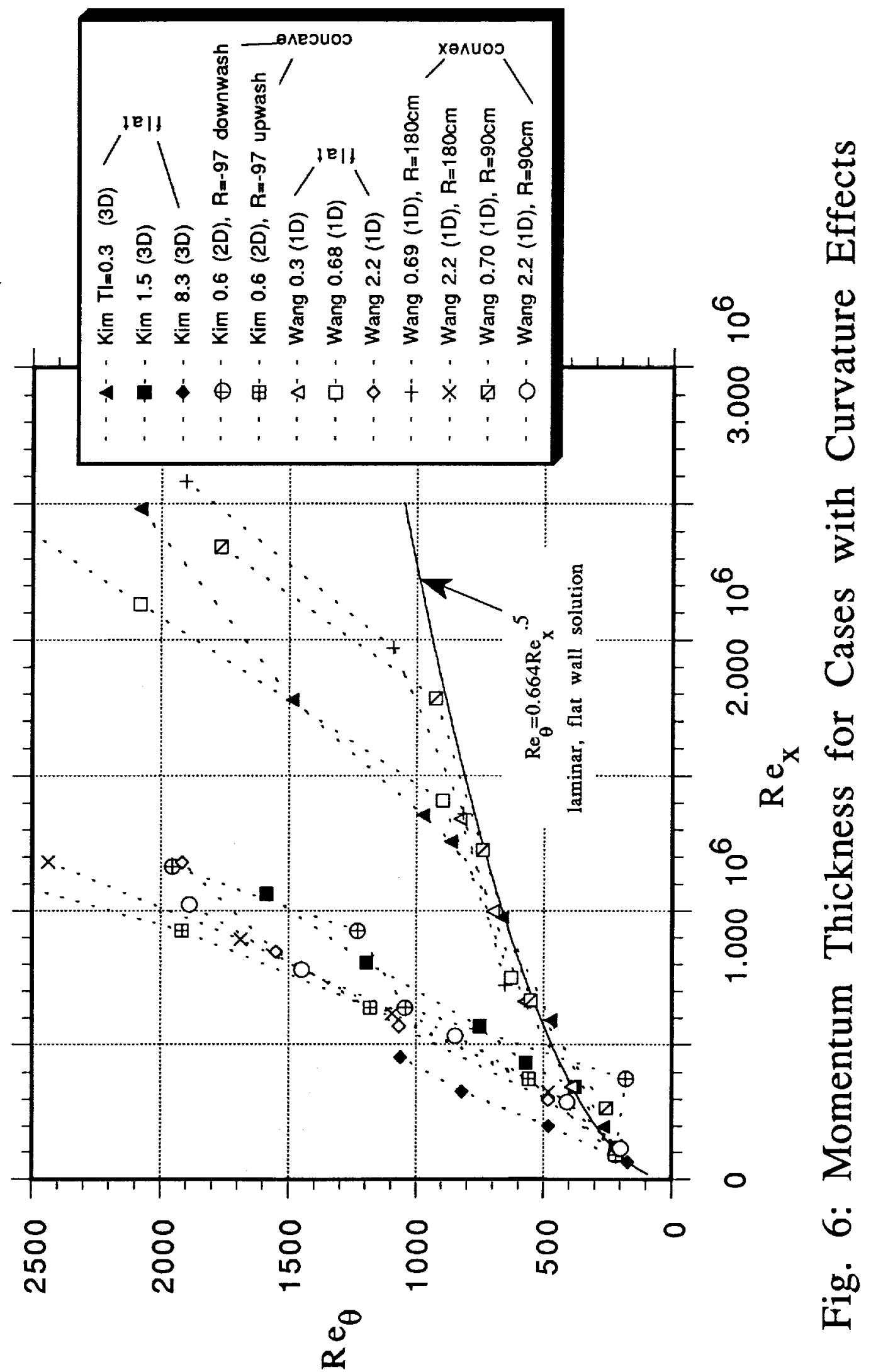




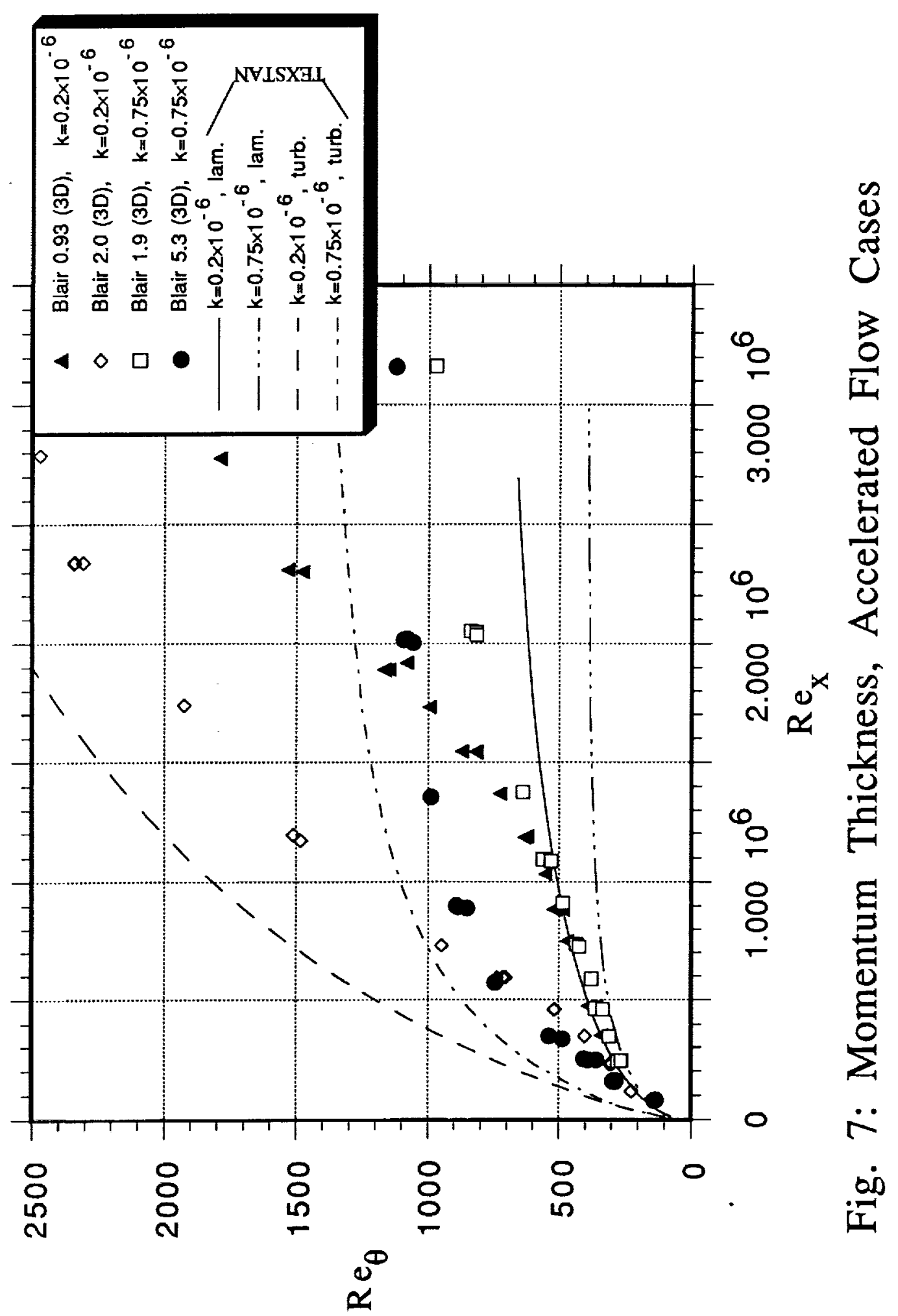




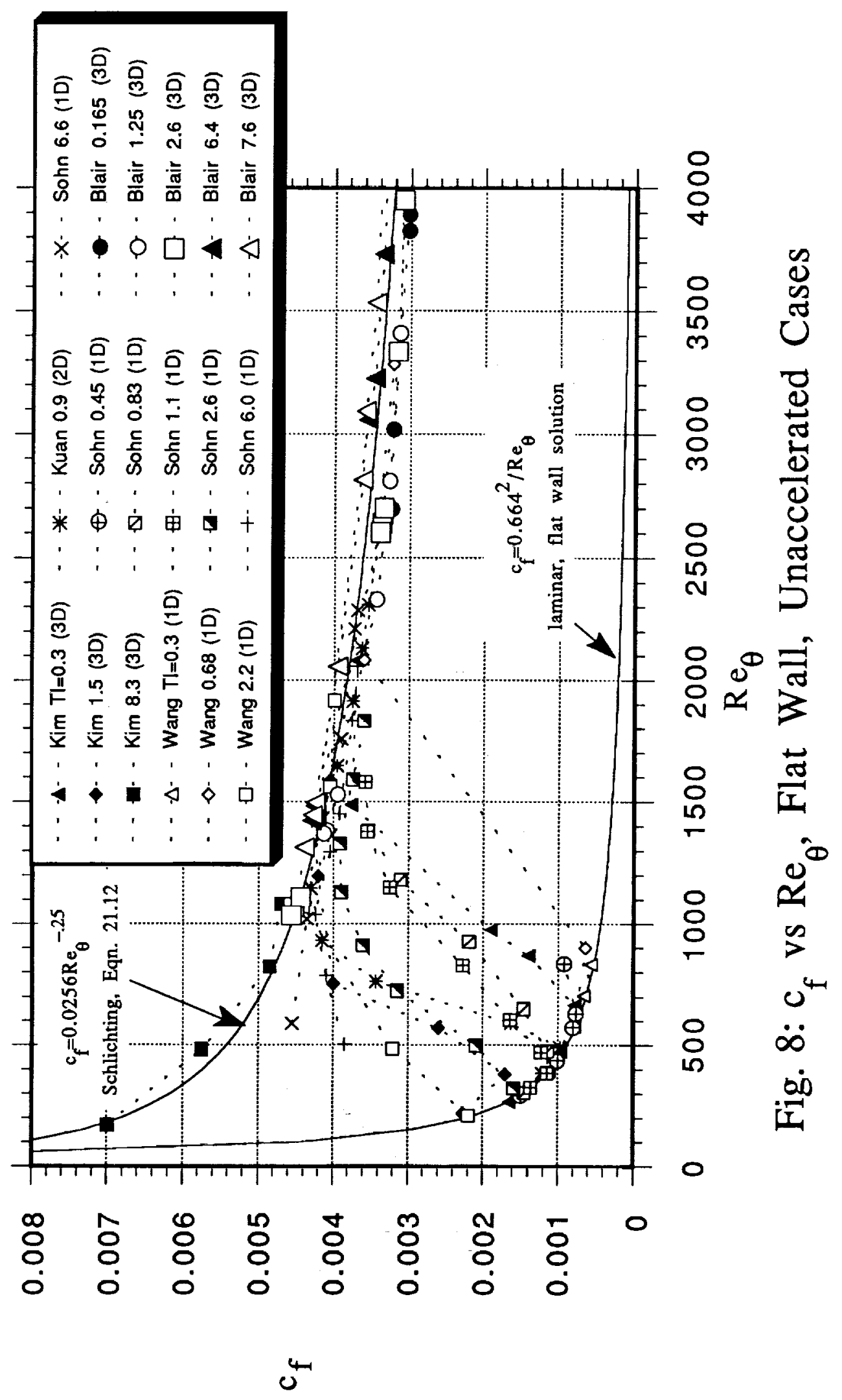




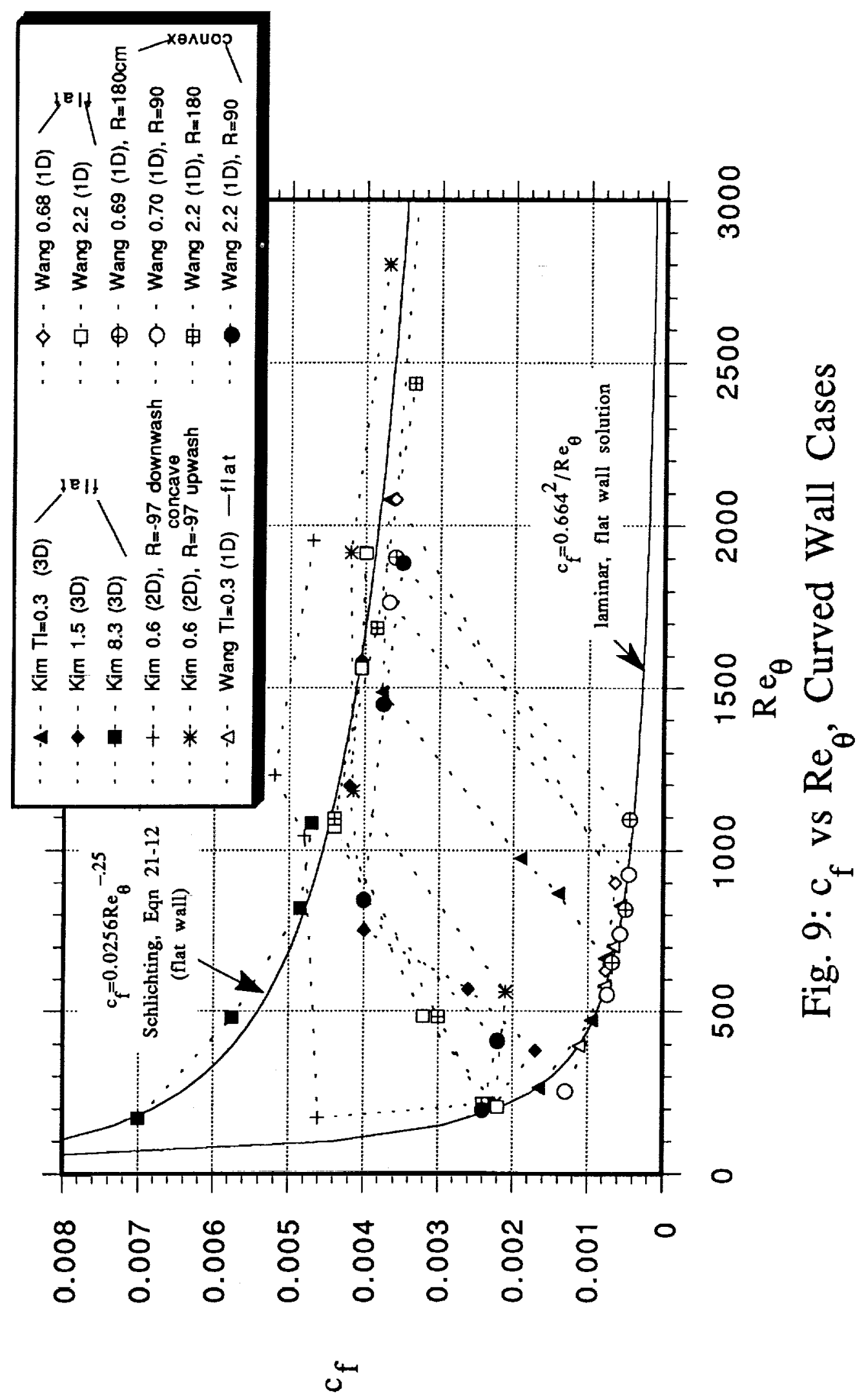




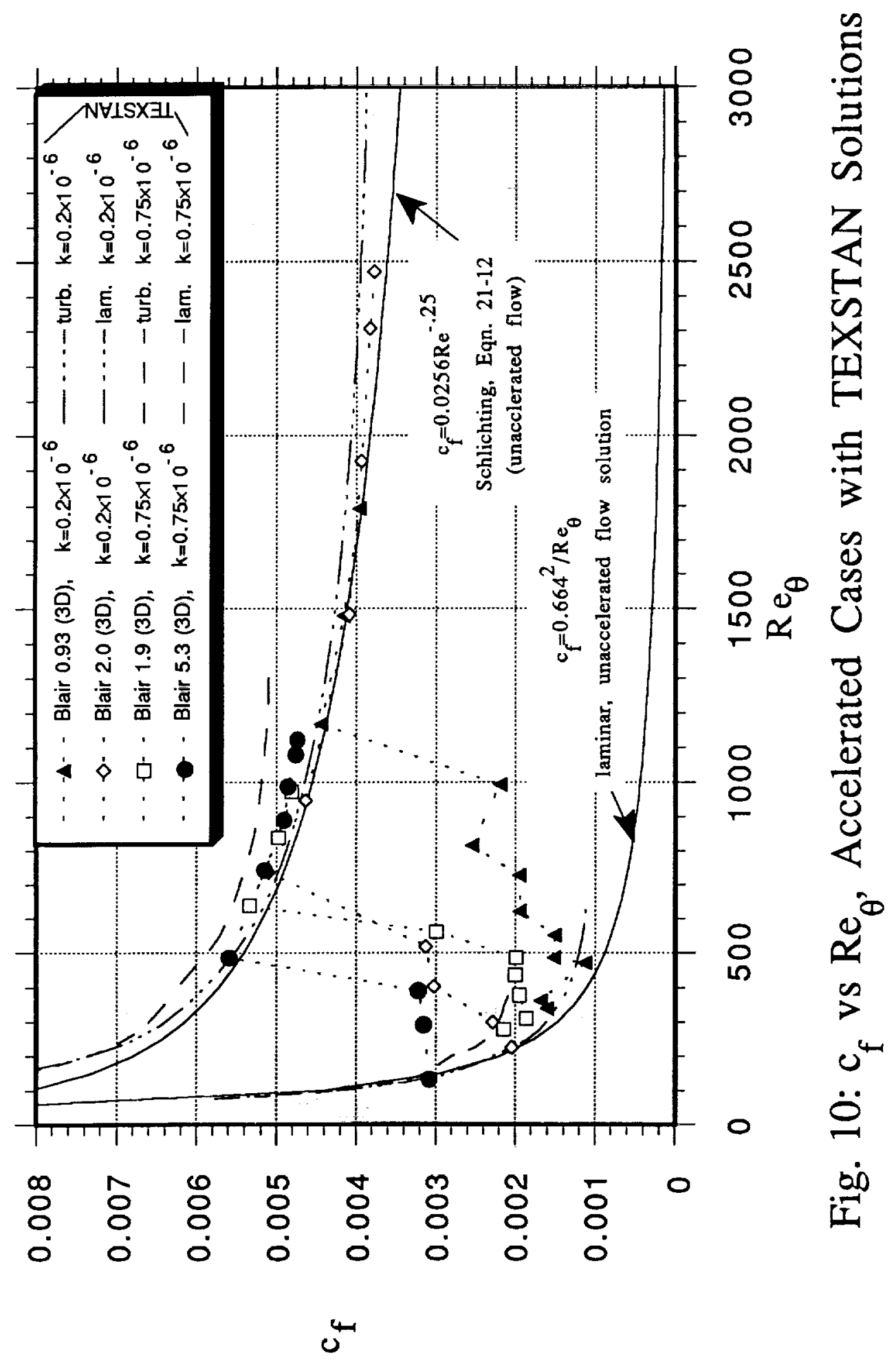




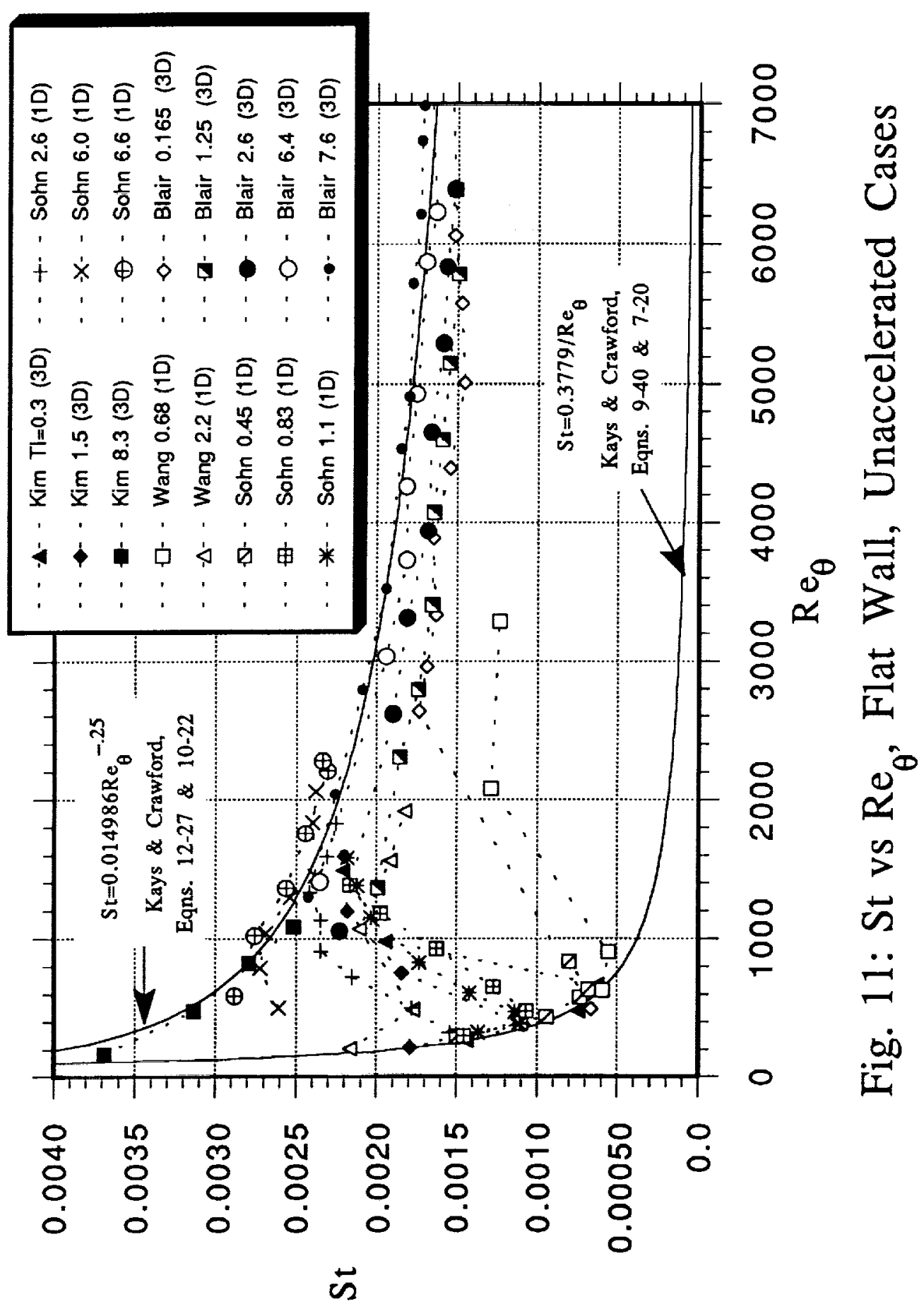




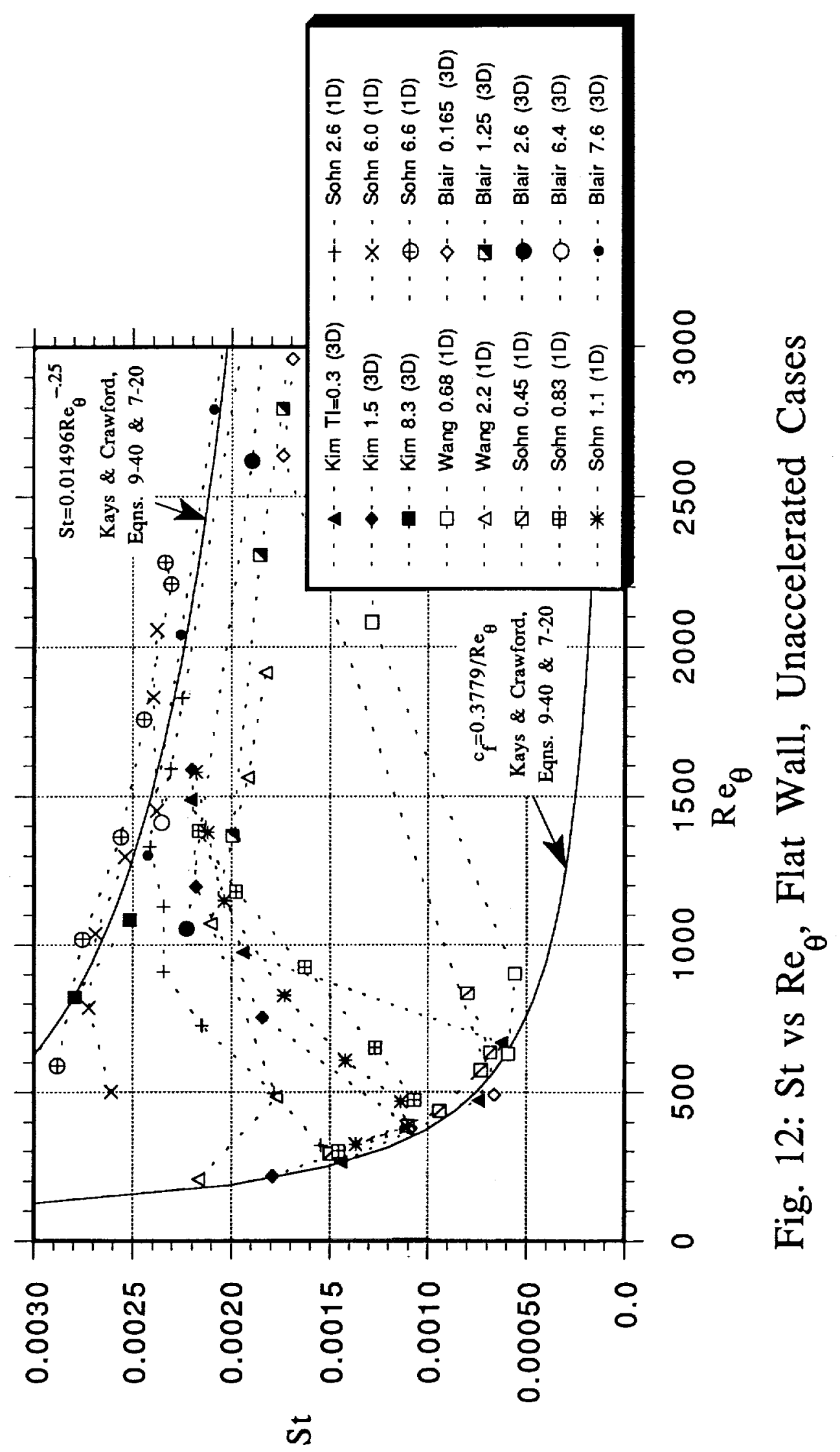




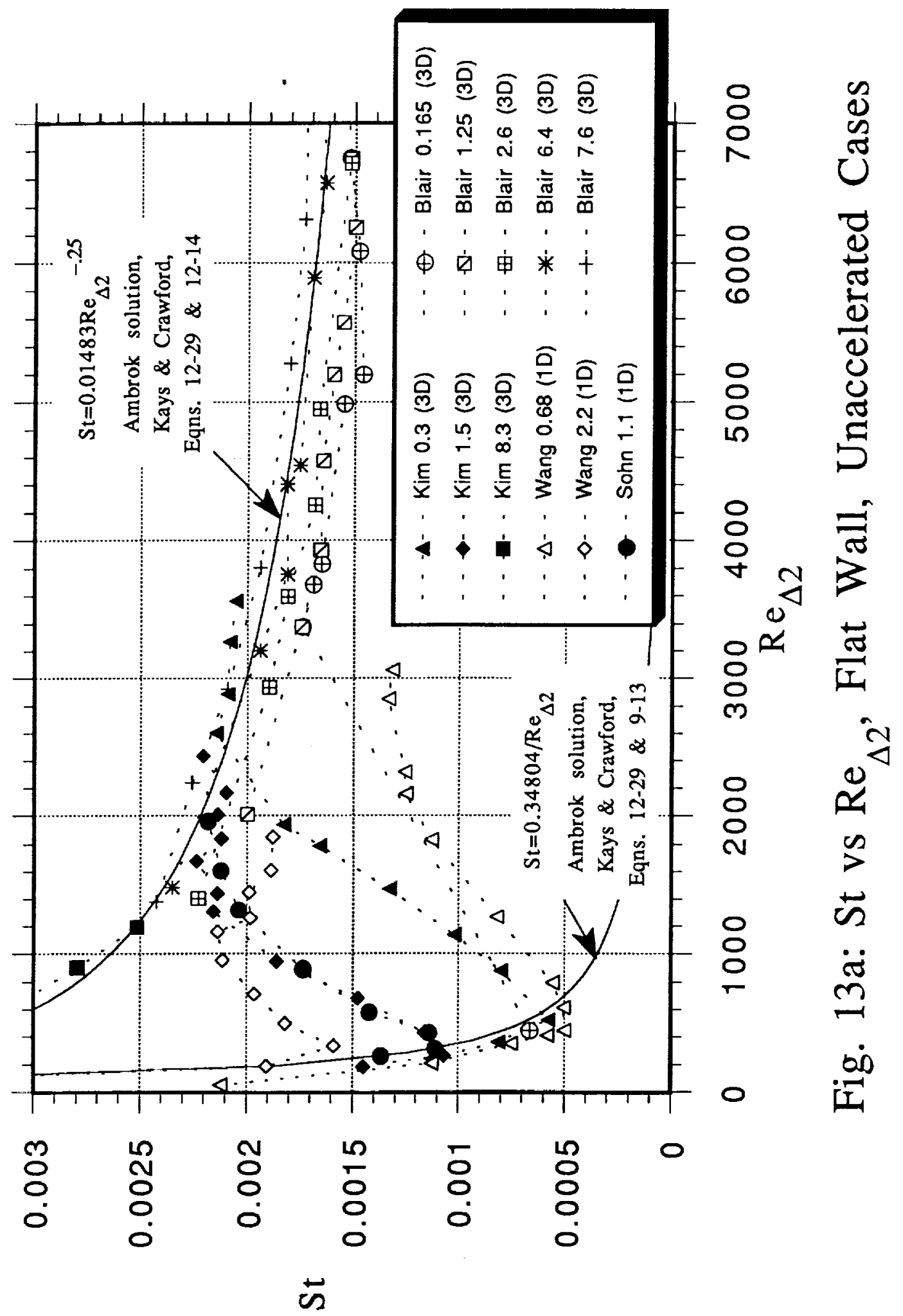




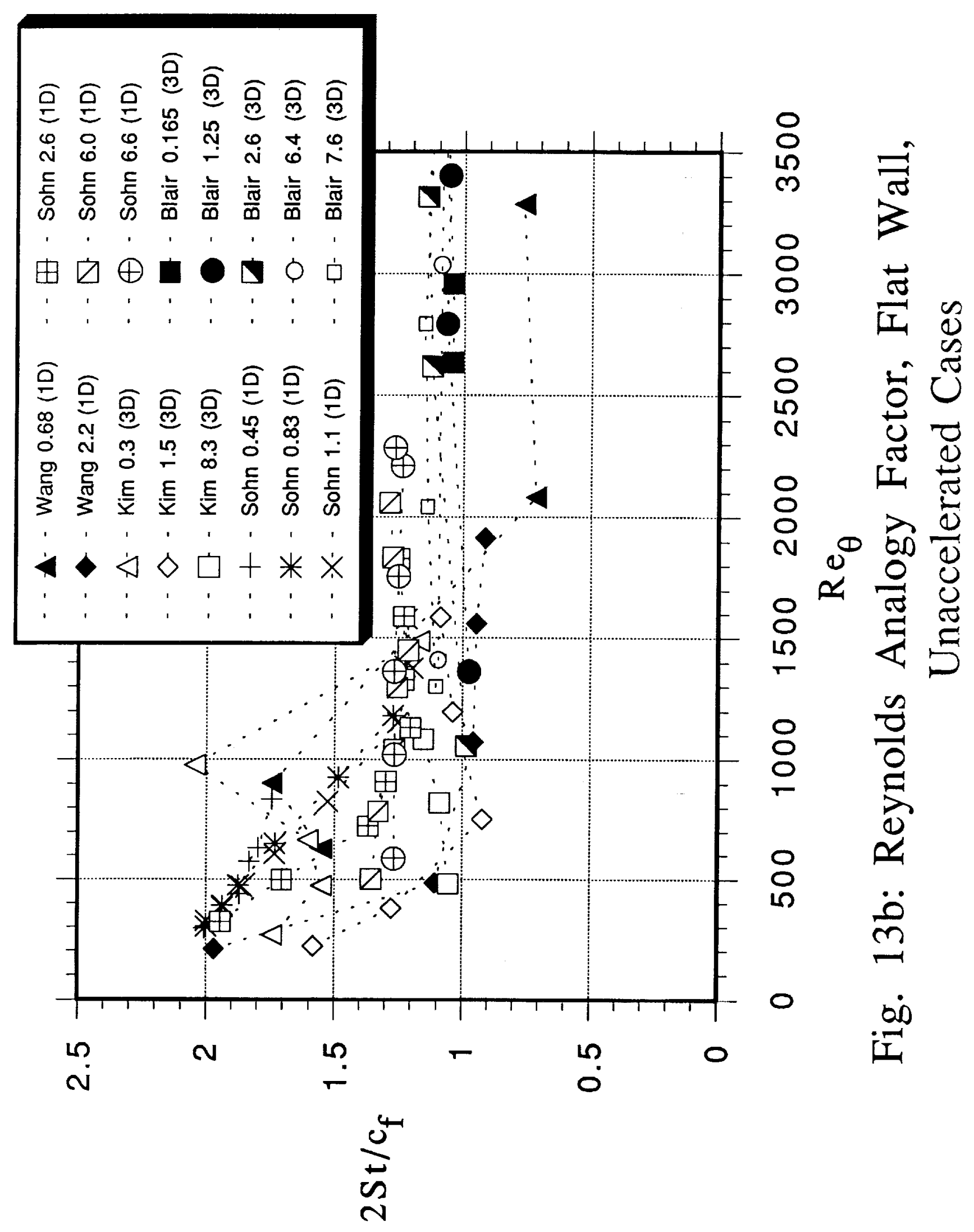




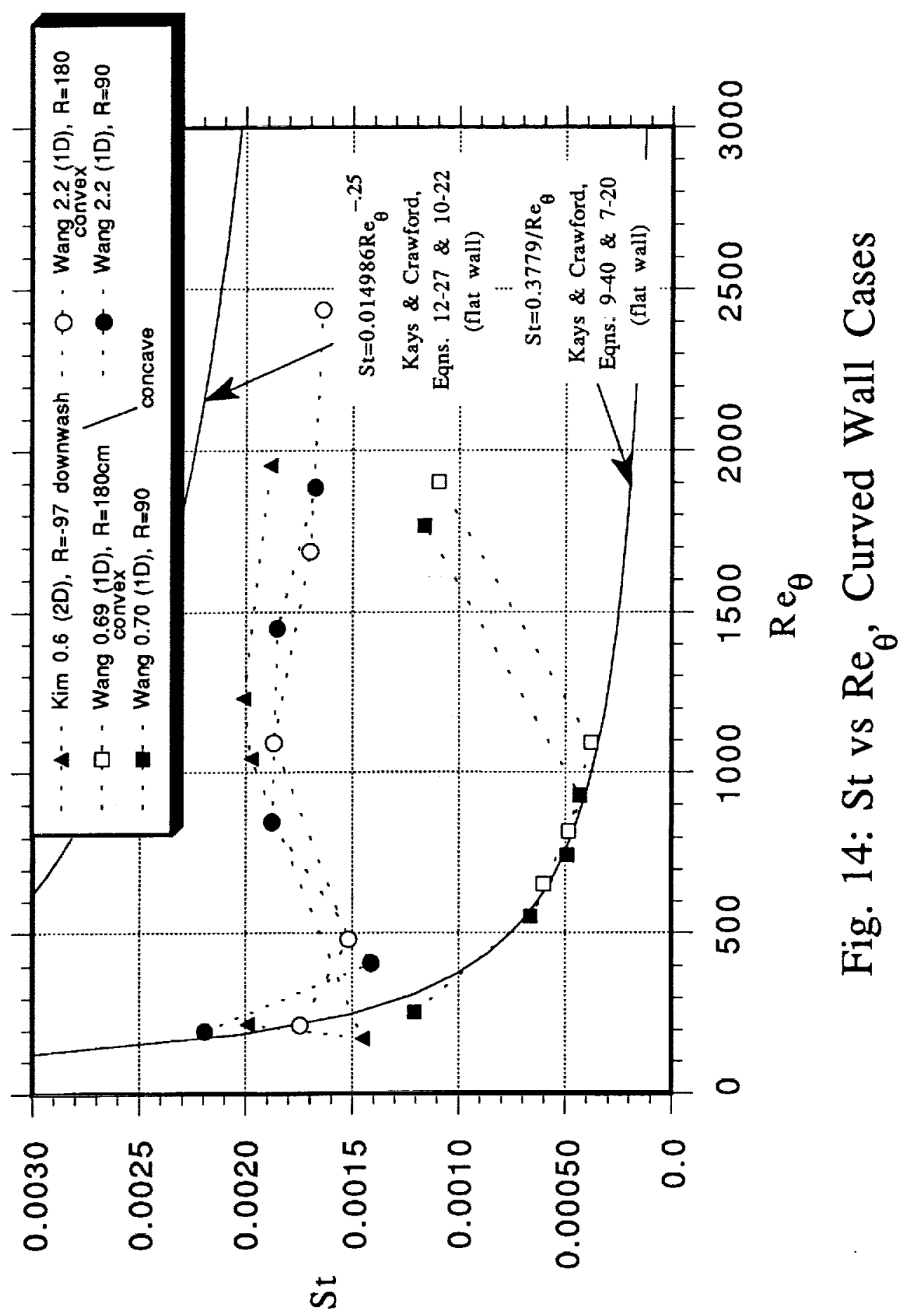




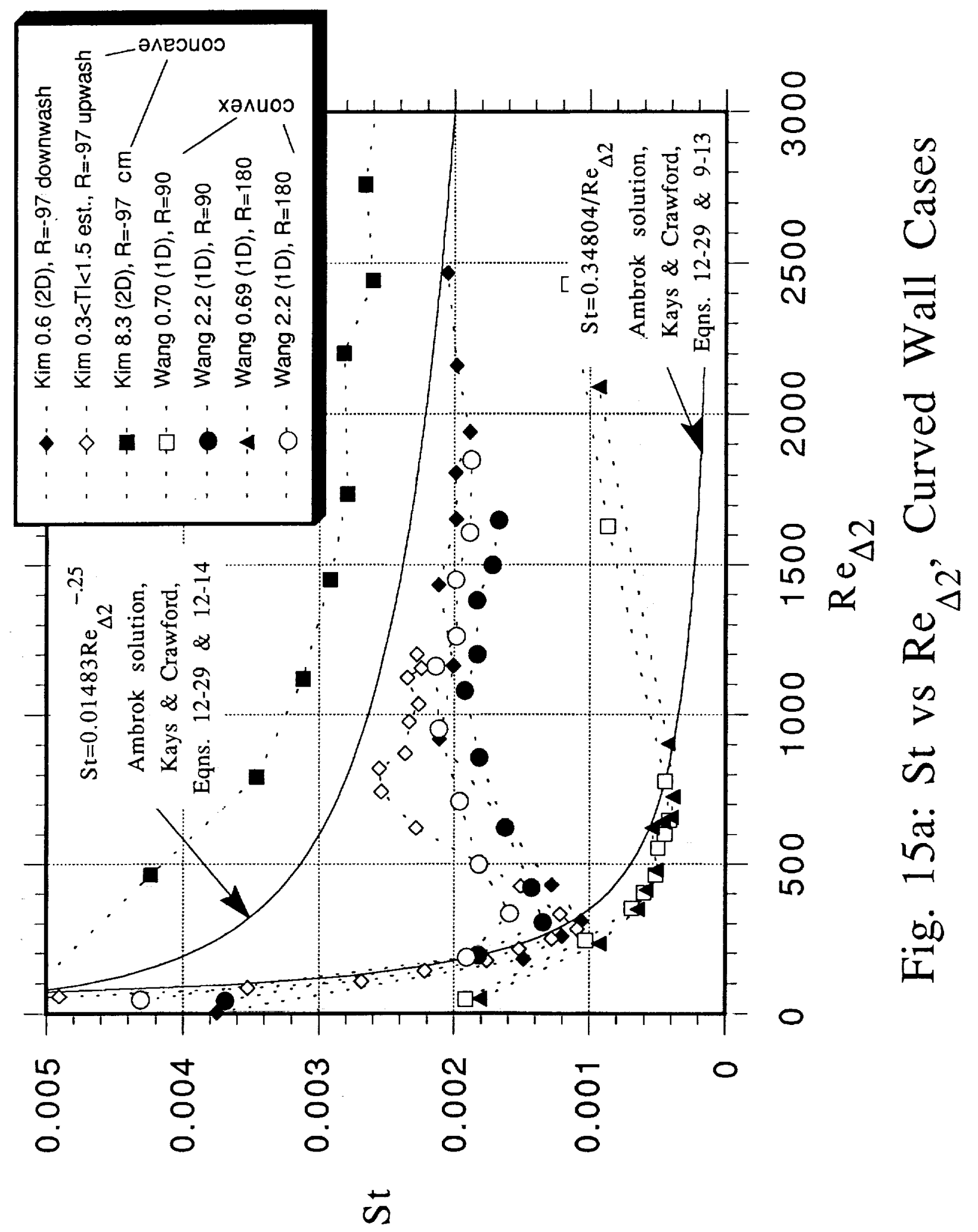




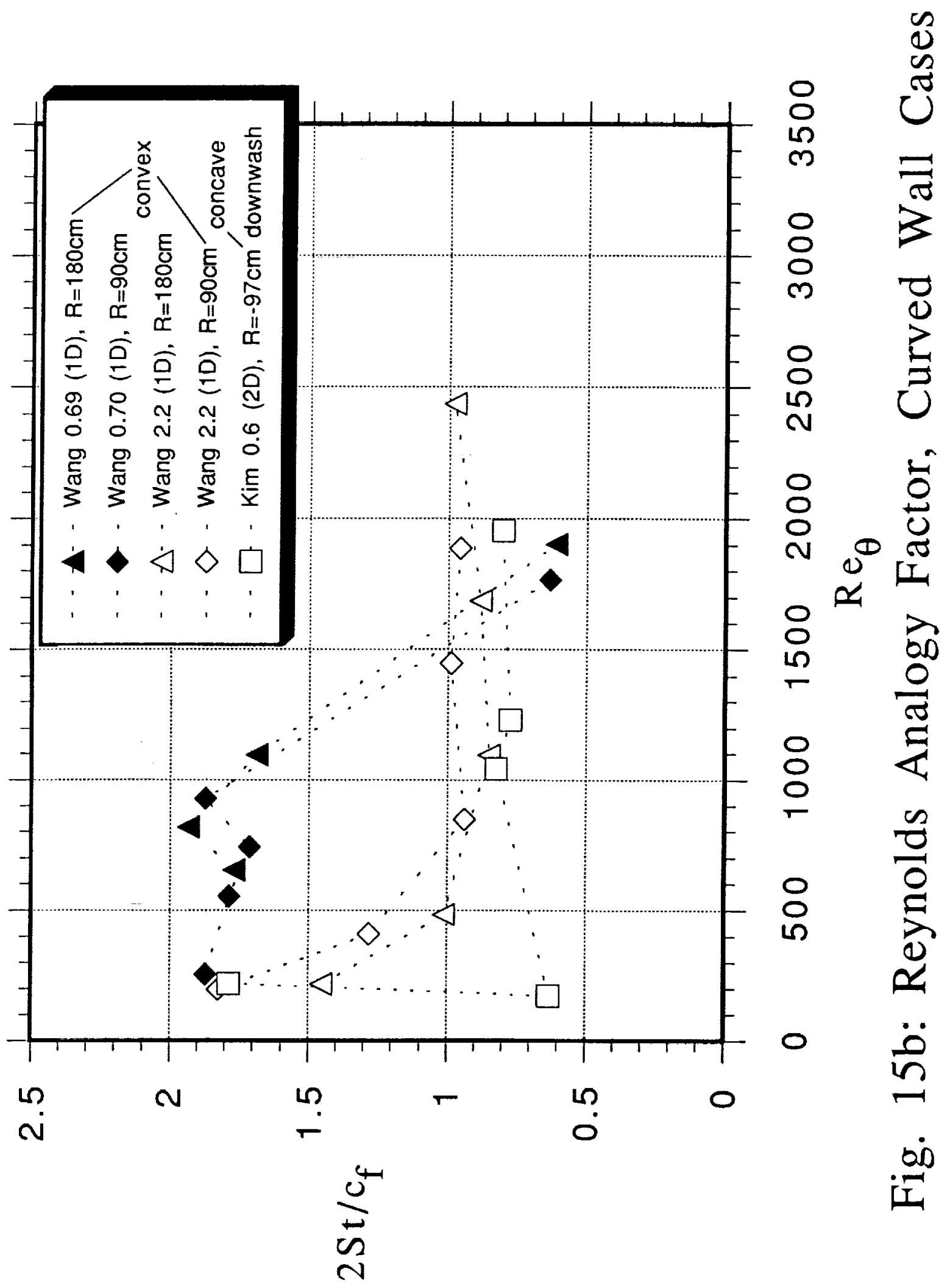




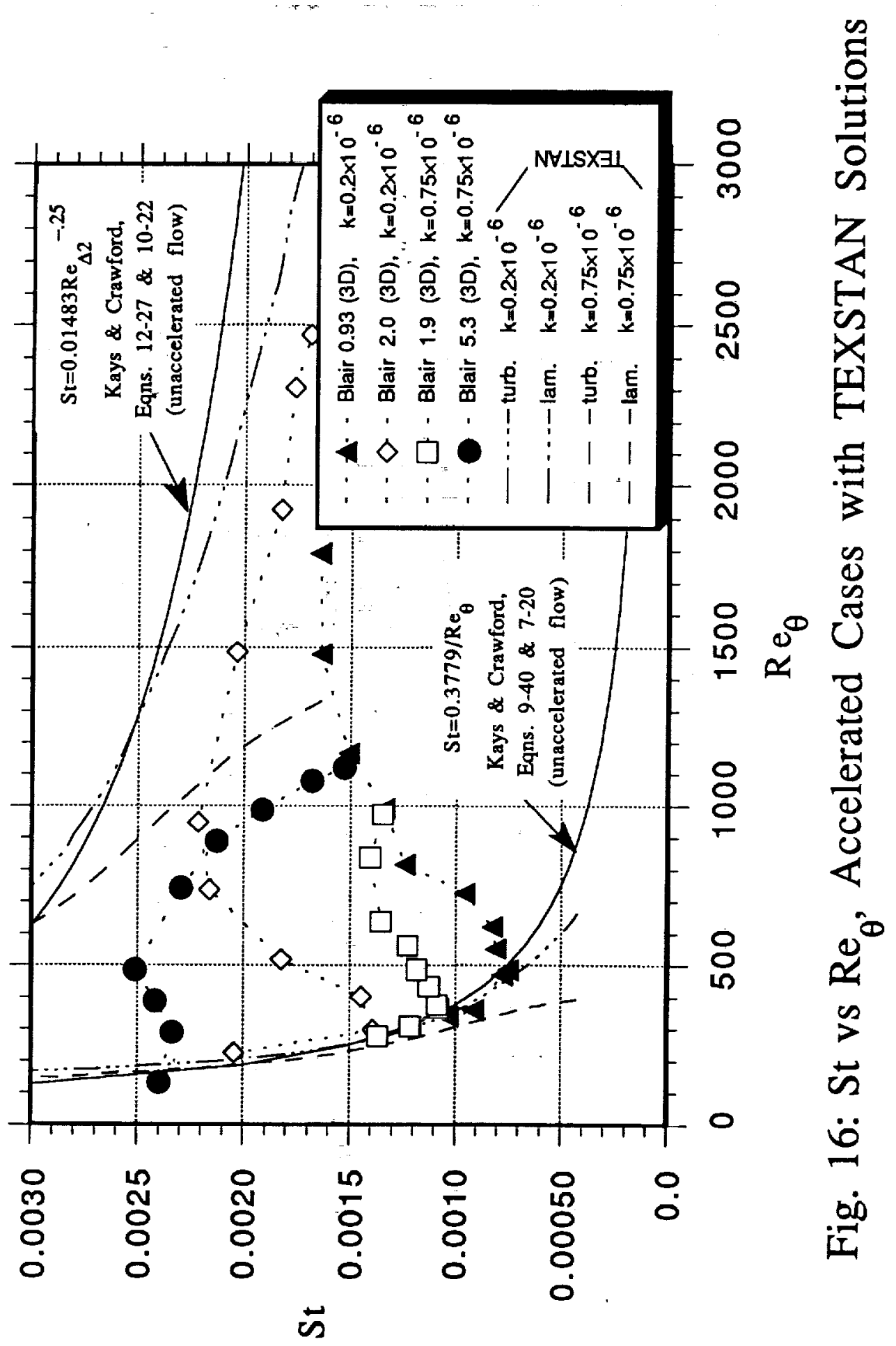




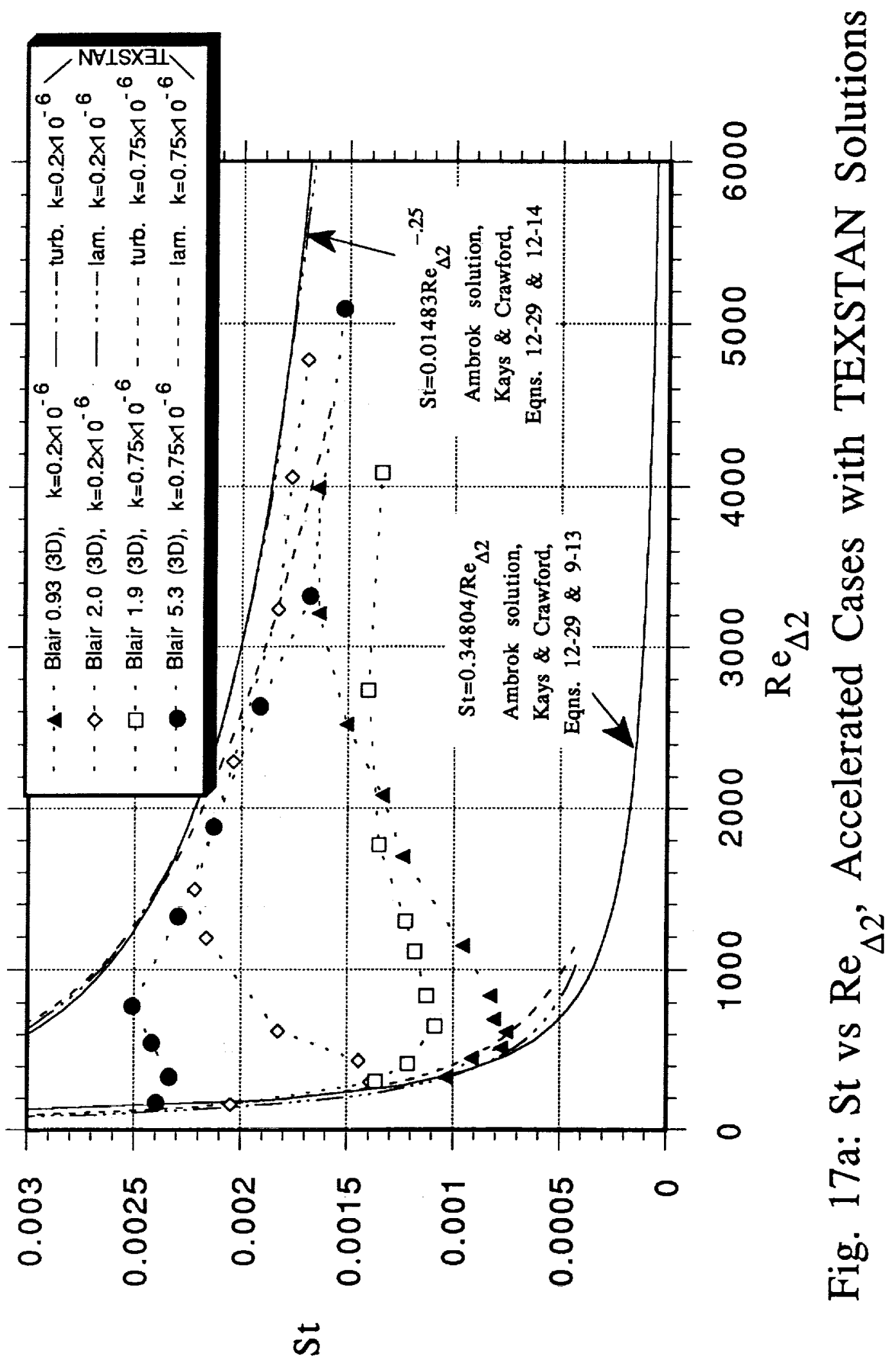




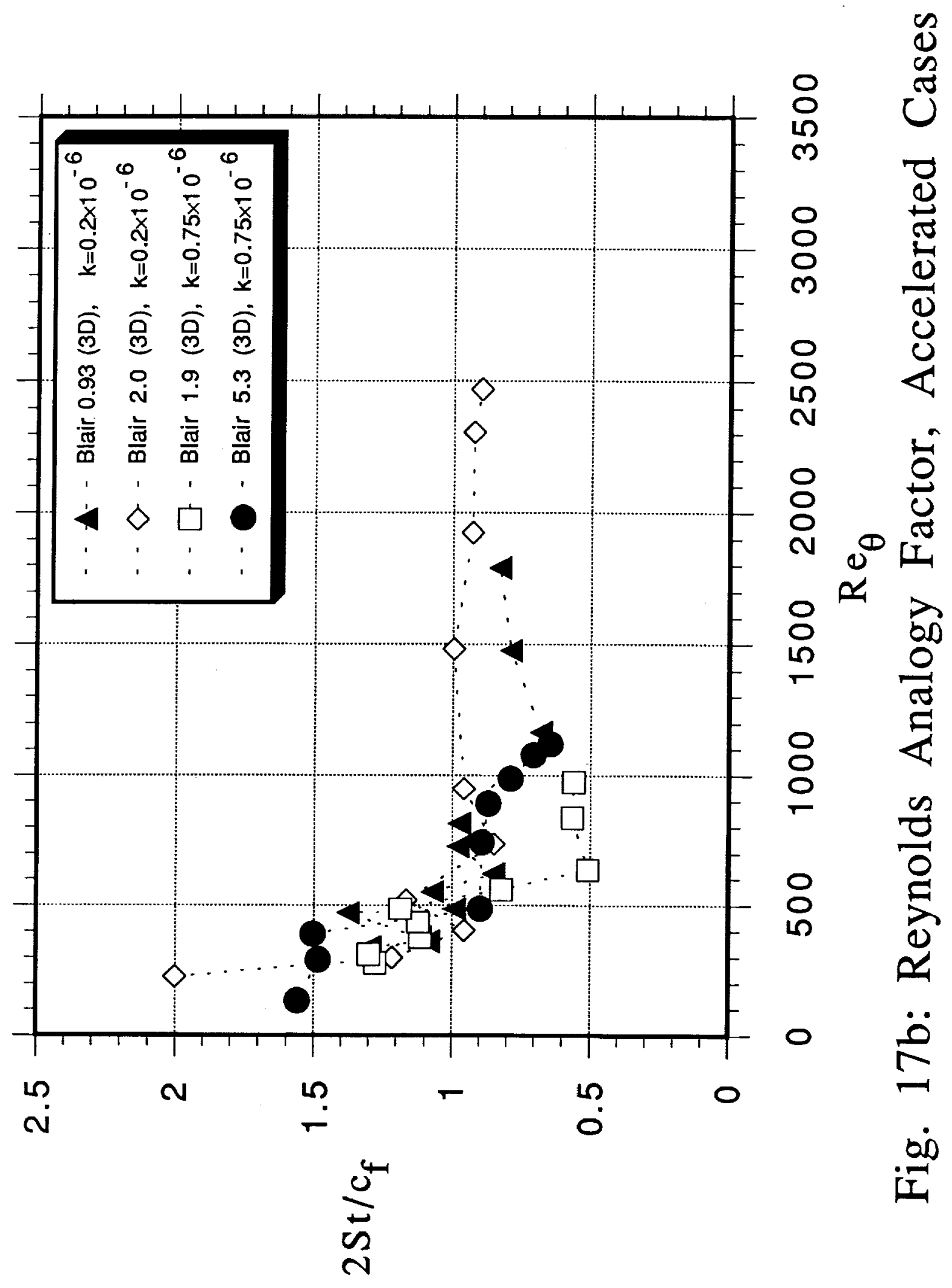




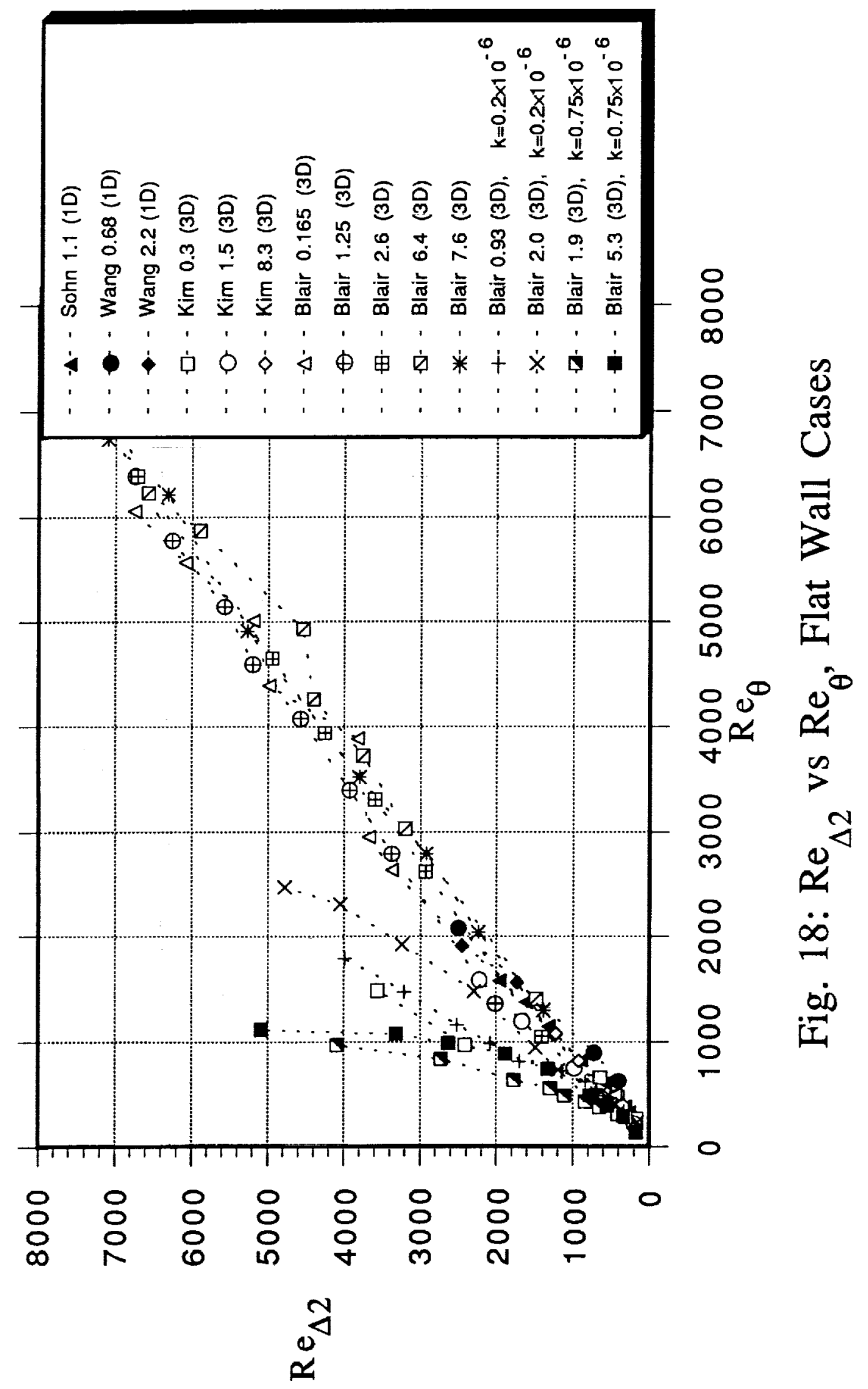




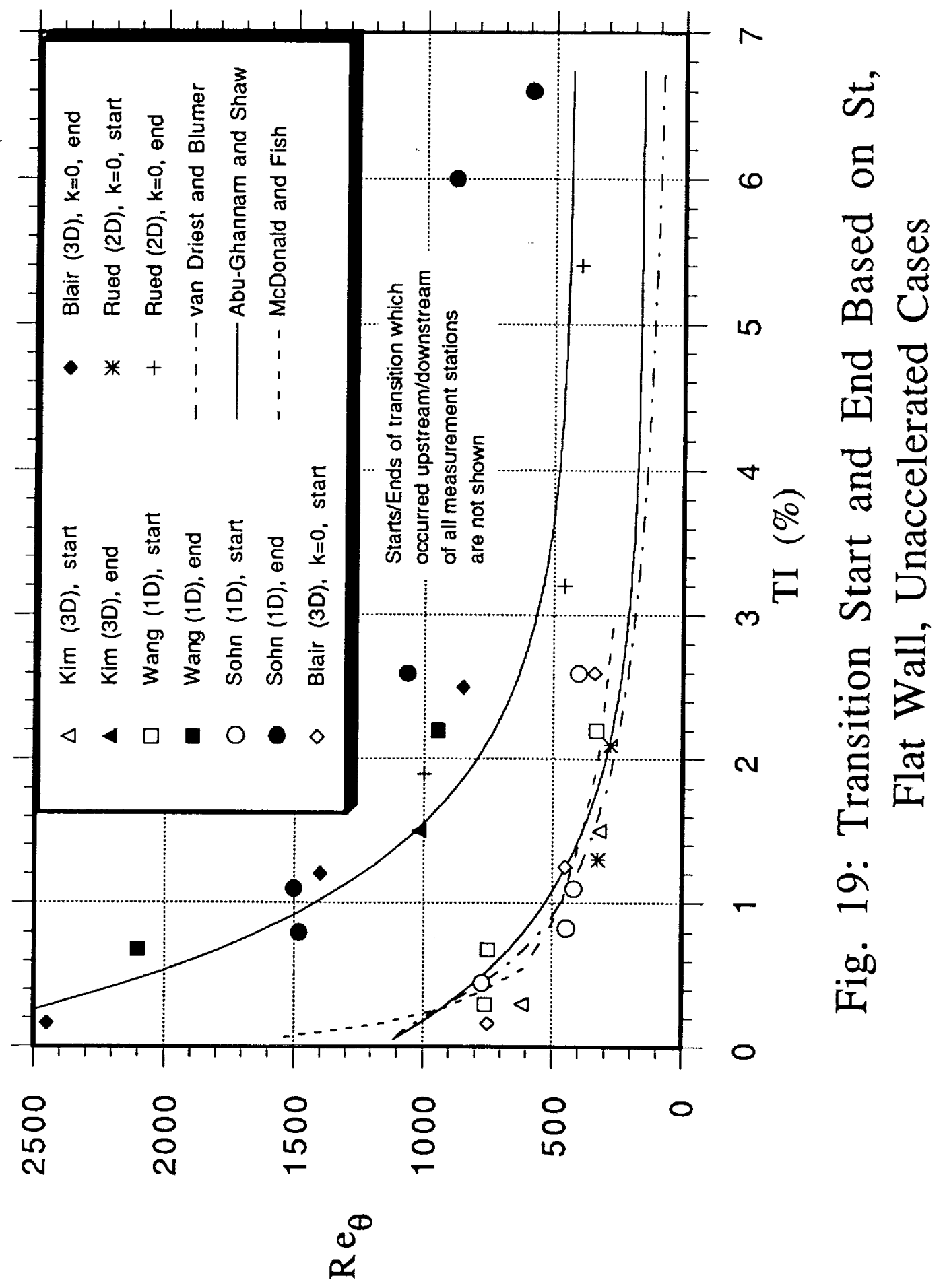




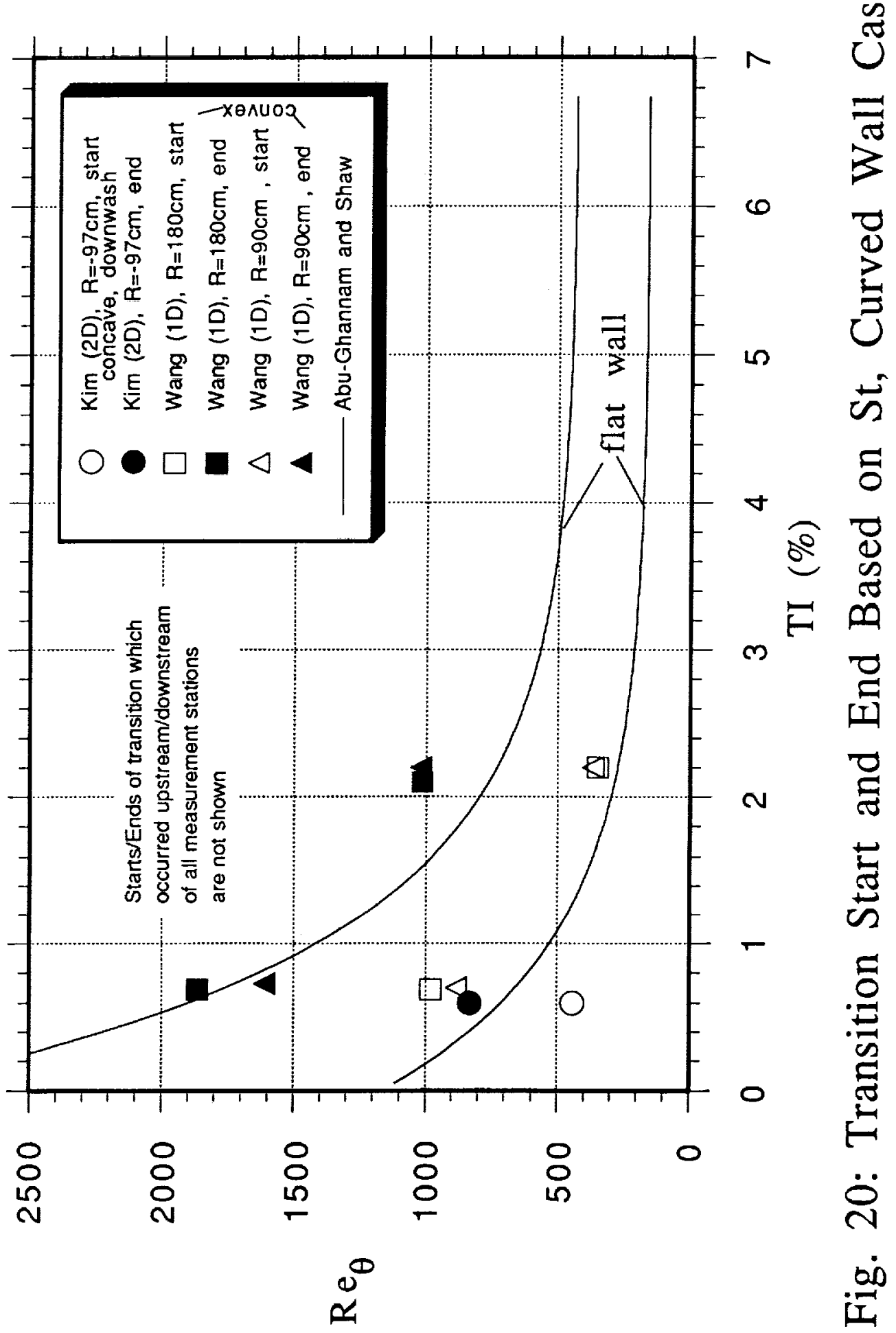




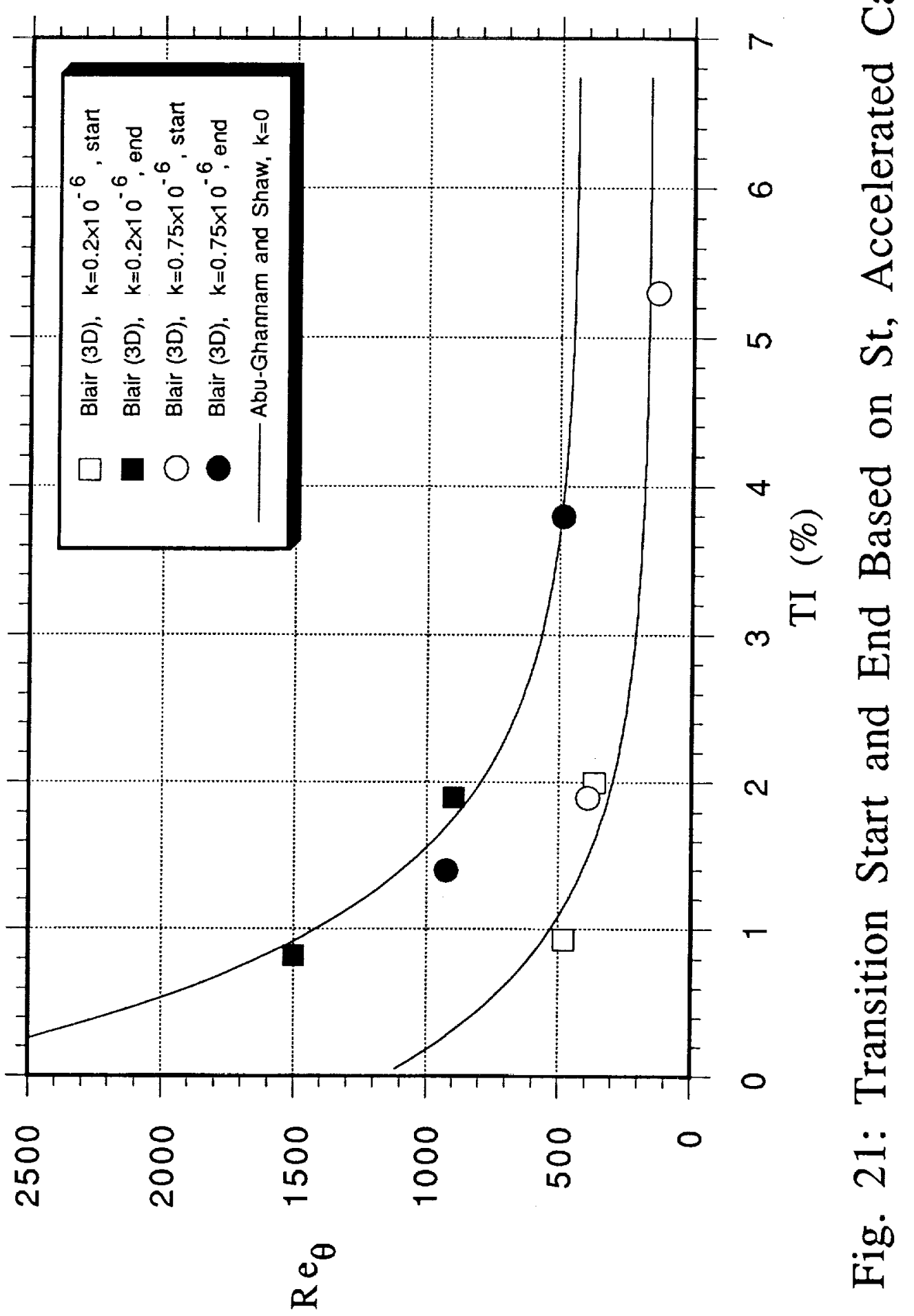




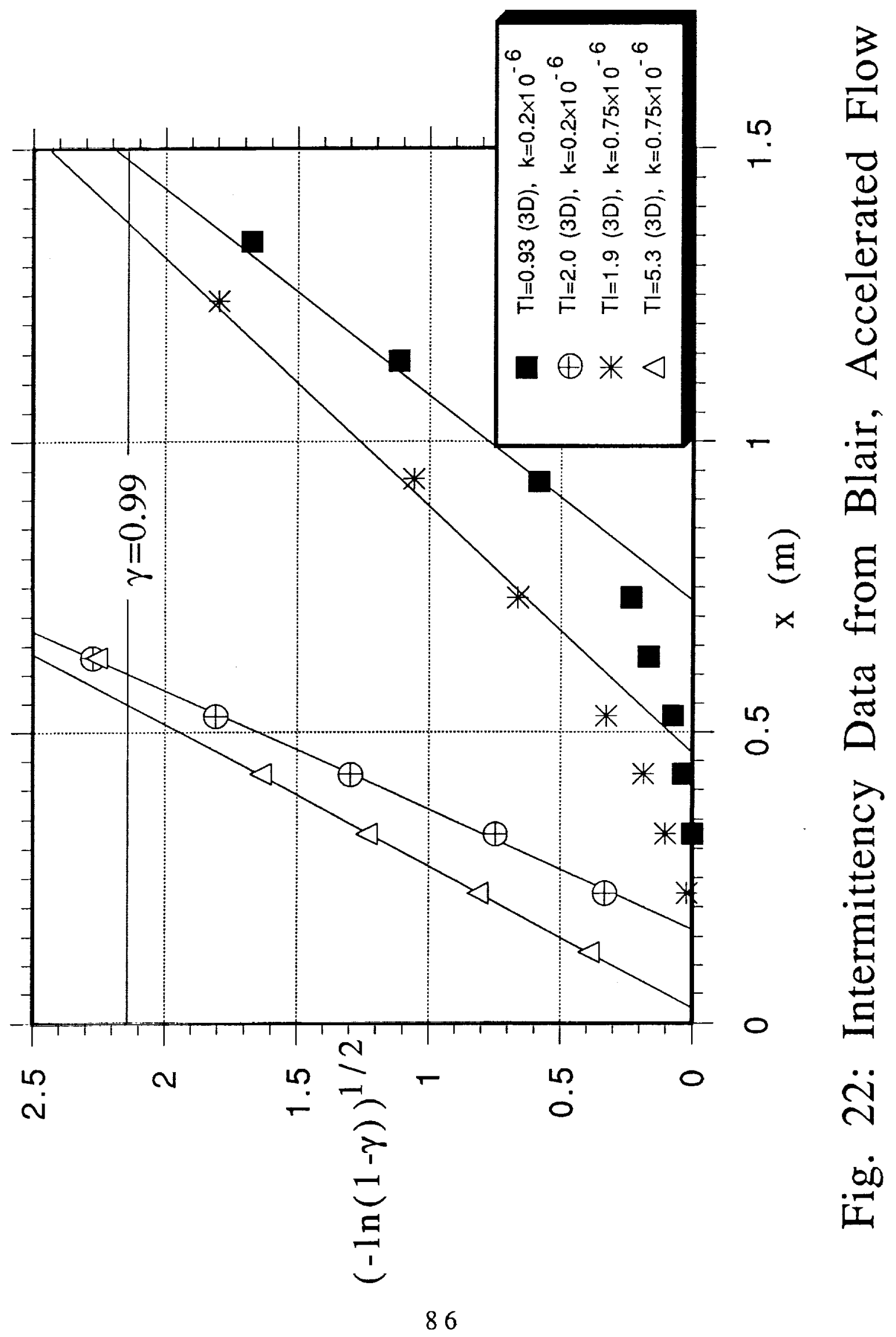




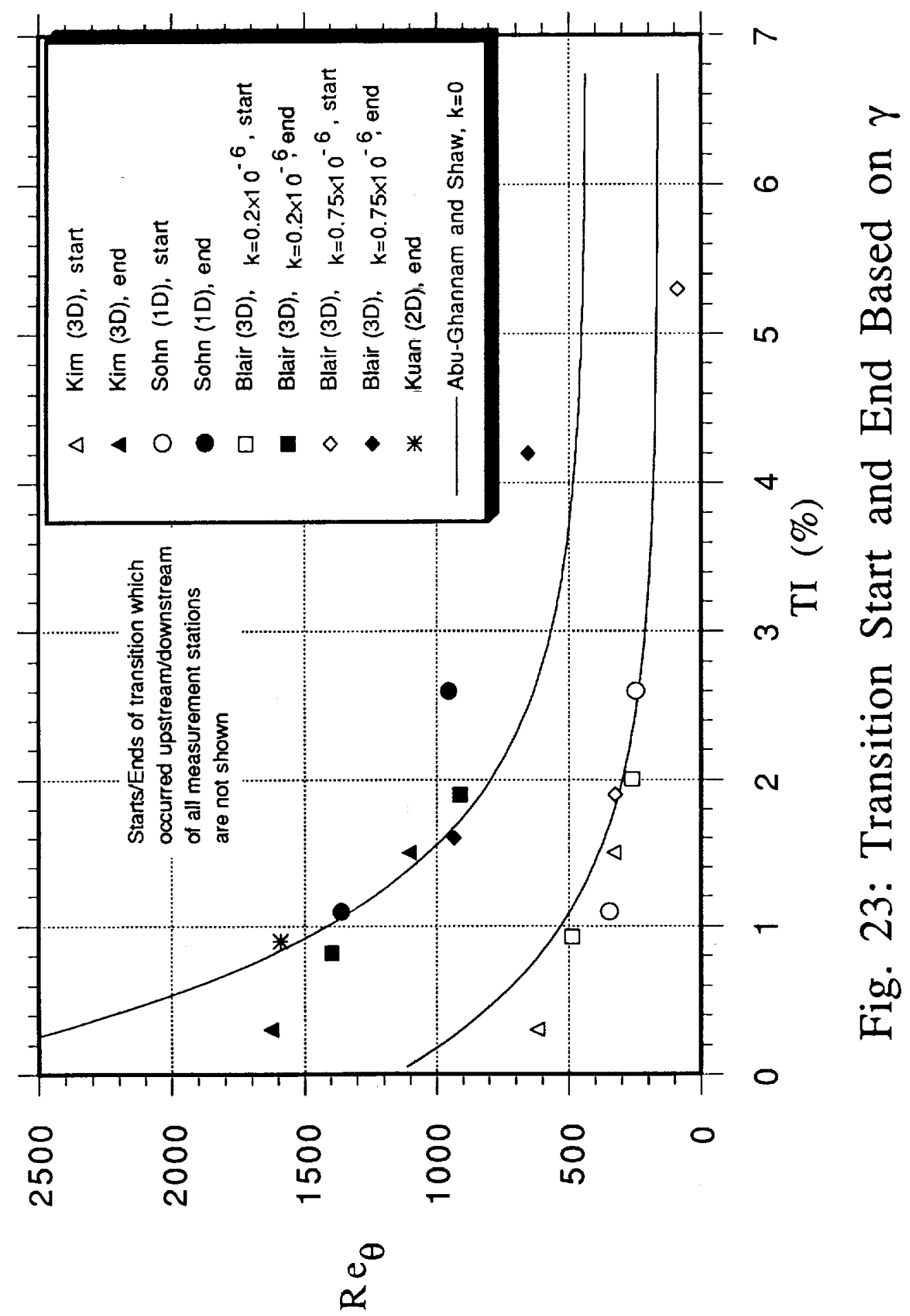




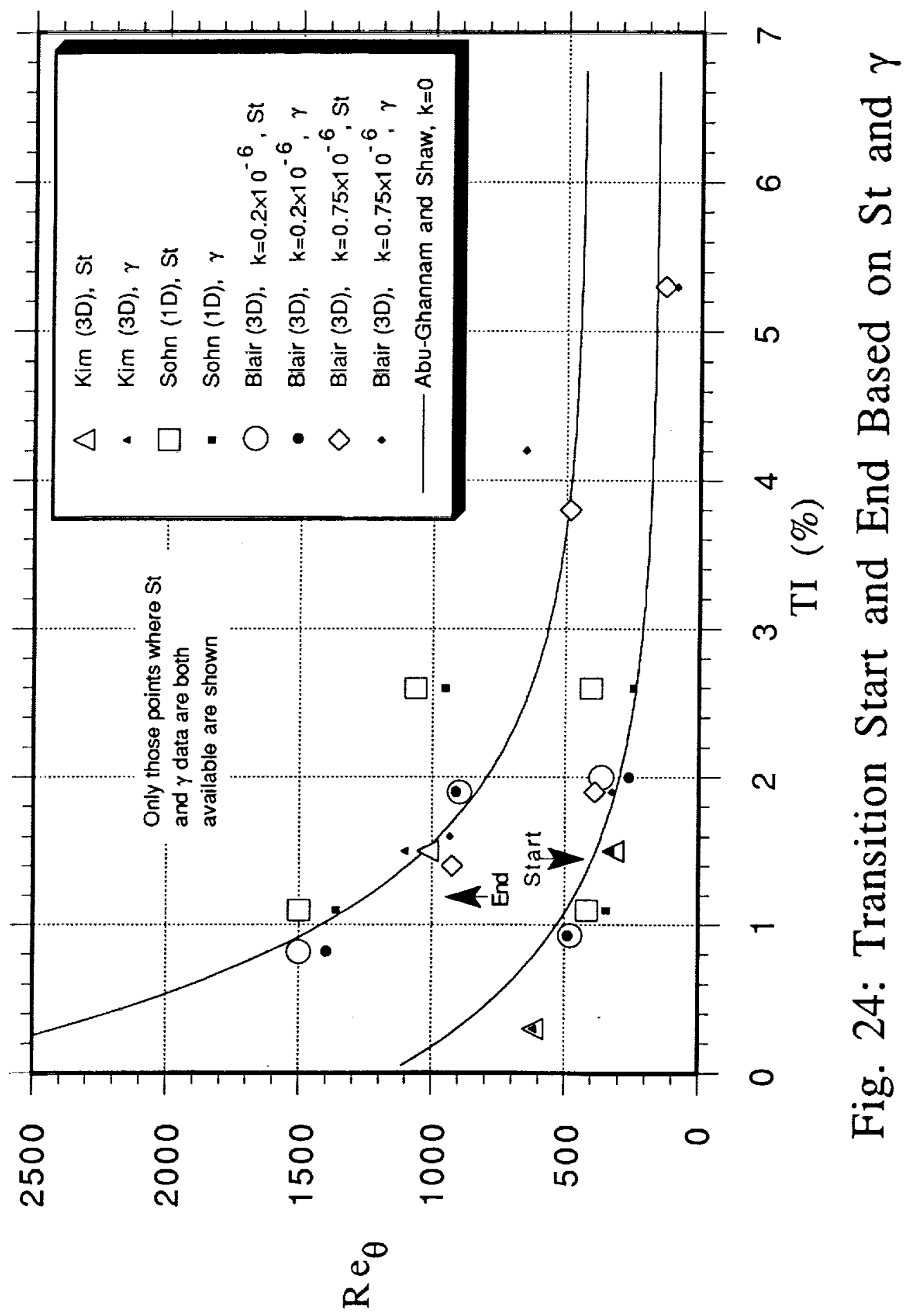




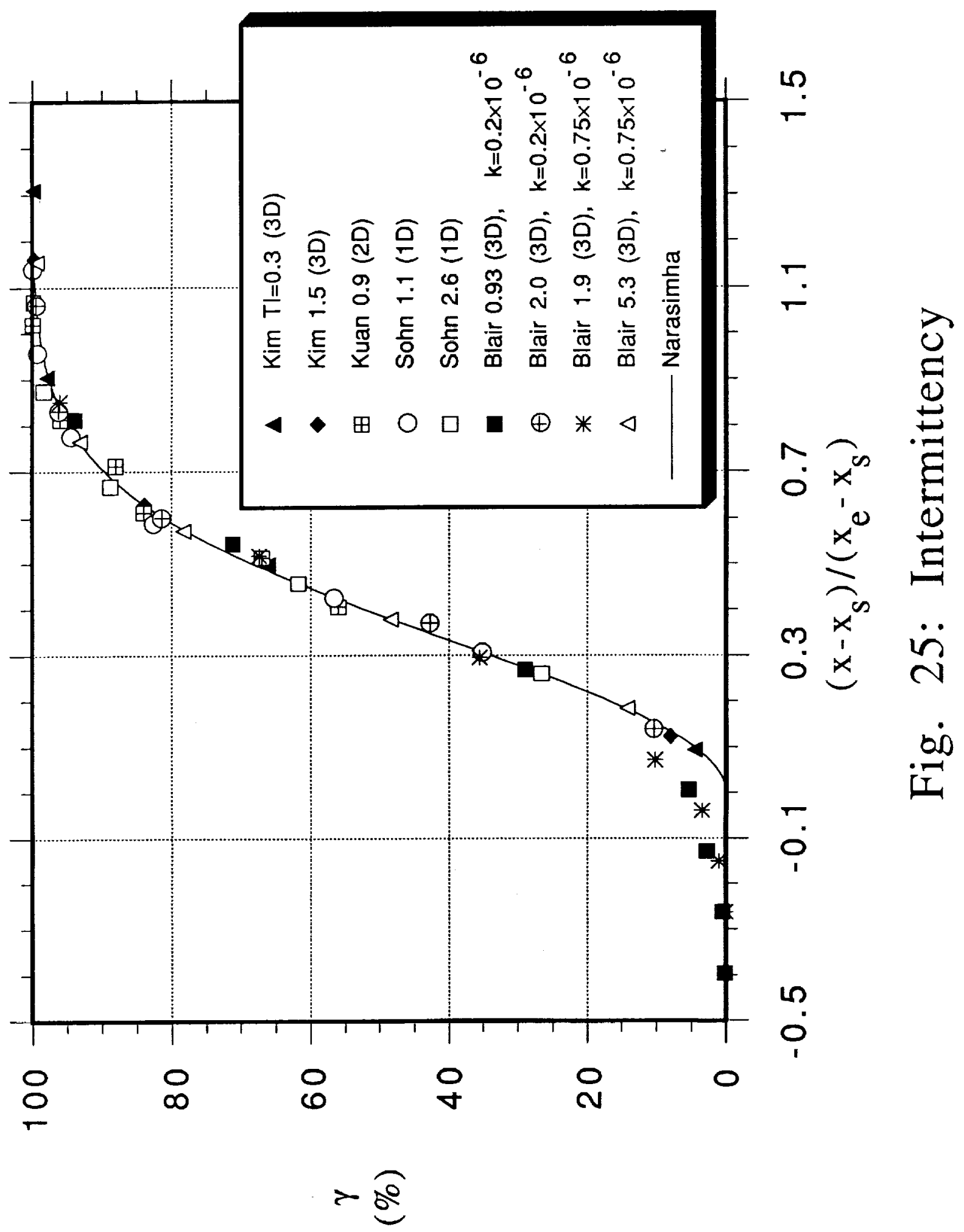




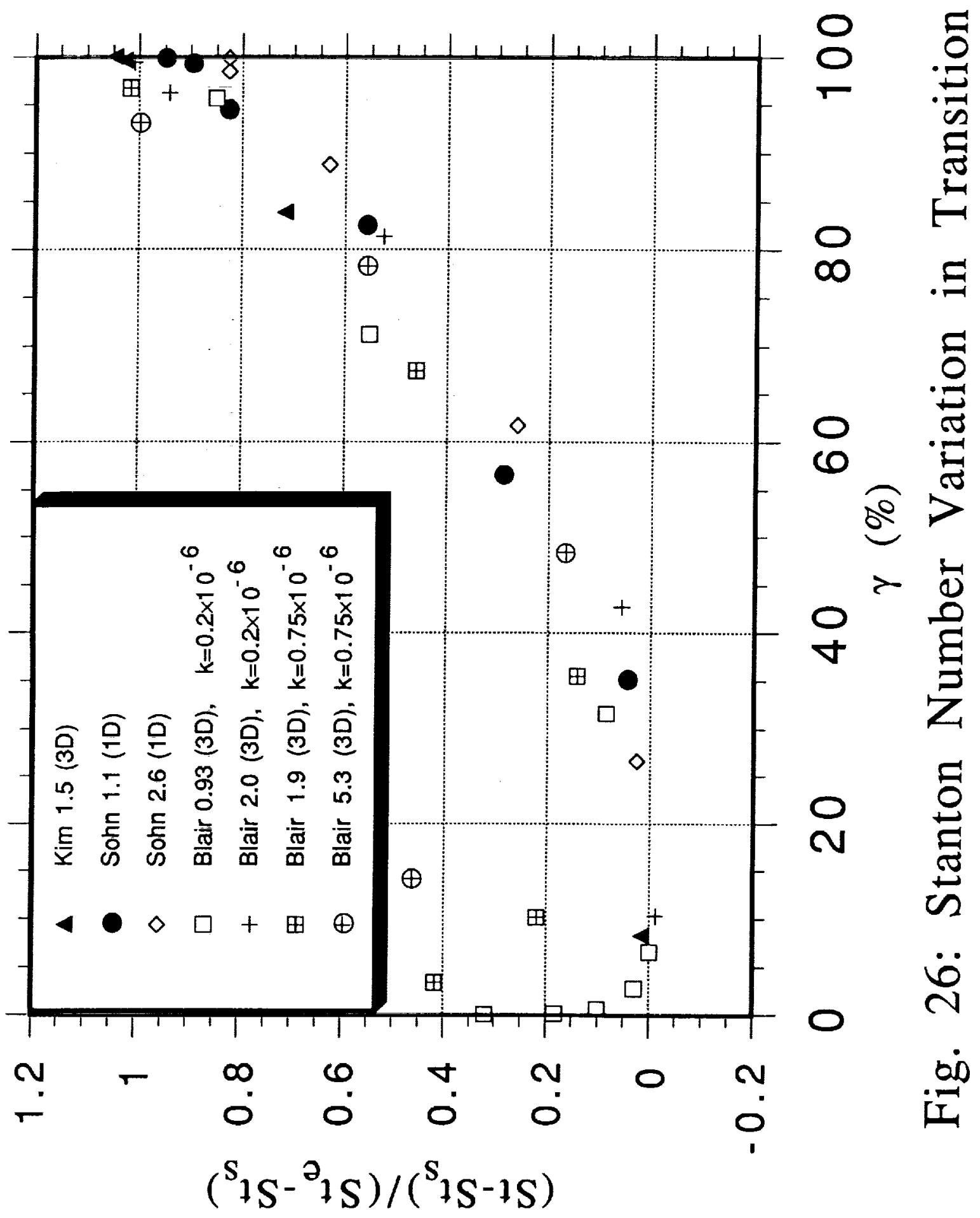




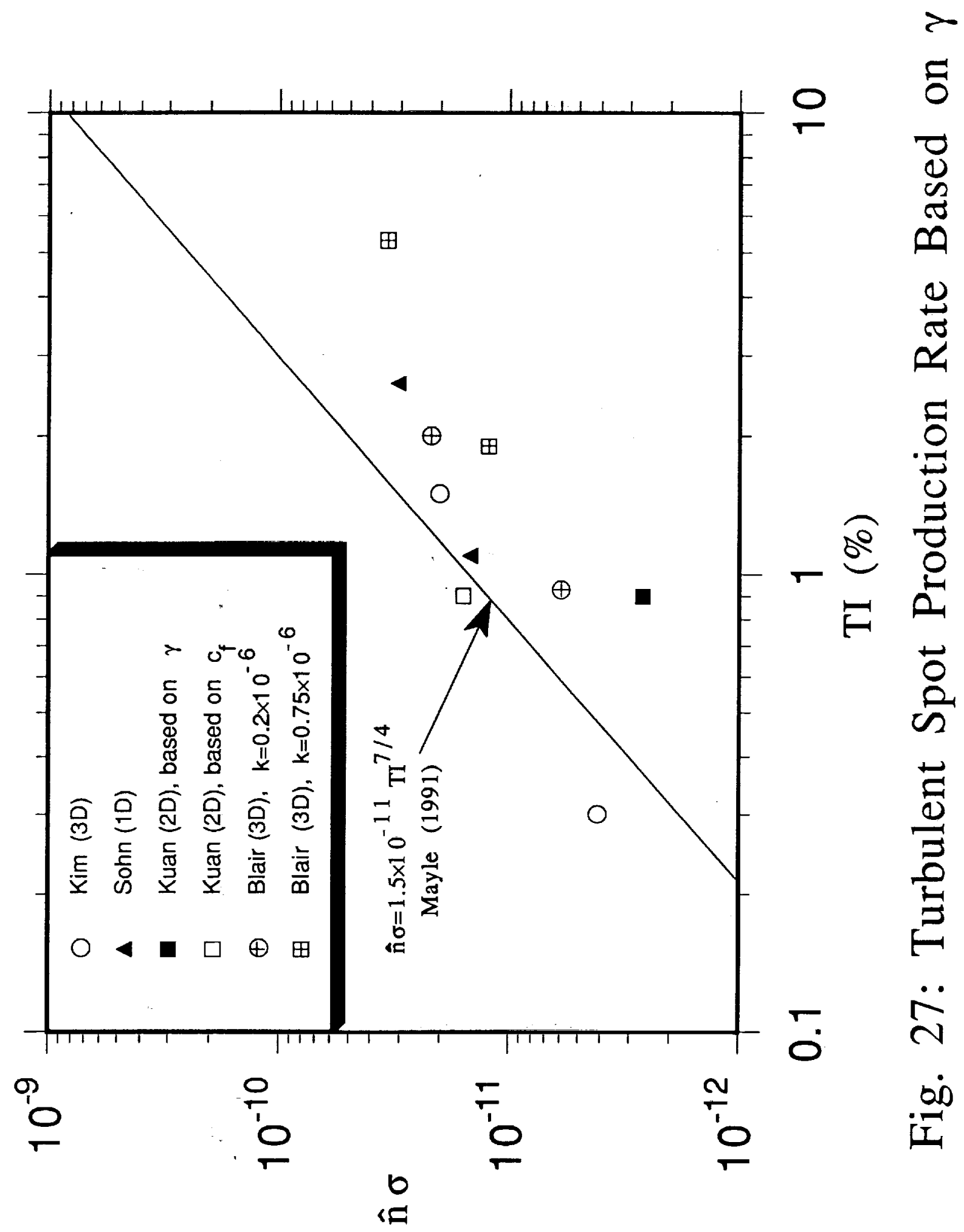


站

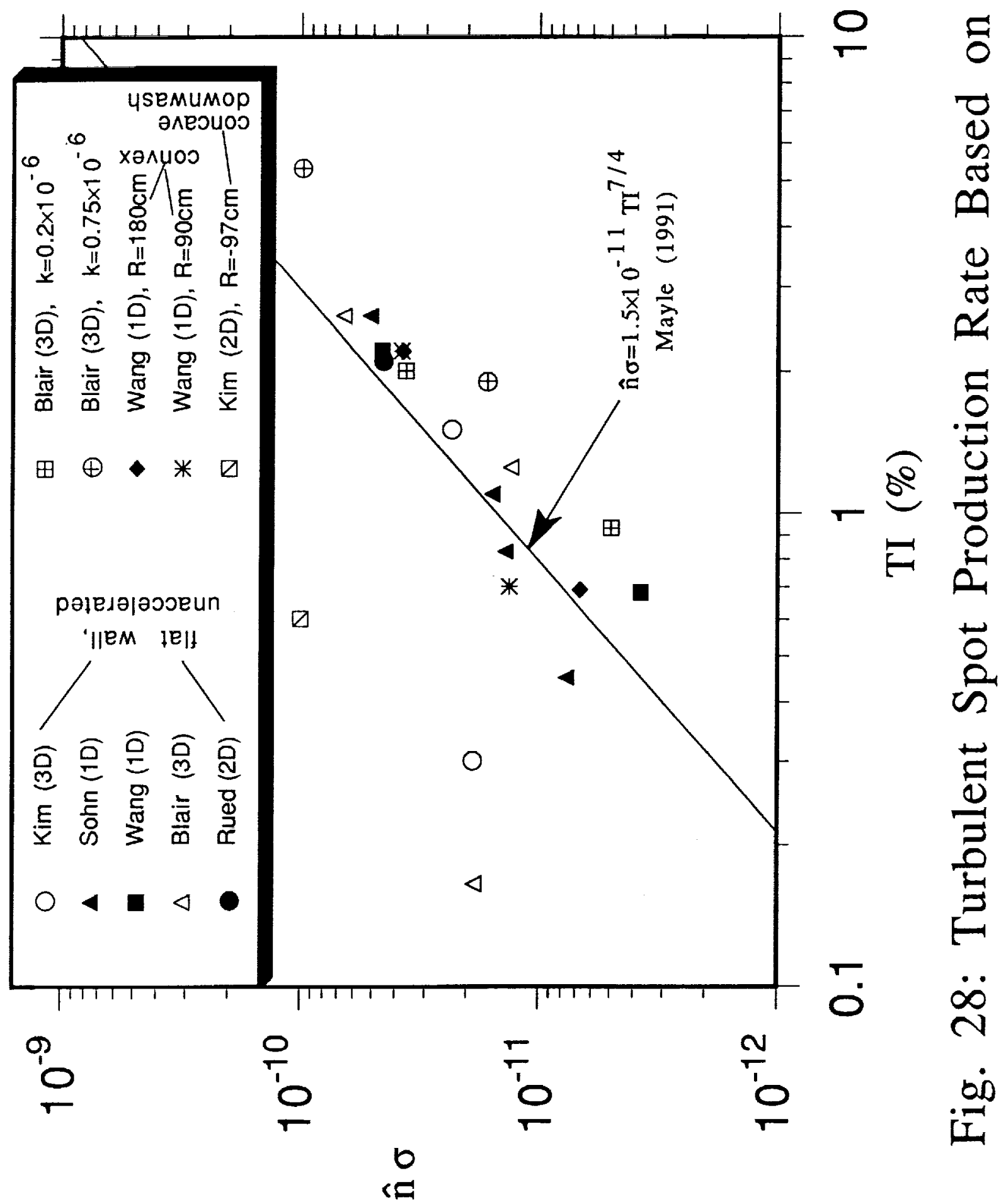

92

$C=2$ 


\section{APPENDIX: TABULATED DATA}

The following tables contain data used in this report. Most of the data were taken directly from tabulated sources. Data in columns headed by the word "units" were converted from British units to SI units. 'Data in columns headed "interp." were interpolated from the original data. Data in columns headed "graph" were read from graphs. Data in columns headed "calc." were computed in this study based on the data in other columns. Additional and more extensive information is available in the indicated references. 
Table A.1.a. Data from Kim (1990), TI=0.3\% (3D).

\begin{tabular}{|c|c|c|c|c|c|c|c|}
\hline$x(m)$ & $\begin{array}{l}\mathrm{U}_{\infty} \\
(\mathrm{m} / \mathrm{s})\end{array}$ & $\operatorname{Re}_{\theta}$ & $\begin{array}{l}\operatorname{Re}_{\mathrm{X}} \\
\times 10^{-6}\end{array}$ & $c_{f} \times 10^{3}$ & $\mathrm{St} \times 10^{3}$ & $\operatorname{Re}_{\Delta 2}$ & $\gamma(\%)$ \\
\hline & & & & & interp. & & \\
\hline 0.1140 & 28.150 & 265.70 & 0.1964 & 1.6520 & 1.4400 & 232.70 & \\
\hline 0.3430 & 28.280 & 473.60 & 0.5906 & 0.9570 & 0.7428 & 438.70 & \\
\hline 0.5720 & 28.170 & 664.80 & 0.9748 & 0.7800 & 0.6253 & 669.20 & 4.5 \\
\hline 0.8000 & 28.090 & 975.90 & 1.3530 & 1.9000 & 1.9440 & 2312.0 & 66.4 \\
\hline 1.0290 & 28.720 & 1487.0 & 1.7780 & 3.7700 & 2.2070 & 3225.0 & 97.8 \\
\hline 1.2570 & 32.640 & 2080.0 & 2.4820 & 3.7000 & & 4086.0 & 100.0 \\
\hline \multirow{2}{*}{\multicolumn{2}{|c|}{$x(m)$}} & \multicolumn{2}{|c|}{$\mathrm{u}_{\infty}^{\prime} / \mathrm{U}_{\infty} \times 100$} & \multicolumn{2}{|c|}{$\mathrm{v}_{\infty}^{\prime} / \mathrm{U}_{\infty} \times 100$} & \multicolumn{2}{|c|}{$\mathrm{TI}(\%)(3 \mathrm{D})^{*}$} \\
\hline & & \multicolumn{2}{|c|}{ graph } & \multicolumn{2}{|c|}{ graph } & \multicolumn{2}{|c|}{ calc. } \\
\hline \multicolumn{2}{|l|}{0.1140} & \multicolumn{2}{|l|}{0.45} & \multicolumn{2}{|l|}{0.18} & \multicolumn{2}{|l|}{0.30} \\
\hline \multicolumn{2}{|l|}{0.3430} & \multicolumn{2}{|l|}{0.50} & \multicolumn{2}{|l|}{0.21} & \multicolumn{2}{|l|}{0.34} \\
\hline \multicolumn{2}{|l|}{0.5720} & \multicolumn{2}{|l|}{0.47} & \multicolumn{2}{|l|}{0.18} & \multicolumn{2}{|l|}{0.31} \\
\hline \multicolumn{2}{|l|}{0.8000} & \multicolumn{2}{|l|}{0.50} & \multicolumn{2}{|l|}{0.19} & \multicolumn{2}{|l|}{0.33} \\
\hline \multicolumn{2}{|l|}{1.0290} & \multicolumn{2}{|l|}{0.48} & \multicolumn{2}{|l|}{0.22} & \multicolumn{2}{|l|}{0.33} \\
\hline \multicolumn{2}{|l|}{1.2570} & \multicolumn{2}{|l|}{0.48} & \multicolumn{2}{|l|}{0.17} & \multicolumn{2}{|l|}{0.31} \\
\hline
\end{tabular}

${ }^{*} \mathrm{w}^{\prime} \approx \mathrm{v}^{\prime}$ measured at $\mathrm{x}=0.343 \mathrm{~m}$ station and assumed at others.

\begin{tabular}{|l|l|l|l|}
\hline $\mathrm{Re}_{\mathrm{X}} \times 10^{-6}$ & $\Delta_{2} \times 10^{3}(\mathrm{~m})$ & $\operatorname{Re}_{\Delta 2}$ & $\mathrm{St} \times 10^{3}$ \\
\hline & & calc. & \\
\hline 0.28310 & 0.13910 & 237.57 & 1.1240 \\
\hline 0.49880 & 0.21230 & 362.58 & 0.81270 \\
\hline 0.71360 & 0.26920 & 459.76 & 0.67340 \\
\hline 0.88420 & 0.30480 & 520.56 & 0.57540 \\
\hline 1.0620 & 0.51490 & 879.39 & 0.80060 \\
\hline 1.1090 & 0.66550 & 1136.6 & 1.0220 \\
\hline 1.1560 & 0.86240 & 1472.9 & 1.3290 \\
\hline 1.2020 & 1.0460 & 1786.4 & 1.6570 \\
\hline 1.2470 & 1.1350 & 1938.4 & 1.8270 \\
\hline 1.4240 & 1.5240 & 2602.8 & 2.1440 \\
\hline 1.5990 & 1.6890 & 2884.6 & 2.0910 \\
\hline 1.7300 & 1.9140 & 3268.9 & 2.0810 \\
\hline 1.9050 & 2.0860 & 3562.6 & 2.0530 \\
\hline & & & \\
\hline
\end{tabular}


Table A.1.b. Data from Kim (1990), TI=1.5\% (3D).

\begin{tabular}{|l|l|l|l|l|l|l|c|}
\hline $\mathrm{x}(\mathrm{m})$ & $\begin{array}{l}\mathrm{U}_{\infty} \\
(\mathrm{m} / \mathrm{s})\end{array}$ & $\operatorname{Re}_{\theta}$ & $\begin{array}{l}\mathrm{Re}_{\mathrm{x}} \\
\times 10^{-6}\end{array}$ & $\mathrm{c}_{\mathrm{f} \times 10^{3}}$ & $\mathrm{St} \times 10^{3}$ & $\mathrm{Re}_{\Delta 2}$ & $\gamma(\%)$ \\
\hline & & & & & interp. & & \\
\hline 0.1140 & 16.650 & 218.10 & 0.1174 & 2.2630 & 1.7920 & 162.50 & \\
\hline 0.3430 & 16.290 & 379.00 & 0.3442 & 1.7000 & 1.0860 & 364.70 & 8.3 \\
\hline 0.5720 & 16.180 & 753.10 & 0.5691 & 4.0000 & 1.8440 & 1010.0 & 83.9 \\
\hline 0.8000 & 16.380 & 1196.0 & 0.8057 & 4.2000 & 2.1810 & 1726.0 & 99.6 \\
\hline 1.0290 & 16.810 & 1587.0 & 1.0620 & 4.0500 & 2.2010 & 2164.0 & 100.0 \\
\hline
\end{tabular}

\begin{tabular}{|l|l|l|l|l|}
\hline $\mathrm{x}(\mathrm{m})$ & $\mathrm{u}_{\infty}^{\prime} / \mathrm{U}_{\infty} \times 100$ & $\mathrm{v}_{\infty}^{\prime} / \mathrm{U}_{\infty} \times 100$ & $\mathrm{w}_{\infty}^{\prime} / \mathrm{U}_{\infty} \times 100$ & $\mathrm{TI}(\%)(3 \mathrm{D})$ \\
\hline & & & & calc. \\
\hline 0.1140 & 0.78000 & 1.8500 & 1.6600 & 1.5041 \\
\hline 0.3430 & 0.81000 & 1.7900 & 1.7100 & 1.5038 \\
\hline 0.5720 & 0.88000 & 1.7000 & 1.7100 & 1.4819 \\
\hline 0.8000 & 0.91000 & 1.6100 & 1.5400 & 1.3895 \\
\hline 1.0290 & 0.93000 & 1.6300 & 1.5300 & 1.3979 \\
\hline
\end{tabular}

\begin{tabular}{|l|l|l|l|}
\hline $\operatorname{Re}_{X} \times 10^{-6}$ & $\Delta_{2 \times 10^{3}}(\mathrm{~m})$ & $\operatorname{Re}_{\Delta 2}$ & $\mathrm{St} \times 10^{3}$ \\
\hline & & calc. & \\
\hline 0.16440 & 0.18210 & 182.43 & 1.4500 \\
\hline 0.26410 & 0.26320 & 263.68 & 1.0690 \\
\hline 0.39050 & 0.43160 & 432.38 & 1.1620 \\
\hline 0.49340 & 0.67480 & 676.02 & 1.4740 \\
\hline 0.57130 & 0.94420 & 945.91 & 1.8560 \\
\hline 0.67430 & 1.3090 & 1311.4 & 2.1590 \\
\hline 0.75050 & 1.4380 & 1440.6 & 2.1380 \\
\hline 0.85270 & 1.6760 & 1679.0 & 2.2370 \\
\hline 0.95390 & 1.8340 & 1837.3 & 2.1200 \\
\hline 1.0050 & 2.0080 & 2011.6 & 2.1360 \\
\hline 1.1060 & 2.1650 & 2168.9 & 2.0970 \\
\hline 1.2090 & 2.4320 & 2436.4 & 2.2040 \\
\hline
\end{tabular}


Table A.1.c. Data from Kim (1990), TI=8.3\% (3D).

\begin{tabular}{|l|l|l|l|l|l|l|}
\hline $\mathrm{x}(\mathrm{m})$ & $\begin{array}{l}\mathrm{U}_{\infty} \\
(\mathrm{m} / \mathrm{s})\end{array}$ & $\mathrm{Re}_{\theta}$ & $\begin{array}{l}\mathrm{Re}_{\mathrm{X}} \\
\times 10^{-6}\end{array}$ & $\mathrm{c}_{\mathrm{f}} \times 10^{3}$ & $\mathrm{St} \times 10^{3}$ & $\mathrm{Re}_{\Delta 2}$ \\
\hline & & & & & interp. & \\
\hline 0.1140 & 9.0700 & 171.40 & 0.0649 & 7.0000 & 3.6970 & 196.6 \\
\hline 0.3430 & 9.3100 & 481.60 & 0.1985 & 5.7500 & 3.0980 & 558.2 \\
\hline 0.5720 & 9.2400 & 820.80 & 0.3273 & 4.8500 & 2.7570 & 881.0 \\
\hline 0.8000 & 9.1900 & 1083.0 & 0.4549 & 4.7000 & 2.5280 & 1197. \\
\hline
\end{tabular}

\begin{tabular}{|l|l|l|l|l|}
\hline $\mathrm{x}(\mathrm{m})$ & $\mathrm{u}_{\infty}^{\prime} / \mathrm{U}_{\infty} \times 100$ & $\mathrm{v}_{\infty}^{\prime} / \mathrm{U}_{\infty} \times 100$ & $\mathrm{w}_{\infty}^{\prime} / \mathrm{U}_{\infty} \times 100$ & $\mathrm{TI}(\%)(3 \mathrm{D})$ \\
\hline & & & & calc. \\
\hline 0.1140 & 8.3000 & 7.6000 & 9.0000 & 8.3197 \\
\hline 0.3430 & 7.2000 & 6.6000 & 7.2000 & 7.0057 \\
\hline 0.5720 & 6.4000 & 5.6000 & 6.6000 & 6.2150 \\
\hline 0.8000 & 5.9000 & 4.6000 & 5.6000 & 5.3954 \\
\hline
\end{tabular}

\begin{tabular}{|l|l|l|l|}
\hline $\operatorname{Re}_{\mathrm{X}} \times 10^{-6}$ & $\Delta_{2} \times 10^{3}(\mathrm{~m})$ & $\operatorname{Re}_{\Delta 2}$ & $S \mathrm{t} \times 10^{3}$ \\
\hline & & calc. & \\
\hline 0.065010 & 0.33580 & 196.00 & 0.0036900 \\
\hline 0.19460 & 1.0020 & 584.00 & 0.0031330 \\
\hline 0.32380 & 1.5450 & 901.00 & 0.0027940 \\
\hline 0.45260 & 2.0440 & 1193.0 & 0.0025170 \\
\hline
\end{tabular}


Table A.1.d. Data from Kim (1990), $R=-97 \mathrm{~cm}$ (concave curvature), $\mathrm{TI}=0.6 \%$ (2D).

\begin{tabular}{|l|l|l|l|l|l|l|l|l|l|}
\hline $\mathrm{x}(\mathrm{m})$ & $\begin{array}{l}\mathrm{U}_{\mathrm{pw}} \\
(\mathrm{m} / \mathrm{s})\end{array}$ & $\begin{array}{l}\mathrm{Re}_{\theta} \\
\text { up - } \\
\text { wash }\end{array}$ & $\begin{array}{l}\mathrm{Re}_{\theta} \\
\text { down } \\
- \text { wash }\end{array}$ & $\begin{array}{l}\mathrm{Re}_{\mathrm{x}} \\
\times 10^{-6}\end{array}$ & $\begin{array}{l}\mathrm{c}_{\mathrm{f}} \\
\times 10^{3} \\
\text { up- } \\
\text { wash }\end{array}$ & $\begin{array}{l}\mathrm{c}_{\mathrm{f}} \\
\times 10^{3} \\
\text { down } \\
- \text { wash }\end{array}$ & $\begin{array}{l}\mathrm{St} \\
\times 10^{3} \\
\text { down } \\
- \text { wash }\end{array}$ & $\begin{array}{l}\mathrm{Re}_{\Delta 2} \\
\text { up - } \\
\text { wash }\end{array}$ & $\begin{array}{l}\mathrm{Re}_{\Delta 2} \\
\text { down } \\
- \text { was }\end{array}$ \\
\hline & & & & & & & interp & & \\
\hline 0.089 & 16.53 & 219.0 & 219.0 & 0.092 & 2.230 & 2.230 & 1.985 & & \\
\hline 0.356 & 17.24 & 561.0 & 173.0 & 0.376 & 2.100 & 4.600 & 1.471 & & \\
\hline 0.610 & 17.10 & 1181 & 1044 & 0.639 & 4.150 & 4.800 & 1.979 & 1512 & 1081 \\
\hline 0.876 & 17.14 & 1917 & 1231 & 0.924 & 4.200 & 5.200 & 2.011 & 2455 & 2109 \\
\hline 1.130 & 16.76 & 2801 & 1954 & 1.164 & 3.700 & 4.700 & 1.886 & 3305 & 2860 \\
\hline
\end{tabular}

\begin{tabular}{|l|l|l|l|l|}
\hline $\mathrm{x}(\mathrm{m})$ & $\mathrm{U}_{\mathrm{pw}}(\mathrm{m} / \mathrm{s})$ & $\mathrm{U}_{\infty}^{\prime} / \mathrm{U}_{\mathrm{pw}} \times 100$ & $\mathrm{v}_{\infty} / \mathrm{U}_{\mathrm{pw}} \times 100$ & $\mathrm{TI}(\%)(2 \mathrm{D})$ \\
\hline & & $\mathrm{calc}$. & calc. & calc. \\
\hline 0.356 & 17.24 & 0.62 & -- & 0.62 \\
\hline 0.610 & 17.10 & 0.65 & 0.27 & 0.44 \\
\hline 0.876 & 17.14 & 0.71 & 0.50 & 0.58 \\
\hline 1.130 & 16.76 & 0.73 & 0.50 & 0.59 \\
\hline
\end{tabular}

Downwash, $\mathrm{U}_{\mathrm{pw}}=17.2 \mathrm{~m} / \mathrm{s}, \mathrm{TI}=0.6$

\begin{tabular}{|l|l|l|l|}
\hline $\begin{array}{l}\mathrm{Re}_{\mathrm{X}} \\
\times 10^{-6}\end{array}$ & $\begin{array}{l}\Delta_{2} \times 10^{3} \\
(\mathrm{~m})\end{array}$ & $\mathrm{Re}_{\Delta 2}$ & $\mathrm{St} \times 10^{3}$ \\
\hline & & calc. & \\
\hline 0.0400 & 0.0030 & 3.1723 & 3.7520 \\
\hline 0.1455 & 0.1682 & 180.82 & 1.4880 \\
\hline 0.2242 & 0.2388 & 256.71 & 1.2040 \\
\hline 0.2765 & 0.2872 & 308.74 & 1.0630 \\
\hline 0.3300 & 0.3990 & 428.92 & 1.2790 \\
\hline 0.4646 & 0.8546 & 918.70 & 2.1130 \\
\hline 0.5973 & 1.0810 & 1162.1 & 2.0097 \\
\hline 0.7035 & 1.3320 & 1431.9 & 2.1180 \\
\hline 0.8357 & 1.5380 & 1653.4 & 1.9890 \\
\hline 0.9154 & 1.6830 & 1809.2 & 1.9930 \\
\hline 1.0210 & 1.8040 & 1939.3 & 1.8910 \\
\hline 1.1280 & 2.0100 & 2160.7 & 1.9860 \\
\hline 1.2340 & 2.2950 & 2467.1 & 2.0560 \\
\hline
\end{tabular}

Upwash, $\mathrm{U}_{\mathrm{pw}}=6.74 \mathrm{~m} / \mathrm{s}, 0.3<\mathrm{TI}<1.5$ est.

\begin{tabular}{|l|l|l|l|}
\hline $\begin{array}{l}\operatorname{Re}_{\mathrm{X}} \\
\times 10^{-6}\end{array}$ & $\begin{array}{l}\Delta_{2} \times 10^{3} \\
(\mathrm{~m})\end{array}$ & $\mathrm{Re}_{\Delta 2}$ & $S \mathrm{St} \times 10^{3}$ \\
\hline & & calc. & \\
\hline 0.0167 & 0.0054 & 2.2899 & 6.7870 \\
\hline 0.0269 & 0.1321 & 56.435 & 4.9080 \\
\hline 0.0376 & 0.1983 & 84.717 & 3.5260 \\
\hline 0.0419 & 0.2500 & 106.80 & 2.6860 \\
\hline 0.1012 & 0.4118 & 175.93 & 1.7600 \\
\hline 0.1329 & 0.5020 & 214.46 & 1.5210 \\
\hline 0.2169 & 0.6560 & 280.25 & 1.0930 \\
\hline 0.2384 & 0.7744 & 330.84 & 1.2180 \\
\hline 0.2604 & 0.9929 & 424.18 & 1.5120 \\
\hline 0.2938 & 1.4550 & 621.60 & 2.2860 \\
\hline 0.3583 & 1.9220 & 821.11 & 2.5550 \\
\hline 0.4753 & 2.4220 & 1034.7 & 2.2650 \\
\hline 0.5394 & 2.8080 & 1199.6 & 2.2780 \\
\hline
\end{tabular}


Table A.1.e. Data from Kim (1990), $R=-97 \mathrm{~cm}$ (concave curvature), $\mathrm{TI}=8.3 \%(2 \mathrm{D})$.

\begin{tabular}{|l|l|l|l|l|l|}
\hline $\mathrm{x}(\mathrm{m})$ & $\mathrm{U}_{\mathrm{pw}}(\mathrm{m} / \mathrm{s})$ & $\mathrm{Re}_{\mathrm{x}} \times 10^{-6}$ & $\mathrm{c}_{\mathrm{f}} \times 10^{3}$ & $\mathrm{St} \times 10^{3}$ & $\mathrm{Re}_{\Delta 2}$ \\
\hline & & & & interp. & \\
\hline 0.0890 & 17.700 & 0.0965 & 6.0 & 4.2 & 370.70 \\
\hline 0.3560 & 17.700 & 0.3861 & 5.9 & 3.1 & 1006.0 \\
\hline 0.6100 & 17.700 & 0.6635 & 5.3 & 2.7 & 1649.0 \\
\hline 0.8760 & 17.700 & 0.9543 & 5.3 & 2.8 & 2748.0 \\
\hline 1.1300 & 17.700 & 1.2340 & 5.0 & 2.6 & 2979.0 \\
\hline
\end{tabular}

\begin{tabular}{|l|l|l|l|}
\hline $\mathrm{x}(\mathrm{m})$ & $\mathrm{u}_{\infty}^{\prime} / \mathrm{U}_{\infty} \times 100$ & $\mathrm{v}_{\infty}^{\prime} / \mathrm{U}_{\infty} \times 100$ & $\mathrm{TI}(\%)(2 \mathrm{D})$ \\
\hline & calc. & calc. & calc. \\
\hline 0.0890 & 8.3 & 8.00 & 8.1 \\
\hline 0.3560 & 7.2 & 7.6 & 7.5 \\
\hline 0.6100 & 6.4 & 7.2 & 6.9 \\
\hline 0.8760 & 5.7 & 6.9 & 6.5 \\
\hline 1.1300 & 5.1 & 6.1 & 5.8 \\
\hline
\end{tabular}

\begin{tabular}{|l|l|l|l|}
\hline $\operatorname{Re}_{X} \times 10^{-6}$ & $\Delta_{2} \times 10^{3}(\mathrm{~m})$ & $\operatorname{Re}_{\Delta 2}$ & $S \mathrm{t} \times 10^{3}$ \\
\hline & & calc. & \\
\hline 0.043080 & 0.0038210 & 4.4324 & 5.2720 \\
\hline 0.15770 & 0.39890 & 462.72 & 4.2400 \\
\hline 0.27200 & 0.68320 & 792.51 & 3.4590 \\
\hline 0.38620 & 0.96560 & 1120.1 & 3.1190 \\
\hline 0.50040 & 1.2500 & 1450.0 & 2.9210 \\
\hline 0.64310 & 1.4980 & 1737.7 & 2.7940 \\
\hline 0.78600 & 1.8990 & 2202.8 & 2.8210 \\
\hline 0.89970 & 2.1050 & 2441.8 & 2.6060 \\
\hline 1.0430 & 2.3790 & 2759.6 & 2.6630 \\
\hline 1.1280 & 2.5980 & 3013.7 & 2.5840 \\
\hline 1.2140 & 2.7580 & 3199.3 & 2.6960 \\
\hline 1.3570 & 3.1780 & 3686.5 & 2.7400 \\
\hline
\end{tabular}


Table A.2.a. Data from Wang (1984), flat wall, $\mathrm{TI}=0.3 \%$ (1D).

\begin{tabular}{|l|l|l|l|l|l|l|l|}
\hline $\mathrm{x}(\mathrm{m})$ & $\begin{array}{l}\mathrm{U}_{\infty} \\
(\mathrm{m} / \mathrm{s})\end{array}$ & $\begin{array}{l}\theta \times 10^{3} \\
(\mathrm{~m})\end{array}$ & $\mathrm{Re}_{\theta}$ & $\begin{array}{l}\mathrm{Re}_{\mathrm{x}} \\
\times 10^{-6}\end{array}$ & $\mathrm{c}_{\mathrm{f}} \times 10^{3}$ & $\mathrm{St} \times 10^{3}$ & $\begin{array}{l}\Delta 2 \times 10^{3} \\
(\mathrm{~m})\end{array}$ \\
\hline & & & calc. & calc. & & interp. & \\
\hline 0.3429 & 15.654 & 0.3910 & 394.00 & 0.3460 & 1.1200 & 0.9100 & 0.311 \\
\hline 0.6477 & 15.849 & 0.5660 & 579.00 & 0.6610 & 0.7800 & 0.6120 & 0.518 \\
\hline 0.9525 & 16.256 & 0.6720 & 704.00 & 0.9980 & 0.6600 & 0.5400 & 0.629 \\
\hline 1.2573 & 16.519 & 0.7800 & 830.00 & 1.3380 & 0.5700 & 0.5300 & 0.804 \\
\hline
\end{tabular}

\begin{tabular}{|l|l|l|l|}
\hline $\mathrm{x}(\mathrm{m})$ & $\Delta_{2} \times 10^{3}(\mathrm{~m})$ & $\mathrm{Re}_{\Delta 2}$ & $\mathrm{St} \times 10^{3}$ \\
\hline & & & \\
\hline 0.050800 & 0.046000 & 43.900 & 3.6200 \\
\hline 0.27940 & 0.26200 & 261.00 & 1.0480 \\
\hline 0.53340 & 0.35800 & 364.00 & 0.68400 \\
\hline 0.78740 & 0.43600 & 451.00 & 0.54300 \\
\hline 1.0414 & 0.56600 & 596.00 & 0.53500 \\
\hline
\end{tabular}


Table A.2.b. Data from Wang (1984), flat wall, $\mathrm{TI}=0.68 \%$ (1D).

\begin{tabular}{|l|l|l|l|l|l|l|l|l|}
\hline $\mathrm{x}(\mathrm{m})$ & $\begin{array}{l}\mathrm{U}_{\infty} \\
(\mathrm{m} / \mathrm{s})\end{array}$ & $\begin{array}{l}\theta \times 10^{3} \\
(\mathrm{~m})\end{array}$ & $\mathrm{Re}_{\theta}$ & $\begin{array}{l}\operatorname{Re}_{\mathrm{x}} \\
\times 10^{-6}\end{array}$ & $\begin{array}{l}\mathrm{c}_{\mathrm{f}} \\
\times 10^{3}\end{array}$ & $\mathrm{St} \times 10^{3}$ & $\begin{array}{l}\Delta_{2} \\
\times 10^{3} \\
(\mathrm{~m})\end{array}$ & $\begin{array}{l}\mathrm{TI}(\%) \\
(1 \mathrm{D})\end{array}$ \\
\hline & & & calc. & calc. & & interp. & & \\
\hline 0.3429 & 34.449 & 0.287 & 628.0 & 0.7511 & 0.765 & 0.5925 & 0.220 & 0.671 \\
\hline 0.6477 & 34.156 & 0.414 & 900.7 & 1.4070 & 0.640 & 0.5580 & 0.455 & 0.678 \\
\hline 0.9525 & 35.199 & 0.930 & 2082. & 2.1327 & 3.600 & 1.2885 & 1.236 & 0.681 \\
\hline 1.2573 & 35.874 & 1.434 & 3272. & 2.8680 & 3.226 & 1.2373 & 1.827 & 0.700 \\
\hline
\end{tabular}

\begin{tabular}{|l|l|l|l|}
\hline $\mathrm{x}(\mathrm{m})$ & $\Delta_{2} \times 10^{3}(\mathrm{~m})$ & $\operatorname{Re}_{\Delta 2}$ & $\mathrm{St} \times 10^{3}$ \\
\hline & & & \\
\hline 0.050800 & 0.026000 & 53.100 & 2.1230 \\
\hline 0.12700 & 0.10000 & 207.00 & 1.1270 \\
\hline 0.25400 & 0.16400 & 352.00 & 0.75300 \\
\hline 0.35560 & 0.18800 & 413.00 & 0.58100 \\
\hline 0.43180 & 0.20400 & 447.00 & 0.50400 \\
\hline 0.58420 & 0.28100 & 612.00 & 0.50600 \\
\hline 0.68580 & 0.36300 & 793.00 & 0.55900 \\
\hline 0.76200 & 0.57600 & 1270.0 & 0.82200 \\
\hline 0.81280 & 0.83100 & 1830.0 & 1.1310 \\
\hline 0.86360 & 0.97500 & 2160.0 & 1.2520 \\
\hline 0.91440 & 1.0400 & 2320.0 & 1.2570 \\
\hline 1.0414 & 1.2660 & 2850.0 & 1.3350 \\
\hline 1.1176 & 1.3490 & 3060.0 & 1.3180 \\
\hline
\end{tabular}


Table A.2.c. Data from Wang (1984), flat wall, TI=2.2\% (1D).

\begin{tabular}{|c|c|c|c|c|c|c|c|c|}
\hline $\mathrm{x}(\mathrm{m})$ & $\begin{array}{l}\mathrm{U}_{\infty} \\
(\mathrm{m} / \mathrm{s})\end{array}$ & $\begin{array}{l}\theta \times 10^{3} \\
(\mathrm{~m})\end{array}$ & $\operatorname{Re}_{\theta}$ & $\begin{array}{l}\mathrm{Re}_{\mathrm{X}} \\
\times 10^{-6}\end{array}$ & $\begin{array}{l}c_{f} \\
\times 10^{3}\end{array}$ & $\begin{array}{l}\mathrm{St} \\
\times 10^{3}\end{array}$ & $\begin{array}{l}\Delta_{2} \\
\times 10^{3} \\
(\mathrm{~m})\end{array}$ & $\begin{array}{l}\text { TI (\%) } \\
\text { (1D) }\end{array}$ \\
\hline & & & calc. & calc. & & interp & & \\
\hline 0.1270 & 13.044 & 0.246 & 205.1 & 0.1059 & 2.2 & 2.167 & & 2.216 \\
\hline 0.3440 & 13.476 & 0.561 & 483.2 & 0.2963 & 3.2 & 1.771 & \begin{tabular}{|l|}
0.544 \\
\end{tabular} & 2.282 \\
\hline 0.6477 & 13.749 & 1.216 & 1069. & 0.5694 & 4.4 & 2.108 & 1.340 & 2.157 \\
\hline 0.9525 & 13.905 & 1.743 & 1550. & 0.8468 & 4.05 & 1.917 & 1.852 & 2.091 \\
\hline 1.2573 & 14.672 & 2.044 & 1917. & 1.1794 & 4.0 & 1.828 & 2.150 & 1.881 \\
\hline
\end{tabular}

\begin{tabular}{|l|l|l|l|}
\hline $\mathrm{x}(\mathrm{m})$ & $\Delta_{2} \times 10^{3}(\mathrm{~m})$ & $\mathrm{Re}_{\Delta 2}$ & $\mathrm{St} \times 10^{3}$ \\
\hline & & & \\
\hline 0.050800 & 0.054000 & 45.100 & 4.3310 \\
\hline 0.15240 & 0.22100 & 187.00 & 1.9050 \\
\hline 0.27940 & 0.38800 & 334.00 & 1.5890 \\
\hline 0.35560 & 0.57600 & 499.00 & 1.8170 \\
\hline 0.45720 & 0.81600 & 711.00 & 1.9620 \\
\hline 0.55880 & 1.0870 & 953.00 & 2.1130 \\
\hline 0.66040 & 1.3130 & 1160.0 & 2.1360 \\
\hline 0.76200 & 1.4250 & 1260.0 & 1.9830 \\
\hline 0.86360 & 1.6300 & 1450.0 & 1.9900 \\
\hline 0.99060 & 1.7890 & 1610.0 & 1.8880 \\
\hline 1.1176 & 2.0140 & 1850.0 & 1.8770 \\
\hline
\end{tabular}


Table A.2.d. Data from Wang (1984), $\mathrm{R}=90 \mathrm{~cm}$ (convex curvature), $\mathrm{TI}=0.70 \%$ (1D).

\begin{tabular}{|l|l|l|l|l|l|l|l|l|}
\hline $\mathrm{x}(\mathrm{m})$ & $\begin{array}{l}\mathrm{U}_{\mathrm{pw}} \\
(\mathrm{m} / \mathrm{s})\end{array}$ & $\begin{array}{l}\theta \times 10^{3} \\
(\mathrm{~m})\end{array}$ & $\mathrm{Re}_{\theta}$ & $\begin{array}{l}\mathrm{Re}_{\mathrm{X}} \\
\times 10^{-6}\end{array}$ & $\begin{array}{l}\mathrm{c}_{\mathrm{f}} \\
\times 10^{3}\end{array}$ & $\begin{array}{l}\mathrm{St} \\
\times 10^{3}\end{array}$ & $\begin{array}{l}\Delta_{2} \\
\times 10^{3} \\
(\mathrm{~m})\end{array}$ & $\begin{array}{l}\mathrm{TI}(\%) \\
(1 \mathrm{D})\end{array}$ \\
\hline & calc. & & calc. & calc. & & interp & & \\
\hline 0.1270 & 33.3 & 0.122 & 255.72 & 0.2662 & 1.290 & 1.207 & & 0.689 \\
\hline 0.3175 & 33.3 & 0.264 & 553.35 & 0.6655 & 0.740 & 0.662 & 0.212 & 0.695 \\
\hline 0.5842 & 33.4 & 0.354 & 742.00 & 1.2245 & 0.575 & 0.493 & 0.272 & 0.735 \\
\hline 0.8509 & 33.4 & 0.442 & 926.45 & 1.7835 & 0.460 & 0.431 & 0.334 & 0.728 \\
\hline 1.1176 & 33.4 & 0.843 & 1767.0 & 2.3425 & 3.680 & 1.163 & 1.684 & 0.666 \\
\hline
\end{tabular}

\begin{tabular}{|l|l|l|l|}
\hline $\mathrm{x}(\mathrm{m})$ & $\Delta_{2 \times 10^{3}}(\mathrm{~m})$ & $\mathrm{Re}_{\Delta 2}$ & $\mathrm{St} \times 10^{3}$ \\
\hline & & & \\
\hline 0.050800 & 0.023000 & 48.100 & 1.9150 \\
\hline 0.15240 & 0.11600 & 243.00 & 1.0330 \\
\hline 0.27940 & 0.16800 & 351.00 & 0.69100 \\
\hline 0.35560 & 0.19300 & 404.00 & 0.60000 \\
\hline 0.45720 & 0.22100 & 462.00 & 0.51600 \\
\hline 0.55880 & 0.26300 & 552.00 & 0.49700 \\
\hline 0.66040 & 0.28600 & 600.00 & 0.44900 \\
\hline 0.76200 & 0.30900 & 648.00 & 0.41500 \\
\hline 0.86360 & 0.37100 & 778.00 & 0.44300 \\
\hline 0.99060 & 0.78000 & 1630.0 & 0.86900 \\
\hline 1.1176 & 1.1580 & 2430.0 & 1.1630 \\
\hline
\end{tabular}


Table A.2.e. Data from Wang (1984), $\mathrm{R}=90 \mathrm{~cm}$ (convex curvature), $\mathrm{TI}=2.2 \%$ (1D).

\begin{tabular}{|l|l|l|l|l|l|l|l|l|}
\hline $\mathrm{x}(\mathrm{m})$ & $\begin{array}{l}\mathrm{U}_{\mathrm{pw}} \\
(\mathrm{m} / \mathrm{s})\end{array}$ & $\begin{array}{l}\theta \times 10^{3} \\
(\mathrm{~m})\end{array}$ & $\mathrm{Re}_{\theta}$ & $\begin{array}{l}\mathrm{Re}_{\mathrm{x}} \\
\times 10^{-6}\end{array}$ & $\begin{array}{l}\mathrm{c}_{\mathrm{f}} \\
\times 10^{3}\end{array}$ & $\begin{array}{l}\mathrm{St} \\
\times 10^{3}\end{array}$ & $\begin{array}{l}\Delta_{2} \\
\times 10^{3} \\
(\mathrm{~m})\end{array}$ & $\begin{array}{l}\mathrm{TI}(\%) \\
(1 \mathrm{D})\end{array}$ \\
\hline & calc. & & calc. & calc. & & interp & & \\
\hline 0.1270 & 14.5 & 0.216 & 197.86 & 0.1163 & 2.40 & 2.191 & & 2.117 \\
\hline 0.3175 & 14.5 & 0.447 & 409.47 & 0.2908 & 2.20 & 1.410 & 0.483 & 2.238 \\
\hline 0.5842 & 14.6 & 0.925 & 847.33 & 0.5351 & 4.00 & 1.877 & 1.187 & 2.038 \\
\hline 0.8509 & 14.5 & 1.582 & 1449.2 & 0.7795 & 3.75 & 1.853 & 1.643 & 2.176 \\
\hline 1.1176 & 14.7 & 2.060 & 1887.0 & 1.0238 & 3.50 & 1.675 & 2.439 & 2.639 \\
\hline
\end{tabular}

\begin{tabular}{|l|l|l|l|}
\hline $\mathrm{x}(\mathrm{m})$ & $\Delta_{2} \times 10^{3}(\mathrm{~m})$ & $\operatorname{Re}_{\Delta 2}$ & $\mathrm{St} \times 10^{3}$ \\
\hline & & & \\
\hline 0.050800 & 0.046000 & 42.500 & 3.6890 \\
\hline 0.15240 & 0.21200 & 194.00 & 1.8230 \\
\hline 0.27940 & 0.33300 & 304.00 & 1.3450 \\
\hline 0.35560 & 0.45900 & 420.00 & 1.4270 \\
\hline 0.45720 & 0.68100 & 623.00 & 1.6260 \\
\hline 0.55880 & 0.93700 & 858.00 & 1.8160 \\
\hline 0.66040 & 1.1810 & 1080.0 & 1.9220 \\
\hline 0.76200 & 1.3130 & 1200.0 & 1.8290 \\
\hline 0.86360 & 1.5020 & 1380.0 & 1.8350 \\
\hline 0.99060 & 1.6350 & 1500.0 & 1.7220 \\
\hline 1.1176 & 1.8060 & 1650.0 & 1.6750 \\
\hline
\end{tabular}


Table A.2.f. Data from Wang (1984), $R=180 \mathrm{~cm}$ (convex curvature), $\mathrm{TI}=0.69 \%$ (1D).

\begin{tabular}{|l|l|l|l|l|l|l|l|l|}
\hline $\mathrm{x}(\mathrm{m})$ & $\begin{array}{l}\mathrm{U}_{\mathrm{pw}} \\
(\mathrm{m} / \mathrm{s})\end{array}$ & $\begin{array}{l}\theta \times 10^{3} \\
(\mathrm{~m})\end{array}$ & $\mathrm{Re}_{\theta}$ & $\begin{array}{l}\mathrm{Re}_{\mathrm{x}} \\
\times 10^{-6}\end{array}$ & $\begin{array}{l}\mathrm{c}_{\mathrm{f}} \\
\times 10^{3}\end{array}$ & $\begin{array}{l}\mathrm{St} \\
\times 10^{3}\end{array}$ & $\begin{array}{l}\Delta_{2} \\
\times 10^{3} \\
(\mathrm{~m})\end{array}$ & $\begin{array}{l}\mathrm{TI}(\%) \\
(1 \mathrm{D})\end{array}$ \\
\hline & calc. & & calc. & calc. & & interp & & \\
\hline 0.330 & 35.10 & 0.299 & 653.5 & 0.722 & 0.680 & 0.602 & 0.191 & 0.694 \\
\hline 0.622 & 35.20 & 0.374 & 817.4 & 1.360 & 0.500 & 0.484 & 0.272 & 0.686 \\
\hline 0.902 & 35.10 & 0.501 & 1095. & 1.971 & 0.450 & 0.380 & 0.388 & 0.705 \\
\hline 1.181 & 35.10 & 0.871 & 1904. & 2.581 & 3.600 & 1.099 & 1.542 & 0.756 \\
\hline
\end{tabular}

\begin{tabular}{|l|l|l|l|}
\hline $\mathrm{X}(\mathrm{m})$ & $\Delta_{2 \times 10^{3}}(\mathrm{~m})$ & $\operatorname{Re}_{\Delta 2}$ & $\mathrm{St} \times 10^{3}$ \\
\hline & & & \\
\hline 0.050800 & 0.022000 & 49.000 & 1.8140 \\
\hline 0.15240 & 0.10600 & 232.00 & 0.93000 \\
\hline 0.27940 & 0.15900 & 347.00 & 0.64800 \\
\hline 0.35560 & 0.18900 & 413.00 & 0.58400 \\
\hline 0.45720 & 0.21900 & 479.00 & 0.50900 \\
\hline 0.55880 & 0.28400 & 622.00 & 0.53900 \\
\hline 0.66040 & 0.29400 & 642.00 & 0.45900 \\
\hline 0.76200 & 0.30100 & 658.00 & 0.39900 \\
\hline 0.86360 & 0.33200 & 726.00 & 0.38700 \\
\hline 0.99060 & 0.41300 & 902.00 & 0.42400 \\
\hline 1.1176 & 0.95600 & 2090.0 & 0.93900 \\
\hline
\end{tabular}


Table A.2.g. Data from Wang (1984), $R=180 \mathrm{~cm}$ (convex curvature), $\mathrm{TI}=2.2 \%(1 \mathrm{D})$

\begin{tabular}{|l|l|l|l|l|l|l|l|l|}
\hline $\mathrm{x}(\mathrm{m})$ & $\begin{array}{l}\mathrm{U}_{\mathrm{pw}} \\
(\mathrm{m} / \mathrm{s})\end{array}$ & $\begin{array}{l}\theta \times 10^{3} \\
(\mathrm{~m})\end{array}$ & $\mathrm{Re}_{\theta}$ & $\begin{array}{l}\mathrm{Re}_{\mathrm{x}} \\
\times 10^{-6}\end{array}$ & $\begin{array}{l}\mathrm{c}_{\mathrm{f}} \\
\times 10^{3}\end{array}$ & $\begin{array}{l}\mathrm{St} \\
\times 10^{3}\end{array}$ & $\begin{array}{l}\Delta_{2} \\
\times 10^{3} \\
(\mathrm{~m})\end{array}$ & $\begin{array}{l}\mathrm{TI}(\%) \\
(1 \mathrm{D})\end{array}$ \\
\hline & calc. & & calc. & calc. & & interp & & \\
\hline 0.1270 & 14.7 & 0.219 & 216.74 & 0.1257 & 2.40 & 1.744 & & 2.246 \\
\hline 0.3302 & 14.6 & 0.488 & 482.97 & 0.3268 & 3.00 & 1.517 & 0.652 & 2.100 \\
\hline 0.6223 & 14.7 & 1.106 & 1094.6 & 0.6159 & 4.40 & 1.870 & 1.230 & 2.128 \\
\hline 0.9017 & 14.6 & 1.705 & 1687.4 & 0.8924 & 3.85 & 1.700 & 1.608 & 1.885 \\
\hline 1.1938 & 14.6 & 2.462 & 2436.6 & 1.1815 & 3.35 & 1.641 & 2.177 & 2.007 \\
\hline
\end{tabular}

\begin{tabular}{|l|l|l|l|}
\hline $\mathrm{x}(\mathrm{m})$ & $\Delta_{2 \times 10^{3}}(\mathrm{~m})$ & $\operatorname{Re}_{\Delta 2}$ & $\mathrm{St} \times 10^{3}$ \\
\hline & & & \\
\hline 0.050800 & 0.045 & 44.4 & 3.577 \\
\hline 0.15240 & 0.183 & 181. & 1.577 \\
\hline 0.27940 & 0.338 & 335. & 1.387 \\
\hline 0.35560 & 0.506 & 501. & 1.599 \\
\hline 0.45720 & 0.723 & 716. & 1.743 \\
\hline 0.55880 & 0.978 & 968. & 1.906 \\
\hline 0.66040 & 1.180 & 1170. & 1.923 \\
\hline 0.76200 & 1.290 & 1280. & 1.799 \\
\hline 0.86360 & 1.466 & 1450. & 1.792 \\
\hline 0.99060 & 1.620 & 1600. & 1.710 \\
\hline 1.1176 & 1.797 & 1780. & 1.671 \\
\hline
\end{tabular}


Table A.3.a. Data from Suder, O'Brien and Reshotko (1988), TI=0.3\% (1D).

\begin{tabular}{|l|l|l|l|l|l|}
\hline $\mathrm{x}(\mathrm{m})$ & $\mathrm{U}_{\infty}(\mathrm{m} / \mathrm{s})$ & $\theta \times 10^{3}(\mathrm{~m})$ & $\operatorname{Re}_{\theta}$ & $\mathrm{Re}_{\mathrm{X}} \times 10^{-6}$ & $\mathrm{c}_{\mathrm{f}} \times 10^{3}$ \\
\hline units & units & units & & calc. & \\
\hline 0.73660 & 29.718 & 0.37694 & 716 & 1.3992 & 0.571 \\
\hline 0.76962 & 29.627 & 0.37160 & 706 & 1.4622 & 0.551 \\
\hline 0.82042 & 29.444 & 0.39192 & 740 & 1.5491 & 0.525 \\
\hline 0.87122 & 28.682 & 0.39522 & 726 & 1.6004 & 0.518 \\
\hline 0.92202 & 29.230 & 0.41351 & 772 & 1.7214 & 0.524 \\
\hline 0.97282 & 28.621 & 0.41529 & 752 & 1.7616 & 0.512 \\
\hline 1.0236 & 28.407 & 0.45796 & 835 & 1.8664 & 0.609 \\
\hline 1.0744 & 28.285 & 0.50089 & 908 & 1.9477 & 0.965 \\
\hline 1.1252 & 28.316 & 0.55347 & 1005 & 2.0432 & 1.487 \\
\hline 1.1608 & 28.346 & 0.60376 & 1101 & 2.1168 & 1.971 \\
\hline
\end{tabular}

\begin{tabular}{|l|l|}
\hline $\mathrm{X}(\mathrm{m})$ & $\mathrm{TI}(\%)(1 \mathrm{D})$ \\
\hline $\mathrm{graph}$ & $\mathrm{graph}$ \\
\hline-0.18796 & 0.3 \\
\hline 0.16002 & 0.3 \\
\hline 0.51562 & 0.3 \\
\hline 0.82804 & 0.3 \\
\hline 1.1582 & 0.3 \\
\hline 1.4199 & 0.3 \\
\hline
\end{tabular}

\begin{tabular}{|l|l|}
\hline $\operatorname{Re}_{X} \times 10^{-6}$ & $\gamma(\%)$ \\
\hline graph & graph \\
\hline 1.7700 & 0.0000 \\
\hline 1.8800 & 23.400 \\
\hline 2.0800 & 80.200 \\
\hline 2.2900 & 95.800 \\
\hline 2.5000 & 100.00 \\
\hline
\end{tabular}


Table A.3.b. Data from Suder, O'Brien and Reshotko (1988), TI=0.65\% (1D).

\begin{tabular}{|l|l|l|l|l|l|}
\hline $\mathrm{x}(\mathrm{m})$ & $\mathrm{U}_{\infty}(\mathrm{m} / \mathrm{s})$ & $\theta \times 10^{3}(\mathrm{~m})$ & $\operatorname{Re}_{\theta}$ & $\mathrm{Re}_{\mathrm{x}} \times 10^{-6}$ & $\mathrm{c}_{\mathrm{f}} \times 10^{3}$ \\
\hline units & units & units & & calc. & \\
\hline 0.12700 & 30.724 & 0.15641 & 310.00 & 0.25171 & 1.2330 \\
\hline 0.16002 & 30.663 & 0.17643 & 350.00 & 0.31745 & 1.1090 \\
\hline 0.21082 & 30.724 & 0.21130 & 420.00 & 0.41904 & 1.0700 \\
\hline 0.26162 & 30.846 & 0.25629 & 512.00 & 0.52266 & 1.4040 \\
\hline 0.31242 & 30.876 & 0.30330 & 607.00 & 0.62525 & 2.1430 \\
\hline 0.36322 & 31.638 & 0.36088 & 737.00 & 0.74177 & 2.8670 \\
\hline 0.41402 & 31.791 & 0.45517 & 934.00 & 0.84956 & 3.9340 \\
\hline 0.46482 & 32.004 & 0.52227 & 1079.0 & 0.96030 & 4.7040 \\
\hline 0.51562 & 32.004 & 0.58905 & 1217.0 & 1.0653 & 4.5690 \\
\hline
\end{tabular}

\begin{tabular}{|l|l|l|}
\hline $\mathrm{x}(\mathrm{m})$ & TI $(\%)(1 \mathrm{D})$ & $\Lambda \times 10^{3}(\mathrm{~m})$ \\
\hline graph & graph & graph \\
\hline-0.18796 & 0.65 & \\
\hline 0.16002 & 0.66 & 8.13 \\
\hline 0.51562 & 0.65 & 8.79 \\
\hline 0.82804 & 0.65 & \\
\hline 1.1582 & 0.66 & \\
\hline 1.4199 & 0.65 & \\
\hline
\end{tabular}

\begin{tabular}{|l|l|}
\hline $\mathrm{Re}_{\mathrm{x}} \times 10^{-6}$ & $\gamma(\%)$ \\
\hline graph & graph \\
\hline 0.20900 & 0.0000 \\
\hline 0.31000 & 2.3000 \\
\hline 0.40700 & 11.300 \\
\hline 0.50600 & 23.200 \\
\hline 0.60500 & 39.100 \\
\hline 0.70000 & 58.600 \\
\hline 0.80000 & 70.400 \\
\hline 0.90000 & 83.800 \\
\hline 1.0000 & 94.100 \\
\hline 1.1100 & 98.400 \\
\hline 1.2000 & 100.00 \\
\hline
\end{tabular}


Table A.3.c. Data from Suder, O'Brien and Reshotko (1988), TI=0.92\% (1D).

\begin{tabular}{|l|l|l|l|l|l|}
\hline $\mathrm{X}(\mathrm{m})$ & $\mathrm{U}_{\infty}(\mathrm{m} / \mathrm{s})$ & $\theta \times 10^{3}(\mathrm{~m})$ & $\operatorname{Re}_{\theta}$ & $\mathrm{Re}_{\mathrm{x}} \times 10^{-6}$ & $\mathrm{c}_{\mathrm{f}} \times 10^{3}$ \\
\hline units & units & units & & calc. & \\
\hline 0.12497 & 30.358 & 0.17524 & 325.00 & 0.23177 & 1.3020 \\
\hline 0.14834 & 30.297 & 0.18633 & 344.00 & 0.27385 & 1.1980 \\
\hline 0.16104 & 30.328 & 0.19660 & 364.00 & 0.29816 & 1.1780 \\
\hline 0.17780 & 30.389 & 0.21052 & 390.00 & 0.32939 & 1.1290 \\
\hline 0.20320 & 30.389 & 0.22482 & 417.00 & 0.37691 & 1.0730 \\
\hline 0.22860 & 30.480 & 0.23609 & 440.00 & 0.42604 & 1.1720 \\
\hline 0.25400 & 30.389 & 0.23970 & 444.00 & 0.47049 & 1.4010 \\
\hline 0.27940 & 30.389 & 0.25085 & 465.00 & 0.51792 & 1.6660 \\
\hline 0.30480 & 30.450 & 0.28991 & 538.00 & 0.56562 & 1.9490 \\
\hline 0.33020 & 30.480 & 0.30784 & 573.00 & 0.61460 & 2.2330 \\
\hline 0.35560 & 30.480 & 0.34539 & 643.00 & 0.66201 & 2.5050 \\
\hline 0.38100 & 30.541 & 0.39040 & 728.00 & 0.71047 & 2.7570 \\
\hline 0.40640 & 30.541 & 0.41712 & 777.00 & 0.75703 & 2.9800 \\
\hline 0.43180 & 30.602 & 0.48286 & 902.00 & 0.80663 & 3.1720 \\
\hline 0.45720 & 30.571 & 0.49771 & 929.00 & 0.85338 & 3.3310 \\
\hline 0.48260 & 30.541 & 0.52824 & 984.00 & 0.89898 & 3.4600 \\
\hline 0.50800 & 30.510 & 0.57485 & 1070.0 & 0.94556 & 3.5650 \\
\hline 0.53340 & 30.541 & 0.61748 & 1152.0 & 0.99515 & 3.6540 \\
\hline
\end{tabular}

\begin{tabular}{|l|l|l|}
\hline $\mathrm{X}(\mathrm{m})$ & TI $(\%)(1 \mathrm{D})$ & $\Lambda \times 10^{3}(\mathrm{~m})$ \\
\hline graph & graph & graph \\
\hline-0.18796 & 0.92 & \\
\hline 0.16002 & 0.94 & 12.2 \\
\hline 0.51562 & 0.91 & 12.5 \\
\hline 0.82804 & 0.88 & 13.1 \\
\hline 1.1582 & 0.86 & 13.5 \\
\hline 1.4199 & 0.82 & 15.2 \\
\hline
\end{tabular}


Table A.3.c. Data from Suder, O'Brien and Reshotko (1988), TI=0.92\% (1D). (Cont'd)

\begin{tabular}{|l|l|}
\hline $\operatorname{Re}_{\mathrm{X}} \times 10^{-6}$ & $\gamma(\%)$ \\
\hline graph & graph \\
\hline 0.20900 & 6.3000 \\
\hline 0.31000 & 21.400 \\
\hline 0.40700 & 39.500 \\
\hline 0.50600 & 59.300 \\
\hline 0.60500 & 78.600 \\
\hline 0.70000 & 92.100 \\
\hline 0.80000 & 98.000 \\
\hline 0.90000 & 100.00 \\
\hline
\end{tabular}


Table A.3.d. Data from Suder, O'Brien and Reshotko (1988), TI=2.0\% (1D).

\begin{tabular}{|l|l|l|l|l|l|}
\hline $\mathrm{x}(\mathrm{m})$ & $\mathrm{U}_{\infty}(\mathrm{m} / \mathrm{s})$ & $\theta \times 10^{3}(\mathrm{~m})$ & $\operatorname{Re}_{\theta}$ & $\operatorname{Re}_{\mathrm{x}} \times 10^{-6}$ & $\mathrm{c}_{\mathrm{f}} \times 10^{3}$ \\
\hline units & units & units & & calc. & \\
\hline 0.12700 & 30.267 & 0.20193 & 391.00 & 0.24591 & 3.3950 \\
\hline 0.15748 & 30.297 & 0.25654 & 498.00 & 0.30570 & 3.7520 \\
\hline 0.18288 & 30.328 & 0.34265 & 667.00 & 0.35600 & 3.9220 \\
\hline 0.20828 & 30.358 & 0.34239 & 668.00 & 0.40635 & 5.3080 \\
\hline 0.23368 & 30.389 & 0.40742 & 796.00 & 0.45656 & 5.0340 \\
\hline 0.25908 & 30.389 & 0.44907 & 878.00 & 0.50654 & 4.8850 \\
\hline 0.30988 & 30.389 & 0.55042 & 1073.0 & 0.60409 & 4.5900 \\
\hline 0.36068 & 30.389 & 0.64110 & 1254.0 & 0.70550 & 4.3910 \\
\hline 0.41148 & 30.419 & 0.71806 & 1405.0 & 0.80513 & 4.2480 \\
\hline 0.46228 & 30.450 & 0.81864 & 1605.0 & 0.90633 & 4.1250 \\
\hline 0.51308 & 30.480 & 0.91161 & 1792.0 & 1.0086 & 4.0160 \\
\hline
\end{tabular}

\begin{tabular}{|l|l|l|}
\hline $\mathrm{x}(\mathrm{m})$ & TI $(\%)(1 \mathrm{D})$ & $\Lambda \times 10^{3}(\mathrm{~m})$ \\
\hline graph & graph & $\mathrm{graph}$ \\
\hline-0.18796 & 2.05 & \\
\hline 0.16002 & 2.00 & 13.7 \\
\hline 0.51562 & 1.88 & 15.6 \\
\hline 0.82804 & 1.75 & 18.3 \\
\hline 1.1582 & 1.67 & 18.1 \\
\hline 1.4199 & 1.59 & 21.4 \\
\hline
\end{tabular}

\begin{tabular}{|l|l|}
\hline $\operatorname{Re}_{X} \times 10^{-6}$ & $\gamma(\%)$ \\
\hline graph & graph \\
\hline 2.0900 & 55.5 \\
\hline 3.1000 & 80.0 \\
\hline 4.0700 & 94.4 \\
\hline 5.0600 & 100.0 \\
\hline
\end{tabular}


Table A.3.e. Data from Suder, O'Brien and Reshotko (1988), TI=4.3\% (1D).

\begin{tabular}{|l|l|l|l|l|l|}
\hline $\mathrm{x}(\mathrm{m})$ & $\mathrm{U}_{\infty}(\mathrm{m} / \mathrm{s})$ & $\theta \times 10^{3}(\mathrm{~m})$ & $\operatorname{Re}_{\theta}$ & $\operatorname{Re}_{\mathrm{x}} \times 10^{-6}$ & $\mathrm{c}_{\mathrm{f}} \times 10^{3}$ \\
\hline units & units & units & & calc. & \\
\hline 0.12700 & 31.151 & 0.26568 & 531.00 & 0.25382 & 5.6700 \\
\hline 0.25908 & 31.242 & 0.52807 & 1059.0 & 0.51957 & 4.6930 \\
\hline 0.51308 & 31.242 & 0.95479 & 1916.0 & 1.0296 & 4.1180 \\
\hline
\end{tabular}

\begin{tabular}{|l|l|l|}
\hline $\mathrm{x}(\mathrm{m})$ & TI $(\%)(1 \mathrm{D})$ & $\Lambda \times 10^{-3}(\mathrm{~m})$ \\
\hline graph & graph & graph \\
\hline-0.18796 & 4.71 & \\
\hline 0.16002 & 4.26 & 21.1 \\
\hline 0.51562 & 3.83 & 22.7 \\
\hline 0.82804 & 3.54 & 26.0 \\
\hline 1.1582 & 3.30 & 26.9 \\
\hline 1.4199 & 3.15 & 33.9 \\
\hline
\end{tabular}

\begin{tabular}{|l|l|}
\hline $\operatorname{Re}_{\mathrm{X}} \times 10^{-6}$ & $\gamma(\%)$ \\
\hline graph & $\mathrm{graph}$ \\
\hline 0.2090 & 87.7 \\
\hline 0.3100 & 95.8 \\
\hline 0.4070 & 100.0 \\
\hline
\end{tabular}


Table A.3.f. Data from Suder, O'Brien and Reshotko (1988), TI=5.2\% (1D).

\begin{tabular}{|l|l|l|l|l|l|}
\hline $\mathrm{x}(\mathrm{m})$ & $\mathrm{U}_{\infty}(\mathrm{m} / \mathrm{s})$ & $\theta \times 10^{3}(\mathrm{~m})$ & $\operatorname{Re}_{\theta}$ & $\operatorname{Re}_{\mathrm{X}} \times 10^{-6}$ & $\mathrm{c}_{\mathrm{f}} \times 10^{3}$ \\
\hline units & units & units & & calc. & \\
\hline 0.12700 & 30.785 & 0.32131 & 634.00 & 0.25059 & 5.4450 \\
\hline 0.25908 & 31.151 & 0.57556 & 1151.0 & 0.51810 & 4.6510 \\
\hline 0.51308 & 31.425 & 1.4016 & 2133.0 & 0.78084 & 4.1240 \\
\hline
\end{tabular}

\begin{tabular}{|l|l|l|}
\hline $\mathrm{x}(\mathrm{m})$ & TI $(\%)(1 \mathrm{D})$ & $\Lambda \times 10^{3}(\mathrm{~m})$ \\
\hline graph & graph & $\mathrm{graph}$ \\
\hline-0.18796 & 5.68 & \\
\hline 0.16002 & 5.04 & 22.7 \\
\hline 0.51562 & 4.50 & 24.4 \\
\hline 0.82804 & 4.41 & 27.3 \\
\hline 1.1582 & 4.06 & 32.7 \\
\hline 1.4199 & 3.86 & 37.9 \\
\hline
\end{tabular}


Table A.4.a. Data from Sohn and Reshotko (1991), TI=0.45\% (1D).

\begin{tabular}{|l|l|l|l|l|l|l|l|}
\hline $\mathrm{x}(\mathrm{m})$ & $\begin{array}{l}\mathrm{U}_{\infty} \\
(\mathrm{m} / \mathrm{s})\end{array}$ & $\begin{array}{l}\theta \times 10^{3} \\
(\mathrm{~m})\end{array}$ & $\operatorname{Re}_{\theta}$ & $\begin{array}{l}\operatorname{Re}_{\mathrm{X}} \\
\times 10^{-6}\end{array}$ & $\mathrm{c}_{\mathrm{f}} \times 10^{3}$ & St $\times 10^{3}$ & $\begin{array}{l}\mathrm{TI}(\%) \\
(1 \mathrm{D})\end{array}$ \\
\hline units & units & units & & & & & graph \\
\hline 0.12700 & 30.998 & 0.16099 & 293.00 & 0.23138 & 1.4924 & 1.4988 & 0.45 \\
\hline 0.25400 & 31.151 & 0.24051 & 437.00 & 0.46096 & 1.0070 & 0.94190 & 0.45 \\
\hline 0.38100 & 31.455 & 0.31585 & 575.00 & 0.69314 & 0.79950 & 0.73270 & 0.45 \\
\hline 0.44450 & 31.577 & 0.34643 & 632.00 & 0.81107 & 0.76040 & 0.68300 & 0.45 \\
\hline 0.50800 & 31.638 & 0.45509 & 835.00 & 0.93211 & 0.91840 & 0.80110 & 0.45 \\
\hline
\end{tabular}

Table A.4.b. Data from Sohn and Reshotko (1991), TI=0.83\% (1D).

\begin{tabular}{|l|l|l|l|l|l|l|l|}
\hline$x(\mathrm{~m})$ & $\begin{array}{l}\mathrm{U}_{\infty} \\
(\mathrm{m} / \mathrm{s})\end{array}$ & $\begin{array}{l}\theta \times 10^{3} \\
(\mathrm{~m})\end{array}$ & $\mathrm{Re}_{\theta}$ & $\begin{array}{l}\mathrm{Re}_{\mathrm{x}} \\
\times 10^{-6}\end{array}$ & $\mathrm{c}_{\mathrm{f}} \times 10^{3}$ & St $\times 10^{3}$ & $\begin{array}{l}\mathrm{TI}(\%) \\
(1 \mathrm{D})\end{array}$ \\
\hline units & units & units & & & & & $\mathrm{graph}$ \\
\hline 0.12700 & 30.632 & 0.16721 & 302.00 & 0.22942 & 1.4559 & 1.4559 & 0.83 \\
\hline 0.17780 & 31.059 & 0.21364 & 389.00 & 0.32359 & 1.1361 & 1.0998 & 0.83 \\
\hline 0.25400 & 31.272 & 0.25827 & 475.00 & 0.46735 & 1.1412 & 1.0699 & 0.80 \\
\hline 0.30480 & 30.693 & 0.35763 & 649.00 & 0.55280 & 1.4658 & 1.2701 & 0.80 \\
\hline 0.38100 & 30.968 & 0.50368 & 925.00 & 0.69961 & 2.1926 & 1.6284 & 0.83 \\
\hline 0.44450 & 31.333 & 0.62649 & 1180.0 & 0.83737 & 3.1065 & 1.9766 & 0.83 \\
\hline 0.50800 & 30.937 & 0.74427 & 1384.0 & 0.94445 & 3.5331 & 2.1665 & 0.80 \\
\hline
\end{tabular}


Table A.4.c. Data from Sohn and Reshotko (1991), TI=1.1\% (1D).

\begin{tabular}{|l|l|l|l|l|l|l|l|l|l|l|}
\hline $\mathrm{x}(\mathrm{m})$ & $\begin{array}{l}\mathrm{U}_{\infty} \\
(\mathrm{m} / \mathrm{s})\end{array}$ & $\begin{array}{l}\theta \times 10^{3} \\
(\mathrm{~m})\end{array}$ & $\mathrm{Re}_{\theta}$ & $\begin{array}{l}\mathrm{Re}_{\mathrm{x}} \\
\times 10^{-6}\end{array}$ & $\begin{array}{l}\mathrm{c}_{\mathrm{f}} \\
\times 10^{3}\end{array}$ & $\begin{array}{l}\mathrm{St} \\
\times 10^{3}\end{array}$ & $\begin{array}{l}\Delta_{2} \\
\times 10^{3}\end{array}$ & $\mathrm{Re}_{\Delta 2}$ & $\gamma(\%)$ & $\begin{array}{l}\mathrm{TI}(\%) \\
(1 \mathrm{D})\end{array}$ \\
\hline units & units & units & & & & & & calc. & & $\mathrm{graph}$ \\
\hline 0.127 & 31.2 & 0.178 & 325 & 0.232 & 1.37 & 1.37 & 0.142 & 259 & & 1.1 \\
\hline 0.178 & 30.8 & 0.214 & 384 & 0.318 & 1.15 & 1.11 & 0.175 & 313 & & 1.1 \\
\hline 0.229 & 31.2 & 0.258 & 470 & 0.415 & 1.22 & 1.14 & 0.235 & 427 & 35.2 & 1.1 \\
\hline 0.279 & 30.1 & 0.345 & 606 & 0.491 & 1.64 & 1.42 & 0.328 & 577 & 56.6 & 1.1 \\
\hline 0.330 & 30.6 & 0.459 & 826 & 0.594 & 2.27 & 1.73 & 0.495 & 891 & 82.6 & 1.1 \\
\hline 0.381 & 31.7 & 0.613 & 1150 & 0.714 & 3.25 & 2.04 & 0.705 & 1320 & 94.5 & 1.1 \\
\hline 0.444 & 31.5 & 0.738 & 1377 & 0.829 & 3.55 & 2.12 & 0.862 & 1608 & 99.3 & 1.1 \\
\hline 0.508 & 31.4 & 0.850 & 1580 & 0.945 & 3.58 & 2.18 & 1.02 & 1897 & 99.9 & 1.1 \\
\hline
\end{tabular}

Table A.4.d. Data from Sohn and Reshotko (1991), TI=2.6\% (1D).

\begin{tabular}{|l|l|l|l|l|l|l|l|l|}
\hline $\mathrm{x}(\mathrm{m})$ & $\begin{array}{l}\mathrm{U}_{\infty} \\
(\mathrm{m} / \mathrm{s})\end{array}$ & $\begin{array}{l}\theta \times 10^{3} \\
(\mathrm{~m})\end{array}$ & $\operatorname{Re}_{\theta}$ & $\begin{array}{l}\mathrm{Re}_{\mathrm{x}} \\
\times 10^{-6}\end{array}$ & $\mathrm{c}_{\mathrm{f}} \times 10^{3}$ & $\begin{array}{l}\mathrm{St} \\
\times 10^{3}\end{array}$ & $\begin{array}{l}\gamma(\%) \\
(1 \mathrm{D})\end{array}$ \\
\hline units & units & units & & & & & & graph \\
\hline 0.1270 & 30.33 & 0.1796 & 322.0 & 0.2278 & 1.590 & 1.546 & 26.62 & 2.6 \\
\hline 0.1778 & 30.18 & 0.2781 & 498.0 & 0.3180 & 2.090 & 1.782 & 61.76 & 2.6 \\
\hline 0.2286 & 30.45 & 0.3987 & 723.0 & 0.4147 & 3.141 & 2.151 & 88.82 & 2.6 \\
\hline 0.2794 & 31.00 & 0.4993 & 909.0 & 0.5087 & 3.611 & 2.346 & 98.41 & 2.5 \\
\hline 0.3302 & 30.78 & 0.6248 & 1130 & 0.5973 & 3.898 & 2.346 & 99.88 & 2.5 \\
\hline 0.3810 & 30.97 & 0.7306 & 1329 & 0.6929 & 3.921 & 2.414 & & 2.4 \\
\hline 0.4445 & 30.88 & 0.8783 & 1590 & 0.8049 & 3.747 & 2.309 & & 2.3 \\
\hline 0.5080 & 30.72 & 1.014 & 1829 & 0.9161 & 3.598 & 2.251 & & 2.3 \\
\hline
\end{tabular}


Table A.4.e. Data from Sohn and Reshotko (1991), TI=6.0\% (1D).

\begin{tabular}{|l|l|l|l|l|l|l|l|}
\hline $\mathrm{x}(\mathrm{m})$ & $\begin{array}{l}\mathrm{U}_{\infty} \\
(\mathrm{m} / \mathrm{s})\end{array}$ & $\begin{array}{l}\theta \times 10^{3} \\
(\mathrm{~m})\end{array}$ & $\mathrm{Re}_{\theta}$ & $\begin{array}{l}\mathrm{Re}_{\mathrm{X}} \\
\times 10^{-6}\end{array}$ & $\mathrm{c}_{\mathrm{f}} \times 10^{3}$ & $\mathrm{St} \times 10^{3}$ & $\begin{array}{l}\mathrm{TI}(\%) \\
(1 \mathrm{D})\end{array}$ \\
\hline units & units & units & & & & & $\mathrm{graph}$ \\
\hline 0.12700 & 30.720 & 0.27785 & 502.00 & 0.22963 & 3.8487 & 2.6087 & 5.6 \\
\hline 0.17780 & 31.090 & 0.42789 & 785.00 & 0.32610 & 4.1002 & 2.7235 & 5.2 \\
\hline 0.25400 & 30.815 & 0.57005 & 1039.0 & 0.46299 & 4.2435 & 2.6876 & 5.0 \\
\hline 0.30480 & 30.907 & 0.71034 & 1296.0 & 0.55609 & 4.0448 & 2.5387 & 4.9 \\
\hline 0.38100 & 29.931 & 0.83271 & 1449.0 & 0.66281 & 3.9265 & 2.3795 & 4.8 \\
\hline 0.44450 & 31.059 & 1.0131 & 1832.0 & 0.80364 & 3.7574 & 2.3960 & 4.6 \\
\hline 0.50800 & 30.785 & 1.1481 & 2058.0 & 0.91055 & 3.6894 & 2.3792 & 4.2 \\
\hline
\end{tabular}

Table A.4.f. Data from Sohn and Reshotko (1991), TI=6.6\% (1D).

\begin{tabular}{|l|l|l|l|l|l|l|l|}
\hline x (m) & $\begin{array}{l}\mathrm{U}_{\infty} \\
(\mathrm{m} / \mathrm{s})\end{array}$ & $\begin{array}{l}\theta \times 10^{3} \\
(\mathrm{~m})\end{array}$ & $\operatorname{Re}_{\theta}$ & $\begin{array}{l}\operatorname{Re}_{\mathrm{x}} \\
\times 10^{-6}\end{array}$ & $\mathrm{c}_{\mathrm{f}} \times 10^{3}$ & $\mathrm{St} \times 10^{3}$ & $\begin{array}{l}\text { TI }(\%) \\
(1 \mathrm{D})\end{array}$ \\
\hline units & units & units & & & & & $\mathrm{graph}$ \\
\hline 0.12700 & 30.754 & 0.32827 & 589.00 & 0.22785 & 4.5466 & 2.8813 & 6.4 \\
\hline 0.20320 & 31.181 & 0.56065 & 1020.0 & 0.36967 & 4.3537 & 2.7542 & 6.2 \\
\hline 0.30480 & 30.693 & 0.76182 & 1363.0 & 0.54535 & 4.0380 & 2.5605 & 5.7 \\
\hline 0.38100 & 30.663 & 0.97851 & 1757.0 & 0.68413 & 3.8981 & 2.4408 & 5.4 \\
\hline 0.44450 & 31.090 & 1.2060 & 2211.0 & 0.81497 & 3.7241 & 2.3056 & 5.2 \\
\hline 0.50800 & 30.876 & 1.2551 & 2285.0 & 0.92497 & 3.6881 & 2.3368 & 5.0 \\
\hline
\end{tabular}


Table A.5. Data from Kuan and Wang (1990).and Kuan(1987), $\mathrm{TI}=0.9 \%$ (2D).

\begin{tabular}{|l|l|l|l|l|l|l|l|l|l|}
\hline $\begin{array}{l}\mathrm{x} \\
(\mathrm{m})\end{array}$ & $\begin{array}{l}\mathrm{U}_{\infty} \\
(\mathrm{m} / \mathrm{s})\end{array}$ & $\begin{array}{l}\theta \times 10^{3} \\
(\mathrm{~m})\end{array}$ & $\mathrm{Re}_{\theta}$ & $\begin{array}{l}\mathrm{Re}_{\mathrm{X}} \\
\times 10^{-6}\end{array}$ & $\begin{array}{l}\mathrm{c}_{\mathrm{f}} \\
\times 10^{3}\end{array}$ & $\begin{array}{l}\mathrm{u}_{\infty}^{\prime} \\
(\mathrm{m} / \mathrm{s})\end{array}$ & $\begin{array}{l}\mathrm{v}_{\infty}^{\prime} \\
(\mathrm{m} / \mathrm{s})\end{array}$ & $\begin{array}{l}\mathrm{TI}(\%) \\
(2 \mathrm{D})\end{array}$ & $\gamma(\%)$ \\
\hline & & & $\mathrm{calc}$. & & & & & $\mathrm{calc}$ & $\mathrm{graph}$ \\
\hline 0.20 & 13.83 & 0.334 & 297.3 & 0.178 & 1.580 & 0.1119 & 0.1254 & 0.887 & \\
\hline 0.35 & 13.85 & 0.430 & 383.3 & 0.312 & 1.210 & 0.1077 & 0.1270 & 0.884 & \\
\hline 0.50 & 13.85 & 0.552 & 492.4 & 0.446 & 0.970 & 0.1065 & 0.1311 & 0.899 & 56. \\
\hline 0.66 & 13.86 & 0.670 & 592.8 & 0.584 & 1.630 & 0.1090 & 0.1269 & 0.884 & 67. \\
\hline 0.81 & 13.80 & 0.857 & 760.7 & 0.719 & 3.430 & 0.1101 & 0.1245 & 0.877 & 84. \\
\hline 0.96 & 13.77 & 1.051 & 930.6 & 0.850 & 4.150 & 0.1167 & 0.1287 & 0.915 & 88. \\
\hline 1.11 & 13.80 & 1.292 & 1147 & 0.985 & 4.300 & 0.1116 & 0.1258 & 0.886 & 96. \\
\hline 1.27 & 13.85 & 1.530 & 1363 & 1.131 & 4.150 & 0.1102 & 0.1291 & 0.902 & \\
\hline 1.42 & 13.80 & 1.863 & 1648 & 1.256 & 3.950 & 0.1108 & 0.1293 & 0.903 & 100. \\
\hline 1.56 & 13.80 & 2.152 & 1911 & 1.385 & 3.750 & 0.1177 & 0.1271 & 0.908 & \\
\hline 1.72 & 13.87 & 2.392 & 2129 & 1.531 & 3.630 & 0.1223 & 0.1253 & 0.905 & \\
\hline 1.87 & 13.90 & 2.591 & 2310 & 1.667 & 3.550 & & & & \\
\hline 2.03 & 13.85 & 2.987 & 2662 & 1.809 & 3.360 & 0.1229 & 0.1248 & 0.906 & \\
\hline
\end{tabular}


Table A.6.a. Data from Blair (1981a), $\mathrm{k}=0, \mathrm{TI}=0.165 \%$ (3D).

\begin{tabular}{|l|l|l|l|l|l|}
\hline $\mathrm{x}(\mathrm{m})$ & $\mathrm{U}_{\infty}(\mathrm{m} / \mathrm{s})$ & $\theta \times 10^{3}(\mathrm{~m})$ & $\operatorname{Re}_{\theta}$ & $\operatorname{Re}_{\mathrm{x}} \times 10^{-6}$ & $\mathrm{c}_{\mathrm{f}} \times 10^{3}$ \\
\hline units & units & units & & & \\
\hline 0.31191 & 30.274 & 0.24232 & 493.00 & 0.63447 & 3.0002 \\
\hline 0.91948 & 30.204 & 1.2896 & 2637.0 & 1.8806 & 3.3300 \\
\hline 1.0236 & 30.102 & 1.4541 & 2959.0 & 2.0830 & 3.2370 \\
\hline 1.3264 & 30.311 & 1.9134 & 3885.0 & 2.6927 & 3.0220 \\
\hline 1.5303 & 30.082 & 2.1816 & 4390.0 & 3.0792 & 2.9480 \\
\hline 1.7323 & 30.318 & 2.4801 & 5011.0 & 3.5000 & 2.8510 \\
\hline 1.9334 & 30.271 & 2.7620 & 5573.0 & 3.9014 & 2.8070 \\
\hline 2.1361 & 30.293 & 3.0107 & 6061.0 & 4.3003 & 2.7440 \\
\hline
\end{tabular}

\begin{tabular}{|l|l|l|l|l|l|l|l|}
\hline $\mathrm{x}(\mathrm{m})$ & $\mathrm{T}_{\infty}\left({ }^{\circ} \mathrm{C}\right)$ & $\mathrm{T}_{\mathrm{W}}\left({ }^{\circ} \mathrm{C}\right)$ & $\begin{array}{l}\mathrm{q}^{\prime \prime} \\
\left(\mathrm{W} / \mathrm{m}^{2}\right)\end{array}$ & $\begin{array}{l}\Delta_{2} \times 10^{3} \\
(\mathrm{in} .)+\end{array}$ & $\begin{array}{l}\Delta_{2} \times 10^{3} \\
(\mathrm{~m}) \ddagger\end{array}$ & $\mathrm{Re}_{\Delta 2} \ddagger$ & St $\times 10^{3}$ \\
\hline units & units & units & & & calc. & calc. & calc. \\
\hline 0.31191 & 20.213 & 39.517 & 460.30 & 0.57 & 0.22002 & 448.30 & 0.6632 \\
\hline 0.91948 & 20.007 & 28.033 & 513.70 & 1.78 & 1.6514 & 3378.6 & 1.7397 \\
\hline 1.0236 & 20.294 & 28.617 & 514.80 & 2.02 & 1.8090 & 3680.8 & 1.6895 \\
\hline 1.3264 & 20.414 & 28.956 & 515.10 & 2.65 & 2.3133 & 4697.0 & 1.6510 \\
\hline 1.5303 & 19.812 & 28.728 & 498.60 & 2.97 & 2.4787 & 4987.9 & 1.5482 \\
\hline 1.7323 & 20.421 & 29.694 & 501.20 & 3.20 & 2.5732 & 5198.4 & 1.4886 \\
\hline 1.9334 & 20.374 & 29.644 & 496.80 & 3.75 & 3.0160 & 6085.8 & 1.4781 \\
\hline 2.1361 & 20.389 & 29.528 & 504.00 & 4.11 & 3.3531 & 6751.5 & 1.5222 \\
\hline
\end{tabular}

$\dagger$ Based on Blair's definition of $\Delta_{2}=\int_{0}^{\delta_{1}} \frac{\rho U\left(T-T_{\infty}\right)}{\rho_{\infty} U_{\infty} T_{\infty}} d y$

$\ddagger$ Based on standard definition of $\Delta_{2}=\int_{0}^{\infty} \frac{\rho U\left(T-T_{\infty}\right)}{\rho_{\infty} U_{\infty}\left(T_{w}-T_{\infty}\right)} d y$

\begin{tabular}{|l|l|l|l|l|}
\hline $\mathrm{x}(\mathrm{m})$ & $\mathrm{u}_{\infty} / \mathrm{U}_{\infty} \times 100$ & $\mathrm{v}_{\infty}^{\prime} / \mathrm{U}_{\infty} \times 100$ & $\mathrm{w}_{\infty}^{\prime} / \mathrm{U}_{\infty} \times 100$ & $\mathrm{TI}(\%)(3 \mathrm{D})$ \\
\hline units & $\mathrm{graph}$ & $\mathrm{graph}$ & $\mathrm{graph}$ & $\mathrm{graph}$ \\
\hline-0.3048 & 0.25900 & 0.20500 & 0.21100 & 0.17800 \\
\hline 0.10160 & 0.22000 & 0.13100 & 0.14900 & 0.11900 \\
\hline 0.40640 & 0.21800 & 0.13100 & 0.14300 & 0.11900 \\
\hline 1.0160 & 0.21100 & 0.11900 & 0.13500 & 0.11900 \\
\hline 1.6256 & 0.19900 & 0.11600 & 0.12300 & 0.11900 \\
\hline 2.2352 & 0.19600 & 0.11900 & 0.13100 & 0.11900 \\
\hline
\end{tabular}


Table A.6.b. Data from Blair (1981a), $\mathrm{k}=0, \mathrm{TI}=1.25 \%$ (3D).

\begin{tabular}{|l|l|l|l|l|l|}
\hline $\mathrm{x}(\mathrm{m})$ & $\mathrm{U}_{\infty}(\mathrm{m} / \mathrm{s})$ & $\theta \times 10^{3}(\mathrm{~m})$ & $\operatorname{Re}_{\theta}$ & $\operatorname{Re}_{\mathrm{X}} \times 10^{-6}$ & $\mathrm{c}_{\mathrm{f}} \times 10^{3}$ \\
\hline units & units & units & & & \\
\hline 0.51384 & 30.047 & 0.67310 & 1365.0 & 1.0423 & 4.0920 \\
\hline 0.91948 & 30.111 & 1.3764 & 2795.0 & 1.8672 & 3.2680 \\
\hline 1.1232 & 30.164 & 1.6843 & 3402.0 & 2.2690 & 3.1370 \\
\hline 1.3254 & 30.335 & 2.0109 & 4077.0 & 2.6872 & 2.9880 \\
\hline 1.5329 & 30.306 & 2.2718 & 4594.0 & 3.1000 & 2.9360 \\
\hline 1.7374 & 30.058 & 2.5494 & 5150.0 & 3.5100 & 2.8490 \\
\hline 1.9380 & 30.075 & 2.8611 & 5785.0 & 3.9189 & 2.7860 \\
\hline 2.1361 & 30.084 & 3.1557 & 6390.0 & 4.3257 & 2.7130 \\
\hline
\end{tabular}

\begin{tabular}{|l|l|l|l|l|l|l|l|}
\hline $\mathrm{x}(\mathrm{m})$ & $\mathrm{T}_{\infty}\left({ }^{\circ} \mathrm{C}\right)$ & $\mathrm{T}_{\mathrm{W}}\left({ }^{\circ} \mathrm{C}\right)$ & $\begin{array}{l}\mathrm{q} " \\
\left(\mathrm{~W} / \mathrm{m}^{2}\right)\end{array}$ & $\begin{array}{l}\Delta_{2 \times 10^{3}} \\
(\mathrm{in} .)+\end{array}$ & $\begin{array}{l}\Delta_{2 \times 10^{3}} \\
(\mathrm{~m}) \ddagger\end{array}$ & $\mathrm{Re}_{\Delta 2} \ddagger$ & $\mathrm{St} \times 10^{3}$ \\
\hline units & units & units & & & calc. & calc. & calc. \\
\hline 0.51384 & 20.578 & 31.389 & 784.80 & 1.44 & 0.99375 & 2013.2 & 1.9956 \\
\hline 0.91948 & 20.739 & 33.028 & 778.50 & 2.74 & 1.6644 & 3379.2 & 1.7429 \\
\hline 1.1232 & 20.855 & 33.867 & 778.40 & 3.39 & 1.9456 & 3929.3 & 1.6558 \\
\hline 1.3254 & 21.200 & 34.217 & 778.40 & 3.93 & 2.2572 & 4576.8 & 1.6477 \\
\hline 1.5329 & 21.464 & 34.728 & 772.00 & 4.48 & 2.5274 & 5111.1 & 1.6073 \\
\hline 1.7374 & 21.133 & 35.006 & 775.90 & 5.12 & 2.7587 & 5572.8 & 1.5512 \\
\hline 1.9380 & 21.082 & 35.311 & 769.70 & 5.89 & 3.0936 & 6255.0 & 1.4977 \\
\hline 2.1361 & 20.894 & 35.022 & 774.90 & 6.29 & 3.3252 & 6733.7 & 1.5171 \\
\hline
\end{tabular}

$\dagger$ Based on Blair's definition of $\Delta_{2}=\int_{0}^{\delta_{1}} \frac{\rho U\left(T-T_{\infty}\right)}{\rho_{\infty} U_{\infty} T_{\infty}} d y$

$\ddagger$ Based on standard definition of $\Delta_{2}=\int_{0}^{\infty} \frac{\rho U\left(T-T_{\infty}\right)}{\rho_{\infty} U_{\infty}\left(T_{w}-T_{\infty}\right)} d y$

\begin{tabular}{|l|l|l|l|l|l|}
\hline x (m) & $\begin{array}{l}\mathrm{u}_{\infty}^{\prime} / \mathrm{U}_{\infty} \\
\times 100\end{array}$ & $\begin{array}{l}\mathrm{v}_{\infty}^{\prime} / \mathrm{U}_{\infty} \\
\times 100\end{array}$ & $\begin{array}{l}\mathrm{w}_{\infty}^{\prime} / \mathrm{U}_{\infty} \\
\times 100\end{array}$ & $\begin{array}{l}\mathrm{TI}(\%) \\
(3 \mathrm{D})\end{array}$ & $\begin{array}{l}\Lambda \times 10^{3} \\
(\mathrm{~m})\end{array}$ \\
\hline units & $\mathrm{graph}$ & $\mathrm{graph}$ & $\mathrm{graph}$ & $\mathrm{graph}$ & $\mathrm{graph}$ \\
\hline-0.3048 & 1.2100 & 1.7000 & 1.4700 & 1.4200 & 9.1694 \\
\hline 0.10160 & 1.1050 & 1.5300 & 1.3100 & 1.2800 & 10.439 \\
\hline 0.40640 & 1.0100 & 1.3200 & 1.1400 & 1.1900 & 13.208 \\
\hline 1.0160 & 0.91900 & 1.1400 & 0.98700 & 0.98000 & 14.351 \\
\hline 1.6256 & 0.81500 & 1.0000 & 0.88900 & 0.91500 & 17.475 \\
\hline 2.2352 & 0.78200 & 0.95400 & 0.83000 & 0.80200 & 20.091 \\
\hline
\end{tabular}


Table A.6.c. Data from Blair (1981a), $k=0, T I=2.6 \%$ (3D).

\begin{tabular}{|l|l|l|l|l|l|}
\hline $\mathrm{x}(\mathrm{m})$ & $\mathrm{U}_{\infty}(\mathrm{m} / \mathrm{s})$ & $\theta \times 10^{3}(\mathrm{~m})$ & $\operatorname{Re}_{\theta}$ & $\operatorname{Re}_{\mathrm{X}} \times 10^{-6}$ & $\mathrm{c}_{\mathrm{f}} \times 10^{3}$ \\
\hline units & units & units & & & \\
\hline 0.31090 & 30.192 & 0.51994 & 1055.0 & 0.63050 & 4.5220 \\
\hline 0.71577 & 30.050 & 1.2857 & 2621.0 & 1.4592 & 3.3730 \\
\hline 0.91745 & 30.018 & 1.6322 & 3314.0 & 1.8626 & 3.1650 \\
\hline 1.1240 & 30.097 & 1.9340 & 3940.0 & 2.2895 & 3.0850 \\
\hline 1.3261 & 30.144 & 2.2822 & 4650.0 & 2.7016 & 2.9640 \\
\hline 1.9334 & 30.084 & 3.1646 & 6393.0 & 3.9060 & 2.7880 \\
\hline 2.1361 & 30.186 & 3.4625 & 7013.0 & 4.3262 & 2.7370 \\
\hline
\end{tabular}

\begin{tabular}{|l|l|l|l|l|l|l|l|}
\hline $\mathrm{x}(\mathrm{m})$ & $\mathrm{T}_{\infty}\left({ }^{\circ} \mathrm{C}\right)$ & $\mathrm{T}_{\mathrm{W}}\left({ }^{\circ} \mathrm{C}\right)$ & $\begin{array}{l}\mathrm{q} " \\
\left(\mathrm{~W} / \mathrm{m}^{2}\right)\end{array}$ & $\begin{array}{l}\Delta_{2} \times 10^{3} \\
(\mathrm{in} .) \dagger\end{array}$ & $\begin{array}{l}\Delta_{2} \times 10^{3} \\
(\mathrm{~m}) \ddagger\end{array}$ & $\mathrm{Re}_{\Delta 2} \ddagger$ & $\mathrm{St} \times 10^{3}$ \\
\hline units & units & units & & & calc. & calc. & calc. \\
\hline 0.31090 & 20.261 & 29.844 & 787.80 & 0.89 & 0.69215 & 1405.4 & 2.2282 \\
\hline 0.71577 & 20.728 & 32.033 & 784.10 & 2.18 & 1.4394 & 2934.9 & 1.8977 \\
\hline 0.91745 & 21.239 & 33.028 & 776.90 & 2.79 & 1.7696 & 3593.4 & 1.8097 \\
\hline 1.1240 & 20.203 & 32.750 & 768.80 & 3.52 & 2.0904 & 4257.6 & 1.6836 \\
\hline 1.3261 & 20.446 & 33.222 & 773.70 & 4.16 & 2.4282 & 4947.7 & 1.6632 \\
\hline 1.9334 & 21.069 & 34.950 & 762.10 & 6.17 & 3.3218 & 6710.8 & 1.5208 \\
\hline 2.1361 & 21.218 & 35.111 & 771.30 & 6.65 & 3.5789 & 7248.8 & 1.5335 \\
\hline
\end{tabular}

$\dagger$ Based on Blair's definition of $\Delta_{2}=\int_{0}^{\delta_{1}} \frac{\rho U\left(T-T_{\infty}\right)}{\rho_{\infty} U_{\infty} T_{\infty}} d y$

$\ddagger$ Based on standard definition of $\Delta_{2}=\int_{0}^{\infty} \frac{\rho U\left(T-T_{\infty}\right)}{\rho_{\infty} U_{\infty}\left(T_{w}-T_{\infty}\right)} d y$

\begin{tabular}{|l|l|l|l|l|l|}
\hline $\mathrm{x}(\mathrm{m})$ & $\begin{array}{l}\mathrm{u}_{\infty}^{\prime} / \mathrm{U}_{\infty} \\
\times 100\end{array}$ & $\begin{array}{l}\mathrm{v}_{\infty}^{\prime} / \mathrm{U}_{\infty} \\
\times 100\end{array}$ & $\begin{array}{l}\mathrm{w}_{\infty}^{\prime} / \mathrm{U}_{\infty} \\
\times 100\end{array}$ & $\begin{array}{l}\mathrm{TI}(\%) \\
(3 \mathrm{D})\end{array}$ & $\begin{array}{l}\Lambda \times 10^{3} \\
(\mathrm{~m})\end{array}$ \\
\hline units & $\mathrm{graph}$ & $\mathrm{graph}$ & $\mathrm{graph}$ & $\mathrm{graph}$ & $\mathrm{graph}$ \\
\hline-0.3048 & 2.5700 & 3.6000 & 3.0800 & 3.0100 & 12.319 \\
\hline 0.10160 & 2.2800 & 2.9000 & 2.5900 & 2.5900 & 13.208 \\
\hline 0.40640 & 2.0000 & 2.4900 & 2.1900 & 2.2400 & 15.494 \\
\hline 1.0160 & 1.7500 & 2.0300 & 1.8900 & 1.8900 & 20.828 \\
\hline 1.6256 & 1.4800 & 1.7600 & 1.6000 & 1.6000 & 22.682 \\
\hline 2.2352 & 1.3900 & 1.6000 & 1.4900 & 1.5150 & 24.105 \\
\hline
\end{tabular}


Table A.6.d. Data from Blair (1981a), $k=0, T I=6.4 \%$ (3D).

\begin{tabular}{|l|l|l|l|l|l|}
\hline $\mathrm{x}(\mathrm{m})$ & $\mathrm{U}_{\infty}(\mathrm{m} / \mathrm{s})$ & $\theta \times 10^{3}(\mathrm{~m})$ & $\operatorname{Re}_{\theta}$ & $\mathrm{Re}_{\mathrm{X}} \times 10^{-6}$ & $\mathrm{c}_{\mathrm{f}} \times 10^{3}$ \\
\hline units & units & units & & & \\
\hline 0.30480 & 30.210 & 0.69164 & 1411.0 & 0.62177 & 4.2890 \\
\hline 0.71882 & 30.291 & 1.5077 & 3036.0 & 1.4474 & 3.5590 \\
\hline 0.92202 & 30.224 & 1.8453 & 3727.0 & 1.8621 & 3.3570 \\
\hline 1.1275 & 30.261 & 2.1115 & 4260.0 & 2.2747 & 3.2990 \\
\hline 1.3264 & 30.288 & 2.4465 & 4931.0 & 2.6732 & 3.1960 \\
\hline 1.5265 & 30.095 & 2.9116 & 5875.0 & 3.0804 & 3.1240 \\
\hline 1.7335 & 30.261 & 3.0853 & 6230.0 & 3.5005 & 3.0550 \\
\hline 2.1387 & 30.331 & 3.7704 & 7549.0 & 4.2820 & 2.9300 \\
\hline
\end{tabular}

\begin{tabular}{|l|l|l|l|l|l|l|l|}
\hline $\mathrm{x}(\mathrm{m})$ & $\mathrm{T}_{\infty}\left({ }^{\circ} \mathrm{C}\right)$ & $\mathrm{T}_{\mathrm{W}}\left({ }^{\circ} \mathrm{C}\right)$ & $\begin{array}{l}\mathrm{q} \\
\left(\mathrm{W} / \mathrm{m}^{2}\right)\end{array}$ & $\begin{array}{l}\Delta_{2} \times 10^{3} \\
(\mathrm{in} .) \dagger\end{array}$ & $\begin{array}{l}\Delta_{2} \times 10^{3} \\
(\mathrm{~m}) \ddagger\end{array}$ & $\mathrm{Re}_{\Delta 2} \ddagger$ & St $\times 10^{3}$ \\
\hline units & units & units & & & calc. & calc. & calc. \\
\hline 0.30480 & 20.262 & 29.361 & 784.30 & 0.89 & 0.72897 & 1486.6 & 2.3515 \\
\hline 0.71882 & 22.043 & 33.111 & 778.30 & 2.35 & 1.5920 & 3205.8 & 1.9403 \\
\hline 0.92202 & 21.506 & 33.311 & 776.30 & 2.93 & 1.8576 & 3751.5 & 1.8139 \\
\hline 1.1275 & 21.893 & 33.694 & 777.20 & 3.44 & 2.1845 & 4407.7 & 1.8166 \\
\hline 1.3264 & 22.205 & 34.311 & 769.60 & 3.64 & 2.2557 & 4545.2 & 1.7548 \\
\hline 1.5265 & 21.433 & 33.967 & 768.40 & 4.89 & 2.9192 & 5889.8 & 1.6948 \\
\hline 1.7335 & 21.197 & 34.456 & 783.70 & 5.77 & 3.2536 & 6571.4 & 1.6359 \\
\hline 2.1387 & 20.611 & 33.633 & 771.00 & 6.41 & 3.6729 & 7354.4 & 1.6545 \\
\hline
\end{tabular}

$\dagger$ Based on Blair's definition of $\Delta_{2}=\int_{0}^{\delta_{1}} \frac{\rho U\left(T-T_{\infty}\right)}{\rho_{\infty} U_{\infty} T_{\infty}} d y$

$\ddagger$ Based on standard definition of $\Delta_{2}=\int_{0}^{\infty} \frac{\rho U\left(T-T_{\infty}\right)}{\rho_{\infty} U_{\infty}\left(T_{w}-T_{\infty}\right)} d y$

\begin{tabular}{|l|l|l|l|l|l|}
\hline $\mathrm{x}(\mathrm{m})$ & $\begin{array}{l}\mathrm{u}_{\infty}^{\prime} / \mathrm{U}_{\infty} \\
\times 100\end{array}$ & $\begin{array}{l}\mathrm{v}_{\infty}^{\prime} / \mathrm{U}_{\infty} \\
\times 100\end{array}$ & $\begin{array}{l}\mathrm{w}_{\infty}^{\prime} / \mathrm{U}_{\infty} \\
\times 100\end{array}$ & $\begin{array}{l}\mathrm{TI}(\%) \\
(3 \mathrm{D})\end{array}$ & $\begin{array}{l}\Lambda \times 10^{3} \\
(\mathrm{~m})\end{array}$ \\
\hline units & $\mathrm{graph}$ & $\mathrm{graph}$ & $\mathrm{graph}$ & $\mathrm{graph}$ & $\mathrm{graph}$ \\
\hline-0.3048 & 6.6200 & 8.6100 & 6.8900 & 7.4000 & 25.324 \\
\hline 0.10160 & 5.5900 & 6.9000 & 5.8400 & 6.1300 & 27.737 \\
\hline 0.40640 & 4.6800 & 5.4600 & 4.8600 & 5.0700 & 30.429 \\
\hline 1.0160 & 4.0400 & 4.3300 & 4.1500 & 4.0700 & 34.239 \\
\hline 1.6256 & 3.3200 & 3.2500 & 3.3800 & 3.3700 & 39.370 \\
\hline 2.2352 & 3.1500 & 2.9700 & 3.0000 & 3.1900 & 46.507 \\
\hline
\end{tabular}


Table A.6.e. Data from Blair (1981a), $\mathrm{k}=0, \mathrm{TI}=7.6 \%$ (3D).

\begin{tabular}{|l|l|l|l|l|l|}
\hline $\mathrm{x}(\mathrm{m})$ & $\mathrm{U}_{\infty}(\mathrm{m} / \mathrm{s})$ & $\theta \times 10^{3}(\mathrm{~m})$ & $\operatorname{Re}_{\theta}$ & $\operatorname{Re}_{\mathrm{x}} \times 10^{-6}$ & $\mathrm{c}_{\mathrm{f}} \times 10^{3}$ \\
\hline units & units & units & & & \\
\hline 0.30861 & 30.655 & 0.64059 & 1302.0 & 0.62726 & 4.3830 \\
\hline 0.51079 & 30.588 & 1.0076 & 2043.0 & 1.0356 & 3.9540 \\
\hline 0.71374 & 30.660 & 1.3764 & 2794.0 & 1.4490 & 3.6250 \\
\hline 0.91694 & 30.715 & 1.7404 & 3523.0 & 1.8563 & 3.4530 \\
\hline 1.3271 & 30.873 & 2.4176 & 4912.0 & 2.6967 & 3.2450 \\
\hline 1.7302 & 30.598 & 3.0744 & 6216.0 & 3.4982 & 3.0770 \\
\hline 1.9350 & 30.550 & 3.3330 & 6738.0 & 3.9119 & 3.0280 \\
\hline 2.1336 & 30.674 & 3.4547 & 6989.0 & 4.7113 & 3.0010 \\
\hline
\end{tabular}

\begin{tabular}{|l|l|l|l|l|l|l|l|}
\hline $\mathrm{x}(\mathrm{m})$ & $\mathrm{T}_{\infty}\left({ }^{\circ} \mathrm{C}\right)$ & $\mathrm{T}_{\mathrm{W}}\left({ }^{\circ} \mathrm{C}\right)$ & $\begin{array}{l}\mathrm{q} " \\
\left(\mathrm{~W} / \mathrm{m}^{2}\right)\end{array}$ & $\begin{array}{l}\Delta_{2} \times 10^{3} \\
(\mathrm{in} .) \dagger\end{array}$ & $\begin{array}{l}\Delta_{2} \times 10^{3} \\
(\mathrm{~m}) \ddagger\end{array}$ & $\mathrm{Re}_{\Delta 2} \ddagger$ & $\mathrm{St} \times 10^{3}$ \\
\hline units & units & units & & & calc. & calc. & calc. \\
\hline 0.30861 & 20.434 & 29.306 & 785.80 & 0.81 & 0.68082 & 1383.8 & 2.4231 \\
\hline 0.51079 & 20.487 & 30.072 & 787.70 & 1.42 & 1.1049 & 2239.5 & 2.2562 \\
\hline 0.71374 & 20.663 & 30.978 & 786.00 & 1.99 & 1.4398 & 2922.5 & 2.0912 \\
\hline 0.91694 & 20.086 & 31.150 & 778.20 & 2.79 & 1.8782 & 3800.6 & 1.9407 \\
\hline 1.3271 & 20.322 & 32.122 & 772.80 & 4.11 & 2.5963 & 5275.0 & 1.8012 \\
\hline 1.7302 & 20.672 & 33.200 & 785.30 & 5.24 & 3.1215 & 6311.0 & 1.7330 \\
\hline 1.9350 & 19.980 & 32.500 & 780.40 & 5.90 & 3.5087 & 7091.7 & 1.7266 \\
\hline 2.1336 & 20.731 & 33.261 & 776.40 & 6.13 & 3.6519 & 7388.3 & 1.7139 \\
\hline
\end{tabular}

$\dagger$ Based on Blair's definition of $\Delta_{2}=\int_{0}^{\delta_{1}} \frac{\rho U\left(T-T_{\infty}\right)}{\rho_{\infty} U_{\infty} T_{\infty}} d y$

$\ddagger$ Based on standard definition of $\Delta_{2}=\int_{0}^{\infty} \frac{\rho U\left(T-T_{\infty}\right)}{\rho_{\infty} U_{\infty}\left(T_{w}-T_{\infty}\right)} d y$

\begin{tabular}{|l|l|l|l|l|l|}
\hline $\mathrm{x}(\mathrm{m})$ & $\begin{array}{l}\mathrm{u}_{\infty}^{\prime} / \mathrm{U}_{\infty} \\
\times 100\end{array}$ & $\begin{array}{l}\mathrm{v}_{\infty}^{\prime} / \mathrm{U}_{\infty} \\
\times 100\end{array}$ & $\begin{array}{l}\mathrm{w}_{\infty}^{\prime} / \mathrm{U}_{\infty} \\
\times 100\end{array}$ & $\begin{array}{l}\text { TI }(\%) \\
(3 \mathrm{D})\end{array}$ & $\begin{array}{l}\Lambda \times 10^{3} \\
(\mathrm{~m})\end{array}$ \\
\hline units & graph & $\mathrm{graph}$ & $\mathrm{graph}$ & $\mathrm{graph}$ & $\mathrm{graph}$ \\
\hline-0.3048 & 8.1000 & 10.500 & 8.9100 & 8.1000 & 33.122 \\
\hline 0.10160 & 6.8600 & 7.8400 & 7.4800 & 7.4000 & 33.020 \\
\hline 0.40640 & 5.8200 & 6.4100 & 6.1800 & 6.0100 & 36.754 \\
\hline 1.0160 & 4.7500 & 5.1100 & 4.8800 & 4.9200 & 37.465 \\
\hline 1.6256 & 4.0000 & 3.7400 & 3.8000 & 3.9000 & 43.637 \\
\hline 2.2352 & 3.6300 & 3.5600 & 3.8000 & 3.5400 & 51.079 \\
\hline
\end{tabular}


Table A.7.a. Data from Blair (1981b) and Blair and Anderson (1987), $\mathrm{k}=0.2 \times 10^{-6}, \mathrm{TI}=0.93 \%$ (3D).

\begin{tabular}{|l|l|l|l|l|l|}
\hline $\mathrm{x}(\mathrm{m})$ & $\mathrm{U}_{\infty}(\mathrm{m} / \mathrm{s})$ & $\theta \times 10^{3}(\mathrm{~m})$ & $\operatorname{Re}_{\theta}$ & $\operatorname{Re}_{\mathrm{X}} \times 10^{-6}$ & $\mathrm{c}_{\mathrm{f}} \times 10^{3}$ \\
\hline units & units & units & & & \\
\hline 0.31496 & 16.929 & 0.30607 & 340.00 & 0.34969 & $1.5977^{*}$ \\
\hline 0.41656 & 17.373 & 0.31674 & 361.00 & 0.47462 & $1.6829^{*}$ \\
\hline 0.61976 & 18.459 & 0.38913 & 471.00 & 0.75006 & $1.1280^{*}$ \\
\hline 0.72136 & 18.688 & 0.39649 & 486.00 & 0.88409 & $1.5162^{*}$ \\
\hline 0.82296 & 19.137 & 0.43942 & 552.00 & 1.0334 & $1.5093^{*}$ \\
\hline 0.92456 & 19.620 & 0.48311 & 622.00 & 1.1897 & $1.9450^{*}$ \\
\hline 1.0262 & 20.342 & 0.54483 & 727.00 & 1.3689 & $1.9556^{*}$ \\
\hline 1.1278 & 20.896 & 0.59665 & 816.00 & 1.5424 & $2.5508^{*}$ \\
\hline 1.2294 & 21.511 & 0.70561 & 993.00 & 1.7307 & $2.1945^{*}$ \\
\hline 1.3310 & 21.988 & 0.82118 & 1166.0 & 1.8898 & 4.4420 \\
\hline 1.5342 & 23.271 & 0.98577 & 1478.0 & 2.3005 & 4.1610 \\
\hline 1.7374 & 24.733 & 1.1209 & 1791.0 & 2.7760 & 3.9670 \\
\hline
\end{tabular}

* calculated in this study

\begin{tabular}{|l|l|l|l|l|l|l|l|}
\hline $\mathrm{x}(\mathrm{m})$ & $\mathrm{T}_{\infty}\left({ }^{\circ} \mathrm{C}\right)$ & $\mathrm{T}_{\mathrm{W}}\left({ }^{\circ} \mathrm{C}\right)$ & $\begin{array}{l}\mathrm{q} " \\
\left(\mathrm{~W} / \mathrm{m}^{2}\right)\end{array}$ & $\begin{array}{l}\Delta_{2 \times 10^{3}} \\
(\mathrm{in} .) \dagger\end{array}$ & $\begin{array}{l}\Delta_{2} \times 10^{3} \\
(\mathrm{~m}) \ddagger\end{array}$ & $\mathrm{Re}_{\Delta 2} \ddagger$ & $\mathrm{St} \times 10^{3}$ \\
\hline units & units & units & & & calc. & calc. & calc. \\
\hline 0.31496 & 23.741 & 44.528 & 425.00 & 0.83 & 0.30110 & 334.48 & 1.0342 \\
\hline 0.41656 & 23.734 & 45.750 & 407.00 & 1.15 & 0.39389 & 448.94 & 0.9129 \\
\hline 0.61976 & 24.124 & 48.828 & 411.00 & 1.39 & 0.42485 & 514.24 & 0.7758 \\
\hline 0.72136 & 24.071 & 49.261 & 410.00 & 1.66 & 0.49750 & 609.81 & 0.7501 \\
\hline 0.82296 & 23.982 & 47.228 & 419.00 & 1.70 & 0.55193 & 693.33 & 0.8085 \\
\hline 0.92456 & 24.122 & 46.628 & 425.00 & 1.94 & 0.65087 & 837.99 & 0.8254 \\
\hline 1.0262 & 24.135 & 43.206 & 435.00 & 2.17 & 0.85920 & 1146.5 & 0.9567 \\
\hline 1.1278 & 24.464 & 39.250 & 452.00 & 2.43 & 1.2423 & 1699.1 & 1.2413 \\
\hline 1.2294 & 24.474 & 37.917 & 457.00 & 2.63 & 1.4790 & 2081.3 & 1.3381 \\
\hline 1.3310 & 24.718 & 36.689 & 464.00 & 2.81 & 1.7760 & 2521.7 & 1.5081 \\
\hline 1.5342 & 25.079 & 35.583 & 469.00 & 2.97 & 2.1418 & 3211.3 & 1.6397 \\
\hline 1.7374 & 24.649 & 34.639 & 477.00 & 3.30 & 2.4986 & 3992.4 & 1.6462 \\
\hline
\end{tabular}

$\dagger$. Based on Blair's definition of $\Delta_{2}=\int_{0}^{\delta_{t}} \frac{\rho U\left(T-T_{\infty}\right)}{\rho_{\infty} U_{\infty} T_{\infty}} d y$

$\ddagger$ Based on standard definition of $\Delta_{2}=\int_{0}^{\infty} \frac{\rho U\left(T-T_{\infty}\right)}{\rho_{\infty} U_{\infty}\left(T_{w}-T_{\infty}\right)} d y$ 
Table A.7.a. Data from Blair (1981b) and Blair and Anderson (1987), $\mathrm{k}=0.2 \times 10^{-6}, \mathrm{TI}=0.93 \% \quad(3 \mathrm{D}) . \quad$ (Cont'd)

\begin{tabular}{|l|l|l|l|l|}
\hline $\mathrm{x}(\mathrm{m})$ & $\mathrm{u}_{\infty}^{\prime} / \mathrm{U}_{\infty} \times 100$ & $\mathrm{v}_{\infty}^{\prime} / \mathrm{U}_{\infty} \times 100$ & $\mathrm{w}_{\infty}^{\prime} / \mathrm{U}_{\infty} \times 100$ & $\mathrm{TI}(\%)(3 \mathrm{D})$ \\
\hline units & $\mathrm{graph}$ & $\mathrm{graph}$ & $\mathrm{graph}$ & \\
\hline-0.3048 & 1.0500 & 1.4600 & 1.1900 & 1.2000 \\
\hline 0.10160 & 0.94000 & 1.2100 & 0.99000 & 1.0000 \\
\hline 0.40640 & 0.85000 & 1.0500 & 0.88000 & 0.92000 \\
\hline 1.0160 & 0.71000 & 0.86000 & 0.71000 & 0.75000 \\
\hline 1.6256 & 0.64000 & 0.73000 & 0.60000 & 0.65000 \\
\hline
\end{tabular}

\begin{tabular}{|l|l|l|}
\hline $\mathrm{x}(\mathrm{m})$ & $\operatorname{Re}_{\mathrm{x}} \times 10^{-6}$ & $\gamma(\%)$ \\
\hline units & calc. & \\
\hline 0.32512 & 0.35800 & 0.0564 \\
\hline 0.42672 & 0.48100 & 0.1358 \\
\hline 0.52832 & 0.60900 & 0.5840 \\
\hline 0.62992 & 0.74400 & 2.7843 \\
\hline 0.73152 & 0.88600 & 6.6137 \\
\hline 0.93472 & 1.1890 & 31.629 \\
\hline 1.1379 & 1.5310 & 71.227 \\
\hline 1.3411 & 1.9070 & 95.651 \\
\hline
\end{tabular}


Table A.7.b. Data from Blair (1981b) and Blair and Anderson (1987), $\mathrm{k}=0.2 \times 10^{-6}, \mathrm{TI}=2.0 \%$ (3D).

\begin{tabular}{|l|l|l|l|l|l|}
\hline $\mathrm{x}(\mathrm{m})$ & $\mathrm{U}_{\infty}(\mathrm{m} / \mathrm{s})$ & $\theta \times 10^{3}(\mathrm{~m})$ & $\operatorname{Re}_{\theta}$ & $\operatorname{Re}_{\mathrm{X}} \times 10^{-6}$ & $\mathrm{c}_{\mathrm{f}} \times 10^{3}$ \\
\hline units & units & units & & & \\
\hline 0.11176 & 16.139 & 0.21412 & 226.00 & 0.11803 & $2.0453^{*}$ \\
\hline 0.21336 & 16.527 & 0.27635 & 299.00 & 0.23102 & $2.2852^{*}$ \\
\hline 0.31496 & 16.842 & 0.36500 & 403.00 & 0.34751 & $3.0225^{*}$ \\
\hline 0.41656 & 17.180 & 0.47015 & 519.00 & 0.46015 & $3.1297^{*}$ \\
\hline 0.51816 & 17.818 & 0.64338 & 737.00 & 0.59368 & 5.1000 \\
\hline 0.61976 & 18.367 & 0.80391 & 948.00 & 0.73093 & 4.6360 \\
\hline 0.92456 & 19.756 & 1.1689 & 1483.0 & 1.1729 & 4.0890 \\
\hline 1.2294 & 21.807 & 1.3599 & 1925.0 & 1.7407 & 3.9360 \\
\hline 1.5342 & 23.482 & 1.5131 & 2307.0 & 2.3393 & 3.8310 \\
\hline 1.7374 & 24.737 & 1.5392 & 2471.0 & 2.7887 & 3.7760 \\
\hline
\end{tabular}

* calculated in this study

\begin{tabular}{|l|l|l|l|l|l|l|l|}
\hline $\mathrm{x}(\mathrm{m})$ & $\mathrm{T}_{\infty}\left({ }^{\circ} \mathrm{C}\right)$ & $\mathrm{T}_{\mathrm{W}}\left({ }^{\circ} \mathrm{C}\right)$ & $\begin{array}{l}\mathrm{q} " \\
\left(\mathrm{~W} / \mathrm{m}^{2}\right)\end{array}$ & $\begin{array}{l}\Delta_{2} \times 10^{3} \\
(\mathrm{in} .) \dagger\end{array}$ & $\begin{array}{l}\Delta_{2} \times 10^{3} \\
(\mathrm{~m}) \ddagger\end{array}$ & $\mathrm{Re}_{\Delta 2} \ddagger$ & $\mathrm{St} \times 10^{3}$ \\
\hline units & units & units & & & calc. & calc. & calc. \\
\hline 0.11176 & 23.618 & 35.567 & 466.00 & 0.24 & 0.15140 & 159.80 & 2.0463 \\
\hline 0.21336 & 23.410 & 39.794 & 442.00 & 0.60 & 0.27585 & 298.46 & 1.3909 \\
\hline 0.31496 & 23.421 & 39.300 & 454.00 & 0.83 & 0.39375 & 434.74 & 1.4455 \\
\hline 0.41656 & 25.731 & 38.289 & 459.00 & 0.93 & 0.56220 & 620.61 & 1.8248 \\
\hline 0.51816 & 25.715 & 36.206 & 473.00 & 1.44 & 1.0420 & 1193.6 & 2.1634 \\
\hline 0.61976 & 25.219 & 35.228 & 476.00 & 1.67 & 1.2645 & 1491.1 & 2.2182 \\
\hline 0.92456 & 25.212 & 35.228 & 471.00 & 2.39 & 1.8083 & 2294.3 & 2.0389 \\
\hline 1.2294 & 25.364 & 35.378 & 472.00 & 3.02 & 2.2866 & 3236.8 & 1.8304 \\
\hline 1.5342 & 25.352 & 34.872 & 468.00 & 3.34 & 2.6601 & 4055.8 & 1.7714 \\
\hline 1.7374 & 25.478 & 35.239 & 484.00 & 3.83 & 2.9762 & 4777.9 & 1.6973 \\
\hline
\end{tabular}

$\dagger$ Based on Blair's definition of $\Delta_{2}=\int_{0}^{\delta_{1}} \frac{\rho U\left(T-T_{\infty}\right)}{\rho_{\infty} U_{\infty} T_{\infty}} d y$

$\ddagger$ Based on standard definition of $\Delta_{2}=\int_{0}^{\infty} \frac{\rho U\left(T-T_{\infty}\right)}{\rho_{\infty} U_{\infty}\left(T_{w}-T_{\infty}\right)} d y$ 
Table A.7.b. Data from Blair (1981b) and Blair and Anderson (1987), $\mathrm{k}=0.2 \times 10^{-6}, \mathrm{TI}=2.0 \%$ (3D). (Cont'd)

\begin{tabular}{|l|l|l|l|l|}
\hline $\mathrm{x}(\mathrm{m})$ & $\mathrm{u}_{\infty}^{\prime} / \mathrm{U}_{\infty} \times 100$ & $\mathrm{v}_{\infty}^{\prime} / \mathrm{U}_{\infty} \times 100$ & $\mathrm{w}_{\infty}^{\prime} / \mathrm{U}_{\infty} \times 100$ & $\mathrm{TI}(\%)(3 \mathrm{D})$ \\
\hline $\mathrm{units}$ & $\mathrm{graph}$ & $\mathrm{graph}$ & $\mathrm{graph}$ & \\
\hline-0.3048 & 2.2000 & 3.0200 & 2.6100 & 2.6000 \\
\hline 0.10160 & 1.7700 & 2.3300 & 2.0000 & 2.0000 \\
\hline 0.40640 & 1.5300 & 2.0000 & 1.7000 & 1.8000 \\
\hline 1.0160 & 1.2100 & 1.5400 & 1.3400 & 1.4000 \\
\hline 1.6256 & 0.95000 & 1.1800 & 1.0500 & 1.1000 \\
\hline
\end{tabular}

\begin{tabular}{|l|l|l|}
\hline $\mathrm{x}(\mathrm{m})$ & $\mathrm{Re}_{\mathrm{X}} \times 10^{-6}$ & $\gamma(\%)$ \\
\hline units & calc. & \\
\hline 0.22352 & 0.24000 & 10.360 \\
\hline 0.32512 & 0.35800 & 42.700 \\
\hline 0.42672 & 0.48100 & 81.380 \\
\hline 0.52832 & 0.60900 & 96.190 \\
\hline 0.62992 & 0.74400 & 99.430 \\
\hline
\end{tabular}


Table A.7.c. Data from Blair (1981b) and Blair and Anderson (1987), $\mathrm{k}=0.75 \times 10^{-6}, \mathrm{TI}=1.9 \%$ (3D).

\begin{tabular}{|l|l|l|l|l|l|}
\hline $\mathrm{x}(\mathrm{m})$ & $\mathrm{U}_{\infty}(\mathrm{m} / \mathrm{s})$ & $\theta \times 10^{3}(\mathrm{~m})$ & $\operatorname{Re}_{\theta}$ & $\operatorname{Re}_{\mathrm{x}} \times 10^{-6}$ & $\mathrm{c}_{\mathrm{f}} \times 10^{3}$ \\
\hline units & units & units & & & \\
\hline 0.31496 & 11.837 & 0.35890 & 279.00 & 0.24456 & $2.1413^{*}$ \\
\hline 0.41656 & 12.571 & 0.37389 & 310.00 & 0.34508 & $1.8650^{*}$ \\
\hline 0.61976 & 14.631 & 0.39599 & 377.00 & 0.59036 & $1.9489^{*}$ \\
\hline 0.72136 & 15.680 & 0.42494 & 434.00 & 0.73628 & $2.0032^{*}$ \\
\hline 0.82296 & 17.051 & 0.43764 & 486.00 & 0.91415 & $1.9910^{*}$ \\
\hline 0.92456 & 18.159 & 0.47473 & 562.00 & 1.0938 & $2.9887^{*}$ \\
\hline 1.0262 & 20.554 & 0.47625 & 638.00 & 1.3753 & 5.3350 \\
\hline 1.2294 & 25.426 & 0.50190 & 838.00 & 2.0532 & 4.9760 \\
\hline 1.4326 & 33.677 & 0.44069 & 973.00 & 3.1644 & 4.8060 \\
\hline
\end{tabular}

\begin{tabular}{|l|l|l|l|l|l|l|l|}
\hline $\mathrm{x}(\mathrm{m})$ & $\mathrm{T}_{\infty}\left({ }^{\circ} \mathrm{C}\right)$ & $\mathrm{T}_{\mathrm{w}}\left({ }^{\circ} \mathrm{C}\right)$ & $\begin{array}{l}\mathrm{q} " \\
\left(\mathrm{~W} / \mathrm{m}^{2}\right)\end{array}$ & $\begin{array}{l}\Delta_{2} \times 10^{3} \\
(\mathrm{in} .)+\end{array}$ & $\begin{array}{l}\Delta_{2 \times 10^{3}} \\
(\mathrm{~m}) \ddagger\end{array}$ & $\mathrm{Re}_{\Delta 2} \ddagger$ & $S \mathrm{St} \times 10^{3}$ \\
\hline units & units & units & & & calc. & calc. & calc. \\
\hline 0.31496 & 25.334 & 47.589 & 422.00 & 1.16 & 0.39517 & 307.19 & 1.3686 \\
\hline 0.41656 & 25.221 & 48.689 & 420.00 & 1.56 & 0.50378 & 417.69 & 1.2133 \\
\hline 0.61976 & 24.486 & 47.206 & 419.00 & 2.05 & 0.68213 & 649.42 & 1.0864 \\
\hline 0.72136 & 24.523 & 45.256 & 425.00 & 2.25 & 0.82053 & 838.02 & 1.1254 \\
\hline 0.82296 & 24.383 & 42.961 & 437.00 & 2.46 & 1.0007 & 1111.3 & 1.1831 \\
\hline 0.92456 & 24.367 & 41.728 & 452.00 & 2.52 & 1.0969 & 1298.6 & 1.2273 \\
\hline 1.0262 & 24.119 & 38.039 & 455.00 & 2.44 & 1.3235 & 1773.0 & 1.3538 \\
\hline 1.2294 & 23.886 & 35.100 & 476.00 & 2.43 & 1.6349 & 2729.7 & 1.4055 \\
\hline 1.4326 & 24.130 & 33.150 & 487.00 & 2.21 & 1.8501 & 4084.7 & 1.3463 \\
\hline
\end{tabular}

$\dagger$ Based on Blair's definition of $\Delta_{2}=\int_{0}^{\delta_{1}} \frac{\rho U\left(T-T_{\infty}\right)}{\rho_{\infty} U_{\infty} T_{\infty}} d y$

$\ddagger$ Based on standard definition of $\Delta_{2}=\int_{0}^{\infty} \frac{\rho U\left(T-T_{\infty}\right)}{\rho_{\infty} U_{\infty}\left(T_{w}-T_{\infty}\right)} d y$ 
Table A.7.c. Data from Blair (1981b) and Blair and Anderson (1987), $k=0.75 \times 10^{-6}, \mathrm{TI}=1.9 \%$ (3D). (Cont'd)

\begin{tabular}{|l|l|l|l|l|}
\hline $\mathrm{x}(\mathrm{m})$ & $\mathrm{u}_{\infty}^{\prime} / \mathrm{U}_{\infty} \times 100$ & $\mathrm{v}_{\infty}^{\prime} / \mathrm{U}_{\infty} \times 100$ & $\mathrm{w}_{\infty}^{\prime} / \mathrm{U}_{\infty} \times 100$ & $\mathrm{TI}(\%)(3 \mathrm{D})$ \\
\hline units & $\mathrm{graph}$ & $\mathrm{graph}$ & $\mathrm{graph}$ & \\
\hline-0.3048 & 2.3500 & 3.1600 & 2.7200 & 2.7000 \\
\hline 0.10160 & 1.8800 & 2.4600 & 2.0900 & 2.1000 \\
\hline 0.40640 & 1.4600 & 1.9600 & 1.7000 & 1.7000 \\
\hline 0.71120 & 1.1300 & 1.5800 & 1.3300 & 1.4000 \\
\hline 1.3208 & 0.59000 & 0.95000 & 0.84000 & 0.80000 \\
\hline
\end{tabular}

\begin{tabular}{|l|l|l|}
\hline $\mathrm{x}(\mathrm{m})$ & $\mathrm{Re}_{\mathrm{x}} \times 10^{-6}$ & $\gamma(\%)$ \\
\hline units & calc. & \\
\hline 0.22352 & 0.161 & 0.1306 \\
\hline 0.32512 & 0.24900 & 1.0500 \\
\hline 0.42672 & 0.34800 & 3.4140 \\
\hline 0.52832 & 0.46100 & 10.213 \\
\hline 0.73152 & 0.73400 & 35.530 \\
\hline 0.93472 & 1.1200 & 67.440 \\
\hline 1.2395 & 2.0500 & 96.721 \\
\hline
\end{tabular}


Table A.7.d. Data from Blair (1981b) and Blair and Anderson (1987), $\mathrm{k}=0.75 \times 10^{-6}, \mathrm{TI}=5.3 \%$ (3D).

\begin{tabular}{|l|l|l|l|l|l|}
\hline $\mathrm{x}(\mathrm{m})$ & $U_{\infty}(\mathrm{m} / \mathrm{s})$ & $\theta \times 10^{3}(\mathrm{~m})$ & $\operatorname{Re}_{\theta}$ & $\mathrm{Re}_{\mathrm{X}} \times 10^{-6}$ & $\mathrm{c}_{\mathrm{f}} \times 10^{3}$ \\
\hline units & units & units & & & \\
\hline 0.11176 & 11.156 & 0.18313 & 133.50 & 0.08149 & $3.0776^{*}$ \\
\hline 0.21336 & 11.435 & 0.38938 & 292.00 & 0.15976 & $3.1468^{*}$ \\
\hline 0.31496 & 12.129 & 0.49809 & 390.00 & 0.24682 & $3.2153 *$ \\
\hline 0.41656 & 12.457 & 0.60401 & 487.00 & 0.33598 & 5.5880 \\
\hline 0.61976 & 14.297 & 0.80416 & 744.00 & 0.57316 & 5.1460 \\
\hline 0.82296 & 16.829 & 0.81432 & 891.00 & 0.90056 & 4.9040 \\
\hline 1.0262 & 20.329 & 0.74803 & 988.00 & 1.3555 & 4.8560 \\
\hline 1.2294 & 25.212 & 0.65786 & 1080.0 & 2.0183 & 4.7570 \\
\hline 1.4326 & 33.630 & 0.50876 & 1122.0 & 3.1600 & 4.7350 \\
\hline
\end{tabular}

* calculated in this study

\begin{tabular}{|l|l|l|l|l|l|l|l|}
\hline $\mathrm{x}(\mathrm{m})$ & $\mathrm{T}_{\infty}\left({ }^{\circ} \mathrm{C}\right)$ & $\mathrm{T}_{\mathrm{W}}\left({ }^{\circ} \mathrm{C}\right)$ & $\begin{array}{l}\mathrm{q} " \\
\left(\mathrm{~W} / \mathrm{m}^{2}\right)\end{array}$ & $\begin{array}{l}\Delta_{2 \times 10^{3}} \\
(\mathrm{in} .) \dagger\end{array}$ & $\begin{array}{l}\Delta_{2} \times 10^{3} \\
(\mathrm{~m}) \ddagger\end{array}$ & $\mathrm{Re}_{\Delta 2} \ddagger$ & $\mathrm{St} \times 10^{3}$ \\
\hline units & units & units & & & calc. & calc. & calc. \\
\hline 0.11176 & 22.944 & 37.683 & 462. & 0.46 & 0.23472 & 171.75 & 2.3968 \\
\hline 0.21336 & 22.638 & 37.056 & 452. & 0.86 & 0.44813 & 336.06 & 2.3350 \\
\hline 0.31496 & 23.127 & 36.817 & 466. & 1.27 & 0.69812 & 546.62 & 2.4167 \\
\hline 0.41656 & 22.786 & 35.589 & 466. & 1.64 & 0.96286 & 776.33 & 2.5095 \\
\hline 0.61976 & 22.941 & 35.267 & 471. & 2.35 & 1.4339 & 1326.6 & 2.2950 \\
\hline 0.82296 & 23.863 & 35.089 & 473. & 2.56 & 1.7204 & 1882.4 & 2.1297 \\
\hline 1.0262 & 23.976 & 34.461 & 480. & 2.77 & 1.9938 & 2633.4 & 1.9138 \\
\hline 1.2294 & 23.621 & 33.128 & 475. & 2.55 & 2.0219 & 3319.3 & 1.6797 \\
\hline 1.4326 & 24.128 & 32.206 & 495. & 2.47 & 2.3088 & 5091.8 & 1.5278 \\
\hline
\end{tabular}

$\uparrow$ Based on Blair's definition of $\Delta_{2}=\int_{0}^{\delta_{1}} \frac{\rho U\left(T-T_{\infty}\right)}{\rho_{\infty} U_{\infty} T_{\infty}} d y$

$\ddagger$ Based on standard definition of $\Delta_{2}=\int_{0}^{\infty} \frac{\rho \mathrm{U}\left(\mathrm{T}-\mathrm{T}_{\infty}\right)}{\rho_{\infty} \mathrm{U}_{\infty}\left(\mathrm{T}_{\mathrm{w}}-\mathrm{T}_{\infty}\right)} \mathrm{dy}$ 
Table A.7.d. Data from Blair (1981b) and Blair and Anderson (1987), $\mathrm{k}=0.75 \times 10^{-6}, \mathrm{TI}=5.3 \%$ (3D).

\begin{tabular}{|l|l|l|l|l|}
\hline $\mathrm{x}(\mathrm{m})$ & $\mathrm{u}_{\infty}^{\prime} / \mathrm{U}_{\infty} \times 100$ & $\mathrm{v}_{\infty}^{\prime} / \mathrm{U}_{\infty} \times 100$ & $\mathrm{w}_{\infty}^{\prime} / \mathrm{U}_{\infty} \times 100$ & $\mathrm{TI}(\%)(3 \mathrm{D})$ \\
\hline units & graph & graph & graph & \\
\hline-0.3048 & 5.9100 & 7.6200 & 6.0700 & 6.6000 \\
\hline 0.10160 & 4.4300 & 5.5200 & 4.7000 & 4.9000 \\
\hline 0.40640 & 3.3500 & 4.2000 & 3.6500 & 3.8000 \\
\hline 0.71120 & 2.3800 & 3.2600 & 2.7600 & 2.9000 \\
\hline 1.3208 & 1.0800 & 1.7700 & 1.5400 & 1.5000 \\
\hline
\end{tabular}

\begin{tabular}{|l|l|l|}
\hline $\mathrm{X}(\mathrm{m})$ & $\operatorname{Re}_{\mathrm{X}} \times 10^{-6}$ & $\gamma(\%)$ \\
\hline units & calc. & \\
\hline 0.12192 & 0.083200 & 14.211 \\
\hline 0.22352 & 0.16100 & 48.414 \\
\hline 0.32512 & 0.24900 & 78.300 \\
\hline 0.42672 & 0.34800 & 93.160 \\
\hline 0.62992 & 0.59000 & 99.390 \\
\hline
\end{tabular}


Table A.8. Data from Rued (1987).

Unaccelerated Flow Cases

\begin{tabular}{|l|l|l|l|l|l|}
\hline x (m) & $\begin{array}{l}\text { TI (\%)(2D) } \\
\text { no grid }\end{array}$ & $\begin{array}{l}\text { TI (\%)(2D) } \\
\text { grid 1 }\end{array}$ & $\begin{array}{l}\text { TI (\%)(2D) } \\
\text { grid 2 }\end{array}$ & $\begin{array}{l}\text { TI (\%)(2D) } \\
\text { grid 3 }\end{array}$ & $\begin{array}{l}\text { TI (\%)(2D) } \\
\text { grid 4 }\end{array}$ \\
\hline graph & graph & graph & graph & graph & graph \\
\hline 0.00 & 1.51 & 2.44 & 3.72 & 6.16 & 8.84 \\
\hline 0.0320 & 1.40 & 2.15 & 3.37 & 5.47 & 7.67 \\
\hline 0.120 & 1.16 & 1.86 & 2.67 & 4.07 & 5.64 \\
\hline 0.205 & 1.16 & 1.74 & 2.38 & 3.37 & 4.48 \\
\hline 0.305 & 1.16 & 1.53 & 2.07 & 2.91 & 3.84 \\
\hline 0.405 & 1.16 & 1.45 & 1.92 & 2.62 & 3.37 \\
\hline
\end{tabular}

Unaccelerated Flow, No Grid, TI=1.3\% (2D)

\begin{tabular}{|l|l|l|l|}
\hline $\mathrm{x}(\mathrm{m})$ & $\theta \times 10^{3}(\mathrm{~m})$ & $\operatorname{Re}_{\mathrm{X}} \times 10^{-6}$ & $\operatorname{Re}_{\theta}$ \\
\hline graph & graph & calc. & calc. \\
\hline 0.11030 & 0.15000 & 0.22060 & 300.00 \\
\hline 0.21000 & 0.23140 & 0.42000 & 462.80 \\
\hline 0.30670 & 0.34290 & 0.61340 & 685.80 \\
\hline 0.40670 & 0.50000 & 0.81340 & 1000.0 \\
\hline
\end{tabular}


Public reporting burden for this collection of information is estimaled to average 1 hour per response, including the time for revlewing instructions, searching existing data sources gathering and maintaining the date needed, and completing and reviewing the collection of lnformation. Send comments regarding this burden estimate or any other aspect of this Davis Highway, Sullo 1204, Avtington, VA 22202-4302, and to the Office of Manington Headquarters Services, Directorate for information Operations and Reports, 1215 Jefferson 1. AGENCY USE ONIY (Leave Jlant))

\section{\begin{tabular}{l|l} 
1. AGENCY USE ONLY (Leave blank) & 2. REPORT DATE
\end{tabular}}

4. TITLE AND SUBTTTLE

August 1991

Final Contractor Report

Bypass Transition in Boundary Layers Including Curvature and Favorable Pressure Gradient Effects

\section{AUTHOR(S)}

R.J. Volino and T.W. Simon

G-NAG3-881

WU-505-62-52

5. FUNDING NUMBERS

7. PERformina organization NaMe(S) AND ADDRESS(ES)

University of Minnesota

Department of Mechanical Engineering

111 Church Street, S.E.

Minneapolis, Minnesota 55455

3. REPORT TYPE AND DATES COVERED

. SPONSORING/MONITORING AGENCY NAMES(S) AND ADDRESS(ES)

National Aeronautics and Space Administration

Lewis Research Center

Cleveland, Ohio 44135-3191

8. PERFORMING ORGANIZATION REPORT NUMBER

None

10. SPONSORING/MONITORING AGENCY REPORT NUMBER

NASA CR- 187187

\section{SUPPLEMENTARY NOTES}

Project Manager, Frederick F. Simon, Internal Fluid Mechanics Division, NASA Lewis Research Center, (216) 433-5894.

12a. DISTRIBUTION/AVAILABILITY STATEMENT

12b. DISTRIBUTION CODE

Unclassified - Unlimited

Subject Category 34

\section{ABSTRACT (Max/mum 200 words)}

Recent studies of two-dimensional boundary layers undergoing bypass transition have been reviewed. Bypass transition is characterized by the sudden appearance of turbulent spots in the boundary layer without first the regular, observable growth of disturbances predicted by linear stability theory. There are no standard criteria or parameters for defining bypass transition, but it is known to be the mode of transition when the flow is disturbed by perturbations (e.g. freestream turbulence, surface roughness, acoustic fluctuations) of sufficient amplitude. An examination of recent and length scales are documented. which do not. Such models are still, however, dependent on case-specific intermittent nature of the flow generally have more success than those experimental work shows the effects of freer, dependent on case-specific experimental data and are not ready for predictive use. A review of were cast in terms of "Ws effects of freestream turbulence level, acceleration and wall curvature on bypass transition. Results from several studies growth is strongly affected by acceleration and by concave curvature and enthalpy thickness Reynolds numbers) and compared. Boundary layer laminar solution before transition and quickly adjust to curvature. In unaccelerated flow on flat wall, skin friction coefficients match the analytical the laminar region, but do not fit the correlation as well in the turturbulent correlation after transition. Stanton numbers also match the correlation in terms of momentum thickness Reynolds num Reynolds analogy. Concave curvature causes the formation Görter were strongly affected by acceleration, however, indicating a break-down in opposite, and lesser effect. The location and formation Gortler vortices, which strongly influence the skin friction. Convex curvature had an freestream turbulence levels and on concave length of the transition region generally follow the expected trends. Transition occurs earlier at higher some inconsistencies were and on concave surfaces. Convex curvature and acceleration delay transition. When individual cases were compared, ments would help in this regard. Within the transition region the interitency a better characterize the flow. Better spectral and length scale measurean analytical prediction. Turbulent spot the transition region, the intermittency data from all the cases on flat walls (no curvature) was consistent with concave curvature and little furent spot production rates were shown to be mostly dependent on free-stream turbulence, with a noted increase due to

14. SUBJECT TERMS

Transition; Heat transfer; Turbulence; Curvature; Pressure gradients

\begin{tabular}{|c|c|c|}
\hline $\begin{array}{c}\text { 17. SECURTY CLASSIFICATION } \\
\text { OF REPORT } \\
\text { Unclassified }\end{array}$ & $\begin{array}{c}\text { 18. SECUAITY CLASSIFICATION } \\
\text { OF THIS PAGE } \\
\text { Unclassified }\end{array}$ & $\begin{array}{c}\text { 10. SECUAITY CLASSIFICATION } \\
\text { OF ABSTAACT } \\
\text { Unclassified }\end{array}$ \\
\hline
\end{tabular}


